OECD Trade and Environment Working Papers 2017/01

\title{
International trade consequences of climate change
}

\section{Rob Dellink,}

Hyunjeong Hwang,

Elisa Lanzi,

Jean Chateau

https://dx.doi.org/10.1787/9f446180-en 


\section{OECD TRADE AND ENVIRONMENT WORKING PAPERS}

The OECD Trade and Environment Working Paper series is designed to make available to a wide readership selected studies by OECD staff or outside consultants.

OECD Working Papers should not be reported as representing the official views of the OECD or of its member countries. The opinions expressed and arguments employed are those of the authors.

Working Papers describe preliminary results or research in progress by the author(s) and are published to stimulate discussion on a broad range of issues on which the OECD works. Comments on Working Papers are welcomed, and may be sent to the Environment Directorate or the Trade and Agriculture Directorate, OECD, 2 rue André-Pascal, 75775 Paris Cedex 16, France. Comments on Working Papers may also be sent to tad.contact@oecd.org or env.contact@oecd.org.

This document has been prepared under the auspices of the Joint Working Party on Trade and Environment (JWPTE) and declassified by the Environment Policy Committee (EPOC) under the OECD reference number COM/TAD/ENV/JWPTE(2015)63/FINAL.

The publication of this document has been authorised by Simon Upton, Director, Environment Directorate, OECD.

\section{OECD TRADE AND ENVIRONMENT WORKING PAPERS}

are published on the OECD's trade (www.oecd.org/trade) and environment (www.oecd.org/environment) web pages, as well as on the OECD iLibrary (OECD Trade and Environment Working Papers).

This document and any map included herein are without prejudice to the status of or sovereignty over any territory, to the delimitation of international frontiers and boundaries and to the name of any territory, city or area.

The statistical data for Israel are supplied by and under the responsibility of the relevant Israeli authorities. The use of such data by the OECD is without prejudice to the status of the Golan Heights, East Jerusalem and Israeli settlements in the West Bank under the terms of international law.

\section{(C) OECD (2017)}

You can copy, download or print OECD content for your own use, and you can include excerpts from OECD publications, databases and multimedia products in your own documents, presentations, blogs, websites and teaching materials, provided that suitable acknowledgment of OECD as source and copyright owner is given. All requests for commercial use and translation rights should be submitted to rights@oecd.org. 


\begin{abstract}

\section{The International Trade Consequences of Climate Change}

\author{
Rob Dellink, Hyunjeong Hwang, Elisa Lanzi and Jean Chateau (OECD)
}

This report provides an analysis of how climate change damages may affect international trade in the coming decades and how international trade can help limit the costs of climate change. It analyses the impacts of climate change on trade considering both direct effects on infrastructure and transport routes and the indirect economic impacts resulting from changes in endowments and production. A qualitative analysis with a literature review is used to present the direct effects of climate change. The indirect impacts of climate change damages on trade are analysed with the OECD's ENV-Linkages model, a dynamic computable general equilibrium model with global coverage and sector-specific international trade flows. By building on the analysis in the OECD (2015) report "The Economic Consequences of Climate Change", the modelling analysis presents a plausible scenario of future socioeconomic developments and climate damages, to shed light on the mechanisms at work in explaining how climate change will affect trade.

The report highlights the important regional differences in the effects that climate change will have on regional and sectoral economic activities and on competitiveness. Consequently, international trade changes are governed not by domestic climate impacts only, but also by the relative severity of these impacts compared to the major trading partners. By being aware of how climate impacts may affect its economy, not just through impacts on its production factors but also on trade, countries can design climate and trade policies that are aligned and thus avoid the worst climate damages at least cost.

JEL classification: C68, F17, F18, O44, Q56.

Keywords: Trade and environment, Trade and climate change, CGE model 


\section{Résumé}

Ce rapport analyse dans quelle mesure les coûts résultants du changement climatique pourraient altérer le commerce international dans les décennies à venir, ainsi que le rôle du commerce international dans la réduction des coûts liés au changement climatique. Plus précisément, le rapport étudie les effets directs du changement climatique sur les infrastructures et les voies de transport, mais aussi les effets économiques indirects résultant des impacts du changement climatique sur les activités et les facteurs de production. Les effets directs du changement climatique sur le commerce international sont appréhendés de façon qualitative par le biais d'une revue de la littérature existante sur ce sujet. Les effets indirects sont analysés à l'aide du modèle ENV-Linkages de l'OCDE. Ce modèle d'équilibre général calculable est dynamique, mondial et intègre directement le commerce international des biens et services. L'analyse quantitative repose sur celle effectuée dans le rapport de l’OCDE(2015) "Les conséquences économiques du changement climatique », et présente un scénario plausible des tendances socio-économiques et du changement climatique dans les décennies à venir. Ce scénario illustre notamment les mécanismes à l'œuvre, qui expliquent les impacts du changement climatique sur le commerce.

Le rapport met en avant les fortes disparités, entre régions et secteurs d'activité, des effets du changement climatique, qui à leur tour modifient leur compétitivité relative. Par conséquent les changements de la structure du commerce international sont non seulement régis par les impacts domestiques du changement climatique, mais aussi par le différentiel d'impacts entre partenaires commerciaux. Ce n'est seulement qu'en tenant compte de la façon dont les impacts climatiques peuvent affecter leurs économies, non seulement au travers d'effets sur leur production mais aussi sur leur commerce, que les pays pourront élaborer de concert des politiques climatiques et commerciales qui permettront d'éviter un renforcement des impacts négatifs du changement climatique.

Classification JEL : C68, F17, F18, O44, Q56.

Mots clés : Commerce international et environnement, changement climatique et commerce, modèle MEGC. 


\section{Acknowledgements}

This report on "The international trade consequences of climate change" explores the potential economic consequences of climate change with a specific focus on international trade.

The quantitative analysis in this paper builds heavily on the OECD CIRCLE project, especially the 2015 report "The economic consequences of climate change". It extends beyond that analysis by diving much deeper into the consequences for macroeconomic competitiveness and changes in international trade patterns; part of the paper focuses on agricultural damages, as these are both significantly affected by climate change and heavily traded on international markets.

This report was written by Rob Dellink, Hyunjeong Hwang, Elisa Lanzi and Jean Chateau of the OECD Environment Directorate. The report was overseen by the Joint Working Party on Trade and Environment (JWPTE). The paper has benefitted from comments on earlier versions by delegates of the JWPTE and the Joint Working Party on Agriculture and Environment (JWPAE). Shunta Yamaguchi's feedbacks on earlier drafts and coordination of the review process have been essential in preparing this report. Comments and suggestions from colleagues at the OECD Secretariat, not least Andrew Prag from the Environment Directorate and Guillaume Gruère, Jehan Sauvage, Ronald Steenblik from the Trade and Agriculture Directorate, are gratefully acknowledged. Natasha Cline-Thomas and Marie-Jeanne Gaffard provided editorial assistance. Work on this paper was conducted under the overall responsibility of Shardul Agrawala, Head of the Environment and Economy Integration Division. 


\section{Table of contents}

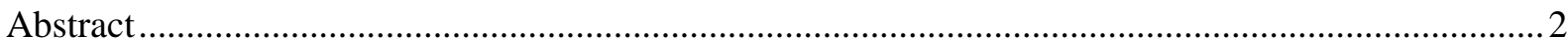

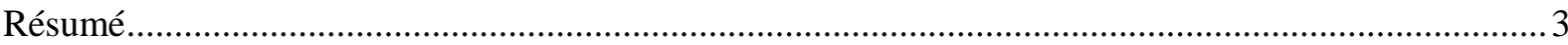

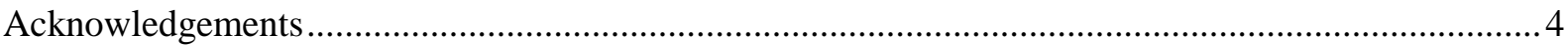

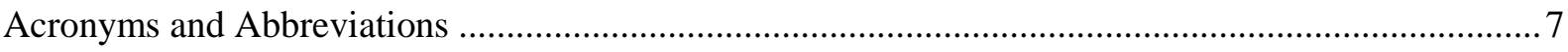

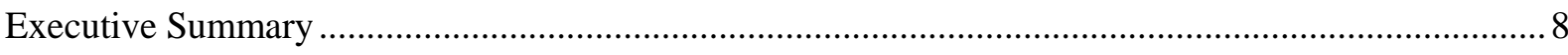

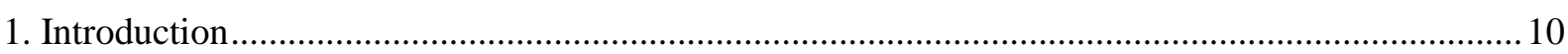

2. The Evolution of International Trade in the Coming Decades ....................................................... 12

2.1 Evolution of regional economic activity and pressure on the climate system............................ 12

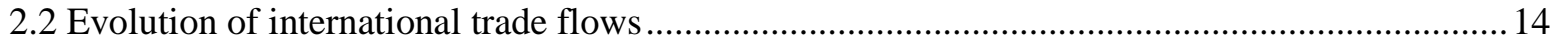

3. Impacts of Climate Change on Domestic Economies and International Trade .................................18

3.1 The direct impacts of climate change on international trade..................................................... 18

3.2 The indirect consequences of climate change on international trade ...........................................23

3.2.1 The regional economic consequences of climate change .....................................................2

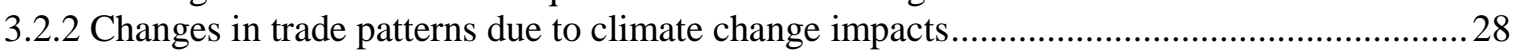

4. Understanding the Indirect Impacts of Climate Change on International Trade ...............................32

4.1 Income effect: changes in macroeconomic competitiveness of countries...................................33

4.2 Compositional effects: changes in comparative advantage in agriculture and food ....................37

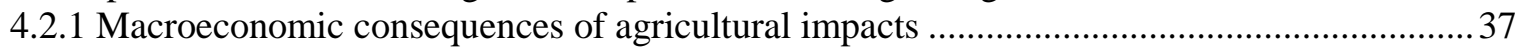

4.2.2 Revealed Comparative Advantage (RCA) in food products....................................................40

4.2.3 A deeper look at RCAs: food exports to the EU......................................................................43

4.3 Sensitivity of domestic consequences to international spillovers ............................................47

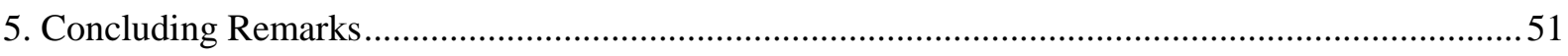

Annex A. Description of the ENV-Linkages Modelling Tool ..........................................................53

Annex B. Details on the Evolution of International Trade in the No-damage Baseline Projection........58

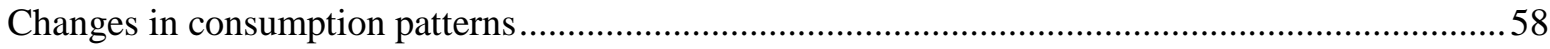

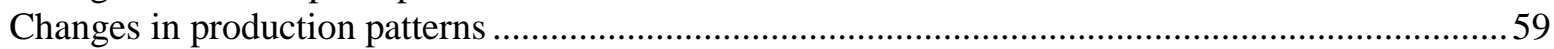

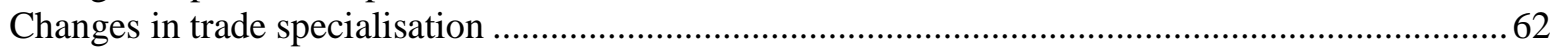

Annex C. Summary of the Approach to Represent Damages from Climate Change in the Model.......64

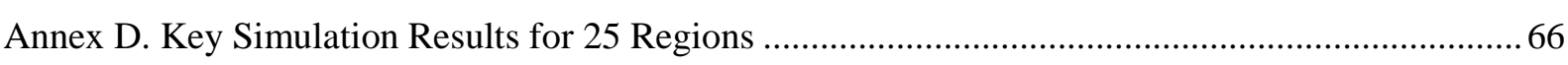

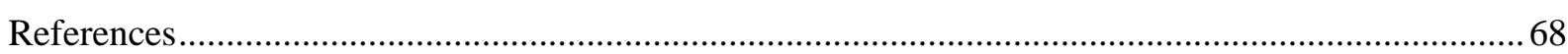




\section{Tables}

Table 1. Geographical distribution of trade in the no-damage baseline projection.........................16

Table 2. Potential direct impacts and consequences on trade infrastructures .................................20

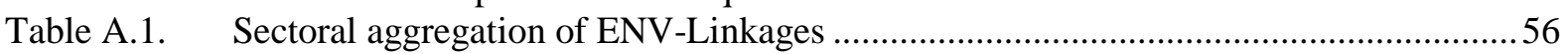

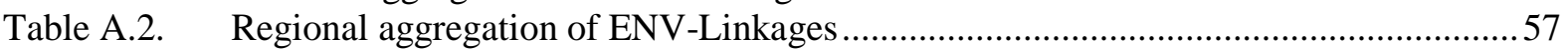

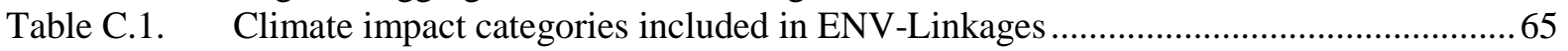

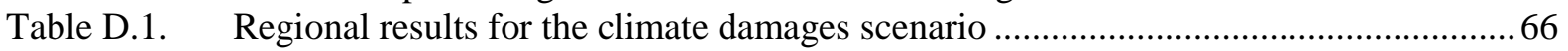

Table D.2. $\quad$ Regional results for the agricultural damages scenario................................................67

\section{Figures}

Figure 1. Trend in real GDP in the no-damage baseline projection ................................................12

Figure 2. Evolution of key climate change indicators in the no-damage baseline projection ...........14

Figure 3. Bilateral trade between OECD and non-OECD countries in the no-damage baseline projection

Figure 4. Regional damages from selected climate change impacts in the climate damages scenario

Figure 5. Sources of damages from selected climate change impacts by production factor in the climate damages scenario........................................................................................... 26

Figure 6. Impact of climate change on yields for selected crops in the climate damages scenario.. 28

Figure 7. Changes in trade volumes from climate impacts in the climate damages scenario ..........29

Figure 8. Change in export shares in the no-damage baseline projection and in the climate damages

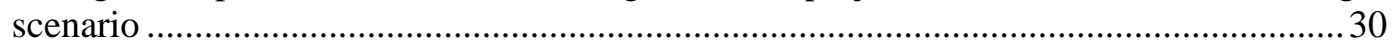

Figure 9. Change in trade volumes and in GDP for a range of climate damages scenarios..............31

Figure 10. Change in trade volumes and in GDP in the climate damages scenario .......................34

Figure 11. Change in real exchange rates in the climate damages scenario.....................................35

Figure 12. Change in sectoral imports in the climate damages scenario........................................36

Figure 13. Change in aggregate crop yields and GDP in the agricultural damages scenario.......... 38

Figure 14. Change in regional GDP in different agricultural damages scenarios .......................... 40

Figure 15. RCA levels for food products and changes due to agricultural damages....................... 41

Figure 16. Changes in RCAs for food products and agricultural damages ..................................... 42

Figure 17. Change in food exports to the EU in the agricultural damages scenario .......................45

Figure 18. Levels and change in RCA of food exports to the EU in the agricultural damages

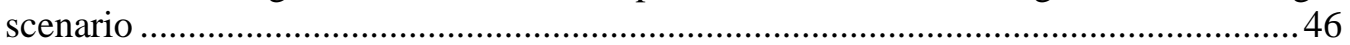

Figure 19. Decomposition of changes in real GDP in 2060 in the climate damages scenario ....... 49

Figure A.1. Production structure of a generic sector in ENV-Linkages...........................................54

Figure B.1. Changes in sectoral composition of world trade ...........................................................58

Figure B.2. Changes in consumption patterns, selected countries ..................................................60

Figure B.3. Changes in industrial structure, selected countries ......................................................61

Figure B.4. Changes in trade specialisation patterns in selected aggregate industries..................... 62

\section{Boxes}

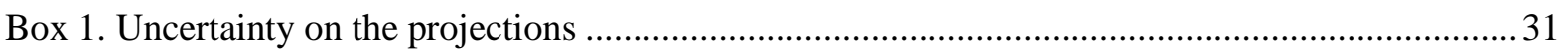

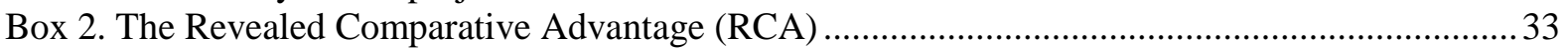

Box 3. Modelling assumptions used for the decomposition ........................................................... 48 


\section{Acronyms and Abbreviations}

$\begin{array}{ll}\text { CGE } & \text { Computable General Equilibrium } \\ \text { CO }_{2} & \text { Carbon dioxide } \\ \text { ECS } & \text { Equilibrium Climate Sensitivity } \\ \text { FAO } & \text { Food and Agriculture Organization of the United Nations } \\ \text { GHG } & \text { Greenhouse Gases } \\ \text { GDP } & \text { Gross Domestic Product } \\ \text { GTAP } & \text { Global Trade Analysis Project } \\ \text { IAM } & \text { Integrated Assessment Model } \\ \text { IEA } & \text { International Energy Agency } \\ \text { IFPRI } & \text { International Food Policy Research Institute } \\ \text { IMO } & \text { International Maritime Organisation } \\ \text { NSR } & \text { Northern Sea Route } \\ \text { NWP } & \text { Northwest Passage } \\ \text { IPCC } & \text { Intergovernmental Panel on Climate Change } \\ \text { PPP } & \text { Purchasing Power Parity } \\ \text { RCA } & \text { Revealed Comparative Advantage } \\ \text { SIC } & \text { International Standard Industrial Classification } \\ \text { WTO } & \text { World Trade Organization }\end{array}$




\section{Executive Summary}

Over the next half century, international trade is projected to continue to outpace growth in global gross domestic product (GDP). While economies will increasingly rely on trade, climate change will affect trade patterns and specialisation. Changes in the climate system, not least sea level rise and the increasing frequency of extreme events, will modify transport routes and infrastructures, thereby changing the access and possibilities for the international transport of goods and services. Other types of climate impacts, such as those on agriculture and labour productivity, will cause changes in production and specialisation, which will also affect trade.

The literature on trade has focused mostly on the trade consequences of climate change mitigation policies or on the effects of trade policies on greenhouse gas emissions. Dedicated analyses that look at the long-term impacts of climate change on international trade are still very scarce.

This paper provides an analysis of how climate change damages will affect international trade in the coming decades and how international trade can help limit the costs of climate change. It analyses the impacts of climate change on trade considering both direct effects on infrastructure and transport routes and the indirect impacts resulting from changes in endowments and production. A qualitative analysis with a literature review is used to present the direct effects of climate change. The indirect impacts of climate change damages on trade are instead analysed with the OECD's ENV-Linkages model, a dynamic computable general equilibrium model with global coverage and sector-specific international trade flows. By building on the analysis in OECD (2015a), the modelling analysis limits itself to presenting one plausible scenario of future developments, to shed light on the mechanisms at work in explaining how climate change will affect trade

The direct consequences of climate change on trade could become manifest in damages to trade from more frequent extreme weather events or rising sea levels. Supply, transport and distribution chains might become more vulnerable to disruptions due to climate change. Maritime shipping, which accounts for around $80 \%$ of global trade by volume, could experience negative consequences, for instance from more frequent port closures due to extreme events. At the same time there could also be positive economic impacts on maritime shipping through the potential further opening of Arctic shipping routes, albeit at the cost of environmental degradation.

Indirect impacts on trade patterns primarily result from regional and sectoral disparities in the economic consequences of climate change. Model simulations show that climate change is projected to impact on the production of goods and services through changes in natural endowments or through the efficiency with which factors of production of such as land, labour, and capital can be deployed.

The effects of climate change on trade lead to changes in the comparative advantage of economies, and hence affect trade patterns. The results from the ENVLinkages model simulations imply that climate damages will place negative pressure on the economies of almost all regions through smaller trade flows than in a projection that ignores feedbacks from climate change on the economy. Notwithstanding this, 
significant growth in baseline trade volumes projected over the coming decades will still see the absolute level of trade flows grow even when climate damages are accounted for. The economic consequences of climate change are especially marked in Africa and Asia, where high economic growth rates are combined with increased trade dependency and large damages from climate change. In terms of economic sectors, trade in agricultural commodities is projected to be relatively strongly impacted by climate damages.

The results of this study show that in the most affected countries exports are projected to decline more than imports and GDP and this will weaken their trade position. In contrast, producers in the least affected countries can improve their competitive position on both domestic and export markets. Therefore, despite being negatively affected by climate damages, a region may increase its competitiveness if other competitors for a certain market are more severely damaged, or there is a move to specialise in the production of other goods.

Focusing on the impact of agricultural damages from climate change on food products, and using Revealed Comparative Advantage (RCA) as an indicator of regional competitiveness, this paper finds that while the ranking of comparative advantage is largely unchanged by climate change damages on the agricultural sector, there are significant effects for some countries. The effects are particularly large for the regions that are most specialised in food and agricultural products.

The regional changes in comparative advantage are driven by complex interactions in the economic system, where all sectors in all regions are intricately tied together and where climate damages affect all parts of the economy. Countries that have larger domestic markets and more diversified trade patterns can absorb climate shocks better than countries that are more specialised. There are numerous interactions between regions and sectors that make it impossible to establish rules of thumb on the competitiveness impacts of climate damages, but it is clear that the relative impacts in a region compared to its trading partners matter more than the absolute size of the regional damages. This highlights the need for each region to understand not only the direct impacts of climate change on its sectoral production and trade flows, but also the possible impacts of climate change on regions it is competing with for specific markets.

This paper only presents results from one single model and baseline. More robust quantitative insights would require a more elaborate modelling analysis, using multiple scenarios on the major modelling assumptions, and ideally comparing different models. Nonetheless, the paper highlights the important effects that climate change will have on economic activities and on competitiveness. By being aware of how climate impacts may affect its economy, not just through impacts on its production factors but also on trade, countries can design climate and trade policies that are aligned and thus avoid the worst climate damages at least cost. 


\section{Introduction}

The atmospheric effects from continued greenhouse gases (GHG) emissions will lead to changes in the climate system (IPCC, 2013). Higher global surface temperatures and changed weather patterns are projected to accelerate the melting of glaciers, lead to rising sea levels, and to result in more frequent temperature extremes and longer-lasting heat weaves in certain parts of the world, among other effects. These impacts will have significant economic consequences for regions around the world, with large changes in sectoral and regional production and consumption (OECD, 2015a) and hence on international trade.

Recent analysis by the OECD projects that the trend of economic integration and intensified global trade will continue in the future, albeit at a slower pace than in the last decades (Chateau et al., 2015). In the long run, global trade and its relative size to global income are driven by (i) transportation and communications costs (including "transaction costs"), (ii) income growth and changes in preferences, (iii) sectoral comparative advantage in production of goods and services, and (iv) trade policies and trade agreements (Feenstra, 1998). Changes in each country's specialisation depend ultimately on differences in these drivers amongst countries. The products in which countries specialise are determined by the availability of inputs used in the manufacture of different products and by access to different technologies. As such, specialisation is strongly driven by unevenly distributed natural resources across the globe.

Climate change will affect some of these elements, thereby changing trade and specialisation patterns through different mechanisms. Some climate impacts, such as higher frequency of extreme events or rising sea levels, will have direct impacts on trade as they will affect transport and distribution chains. Further, changes in factors of production of economies (i.e. land, labour, and capital) will affect production structure and trade specialisation. But, climate change is also expected to have indirect impacts on trade, as all regions and sectors are linked through inputs in production and trade in produced goods and services.

On the policy side, mitigation policies may affect trade. Similarly, trade policies may also impact GHG emissions. Both topics have been dealt with in the literature (OECD, 2007, 2008, 2009; Copeland and Taylor, 2004; Cosbey and Tarasofsky, 2007; WTO-UNEP, 2009). However, dedicated analyses that look at the long-term impacts of climate change on international trade, and at how international trade affects the economic consequences of climate change impacts, are still very scarce. Huang et al. (2011) summarise the key mechanisms at play in the consequences of climate change on trade in agriculture, and highlight the different roles of changes in technology and changes in endowments as drivers of changes in international trade patterns. Willenbockel (2012) investigates the consequences of extreme weather events on food prices and changes in international trade. He shows how regional productivity shocks can have widely varying impacts on food prices, export prices and export volumes. Bosello and Parrado (2014) show that the economic consequences of climate change depend on the possibilities to adapt international trade patterns. Schenker and Stephan (2014) explicitly look at the impacts of international climate policy on international trade. They find that funding adaptation in developing regions can reduce climate 
change costs as developing regions benefit from receiving adaptation funding and high and middle income donor countries will generally benefit from improved termsof-trade. Liu et al. (2014) study the role of trade in analysing the impacts of possible future irrigation shortfalls. They find that regional differences in impacts of irrigation water shortages on local production significantly alter the geographical distribution of international trade.

This paper specifically aims to shed light on how climate change damages will affect international trade in the coming decades, and on how international trade affects climate change costs. The focus of the analysis is on the assessment of the costs of inaction, i.e. the economic consequences that are projected to occur when no further policy action is taken. Thus, an analysis of the trade policy response to climate change is left for future research. It first surveys the direct effects of climate change on the trade infrastructure. Then, the indirect impacts resulting from the economic consequences of climate change will be investigated in detail. ${ }^{1}$ While it is clear that climate policies will have profound effects on different sectors and economies, and on international trade patterns, an analysis of the trade consequences of climate change policies is left for future research. Such analysis could also investigate the trade consequences of international financial flows as part of a multilateral climate agreement.

The analysis of sectoral and regional economic changes in this paper relies on a dynamic computable general equilibrium modelling tool - the OECD's ENV-Linkages model - to draw global economic scenarios up to 2060. These scenarios can be used to analyse the linkage between trade and climate (see Annex A for a brief description of the model and Chateau et al., 2014, for more details). This multi-regional and multisectoral dynamic general equilibrium model has been recently enhanced to consider the impact of climate damages on the economy (OECD, 2015a). CGE models are traditionally well-suited to the type of analysis in this report, as they focus on linkages between economic sectors in various regions. This type of model is based on national accounts and international trade flows at sectoral level. The paper focuses on climate change impacts on trade of goods and services among countries, as opposed to capital flows and labour migration, both important issues but outside the scope of this paper. An important caveat is that the use of one central projection of economic developments with one specific assessment of the impacts of climate change implies that the quantitative results presented in this paper are mostly indicative. More robust quantitative insights would be gained from studying multiple scenarios and comparing different models, and by adopting a risk-based framework. This would, however, imply a major additional effort.

This paper is structured as follows. Section 2 presents a projection of world trade and specialisation patterns in the coming decades, as projected by ENV-Linkages, without considering how these trends are affected by climate change. Section 3 then summarises the main direct impacts of climate change and presents results on indirect impacts as quantified in the model. Section 4 discusses how these changes in trade flows can be explained by the different mechanisms that drive trade patterns, including macroeconomic competitiveness and relative comparative advantage at the sectoral level. Section 5 provides some concluding remarks. topic is however outside the scope of this report. 


\section{The Evolution of International Trade in the Coming Decades}

\subsection{Evolution of regional economic activity and pressure on the climate system}

The ENV-Linkages model projects developments of economic activity at the sectoral and regional level until 2060 (see Annex A for further details on the model structure). Sectoral economic activity is projected using a production function for economic sectors, a utility function for households and international trade flows, with macroeconomic closure, i.e. all commodity flows have an origin and a destination, and are coupled to a reverse financial flow.

Based on a number of exogenous socioeconomic trends concerning population growth, demographic changes, and technological developments, the model projects economic activity, pressure on the climate system and international trade patterns in the coming decades. Figure 1 shows the projected evolution of regional GDP and trade along the no-damage baseline projection. This baseline projection does not contain environmental feedbacks and is detailed in OECD (2015a).

Figure 1. Trend in real GDP in the no-damage baseline projection

Panel A. Evolution over time

(Billions of USD, 2010 PPP exchange rates)

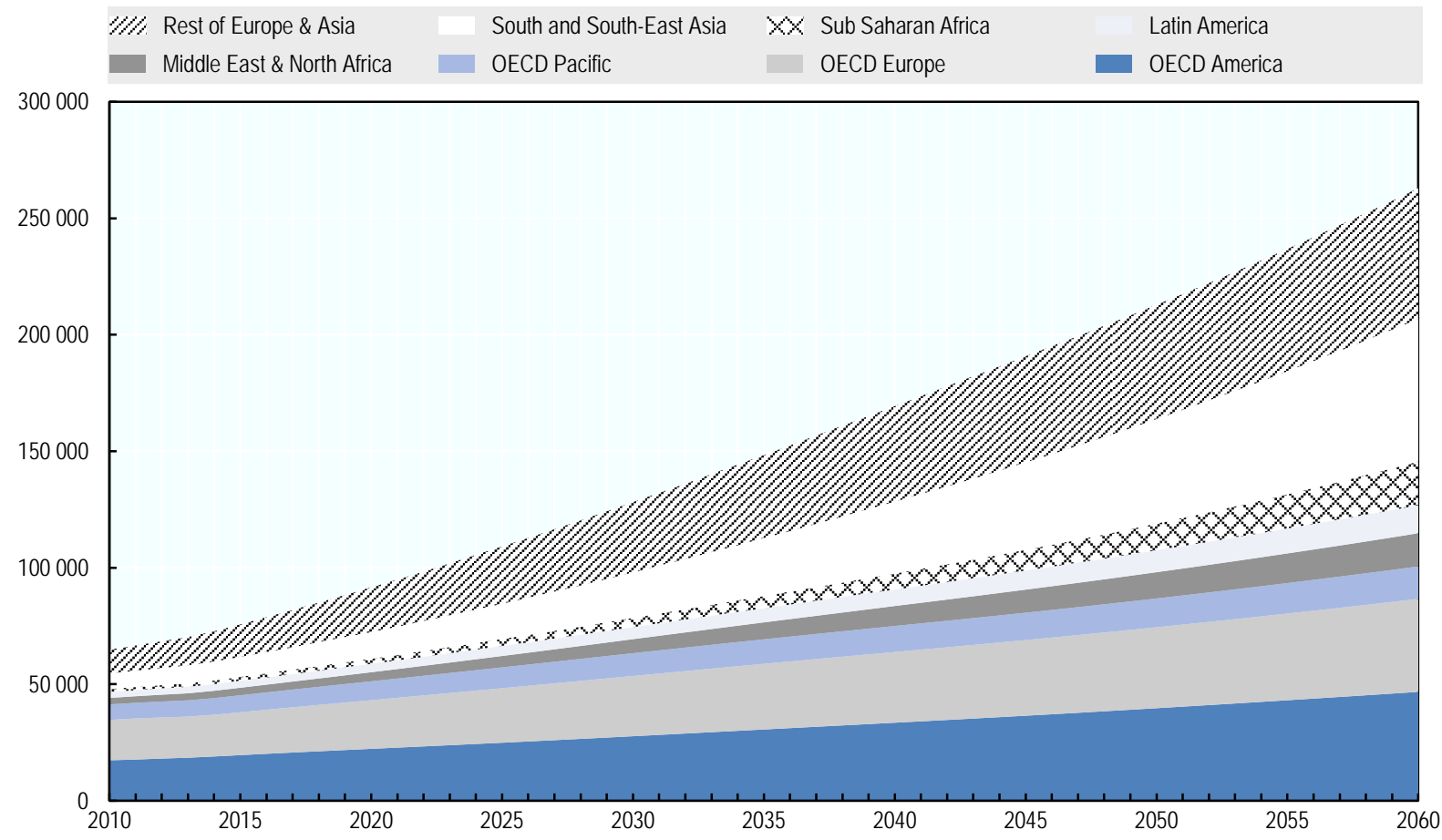




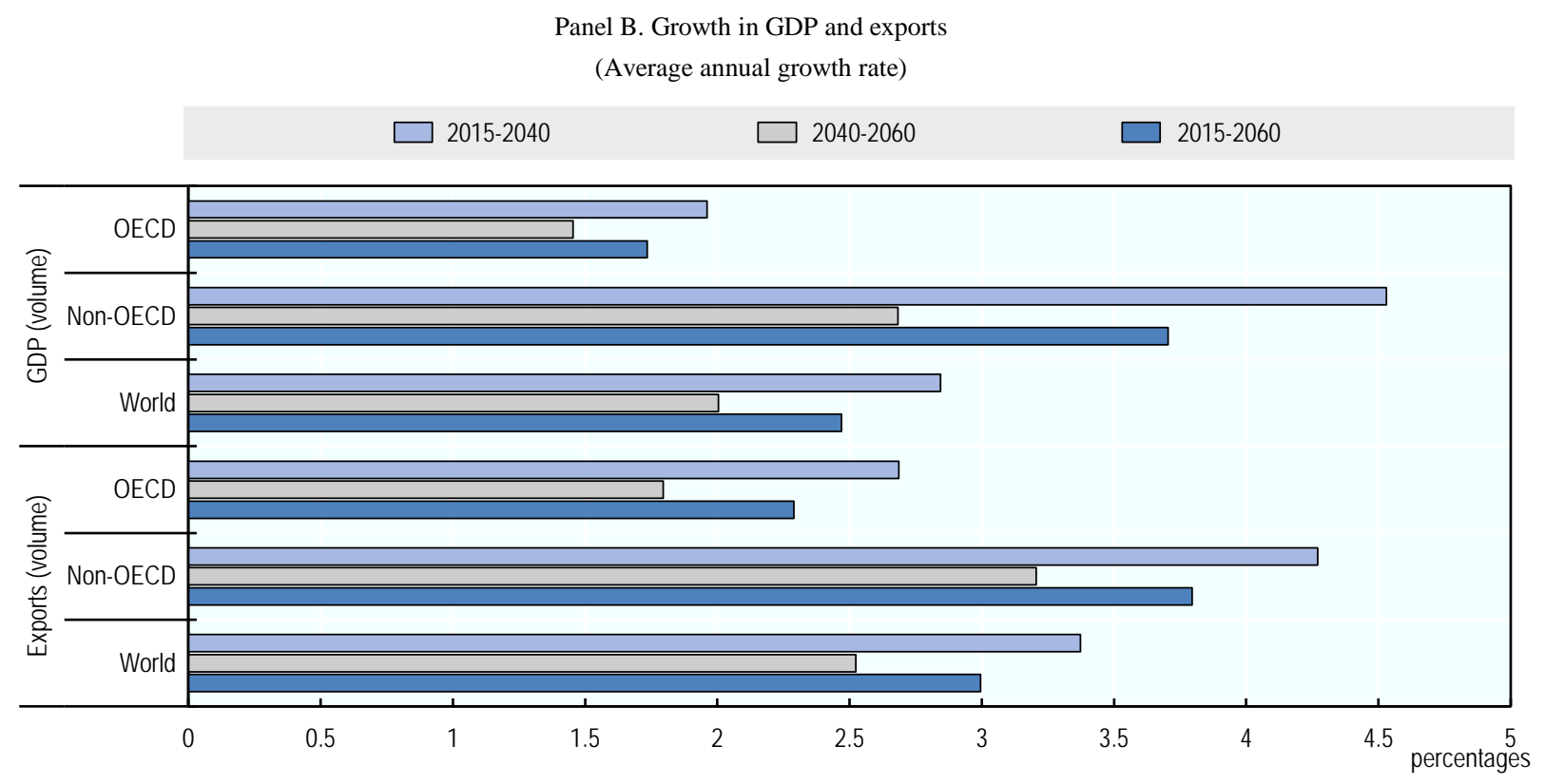

Source: OECD (2015a) based on OECD (2014) for OECD countries and ENV-Linkages model for non-OECD countries.

Over the next half century, world GDP is projected to grow on average around $2.5 \%$ per year, with declining rates in many countries in the last 20 year of the period. The trend GDP growth for the OECD region is projected at about $1.8 \%$ annually until 2060, and growth in emerging economies will continue to outpace the OECD, but the difference will narrow over coming decades as income levels in emerging economies catch up to those in the OECD. Near the middle of the century fast growth in Africa is expected to be the prime source of global economic growth. As a result, the next 50 years will see major changes in country or region shares in global GDP. The faster growth rates in emerging and developing economies imply that the combined GDP of present non-OECD economies are projected to account for around $70 \%$ of world GDP in 2060 versus 50\% in 2015 .

Despite slowdowns in the growth rates of both population and GDP, the shift in economic significance to emerging and developing economies, and - in the absence of new climate policies - unabated use of fossil fuels lead to a sharp increase in GHG emissions. In particular, the increased consumption of coal accelerates increases in emissions. Nonetheless, there is some relative decoupling: emissions grow less rapidly than production. This is caused not least by energy efficiency improvements in many countries. This relative decoupling occurs in many countries, and at the global level, but the strength of this effect varies widely between countries. Global anthropogenic greenhouse gas (GHG) emissions (excl. emissions from land use, land-use change and forestry, which are treated exogenously) are projected to rise from around 45 Gigatonnes (Gt) of $\mathrm{CO}_{2}$ equivalent $\left(\mathrm{CO}_{2} \mathrm{e}\right)$ in 2010 to around $95 \mathrm{GtCO}_{2} \mathrm{e}$ in 2060 (Figure 2, top left panel). Carbon dioxide $\left(\mathrm{CO}_{2}\right)$ is projected to remain the dominant greenhouse gas. The rapid increase in GHG emissions accelerates climate change. Concentrations of $\mathrm{CO}_{2}$ in the atmosphere rise from 390 parts per million (ppm) to 590 ppm between 2010 and 2060 (Figure 2, top right panel). These concentration levels, plus forcing from other GHGs and aerosols lead to an increase in total radiative forcing from anthropogenic sources from just over 2 to almost 5 Watts per square meter $\left(\mathrm{W} / \mathrm{m}^{2}\right)$ (Figure 2, bottom left panel). The central projection delivers temperature increases of more than $2.5^{\circ} \mathrm{C}$ by 2060 above the pre-industrial level OECD TRADE AND ENVIRONMENT WORKING PAPER 2017/01 @ OECD 2017 
(Figure 2, bottom right panel), although there is substantial uncertainty on the temperature changes implied by these carbon concentrations and radiative forcing (Box 1 in Section 3.2.2 discusses these uncertainties in more detail).

Figure 2. Evolution of key climate change indicators in the no-damage baseline projection
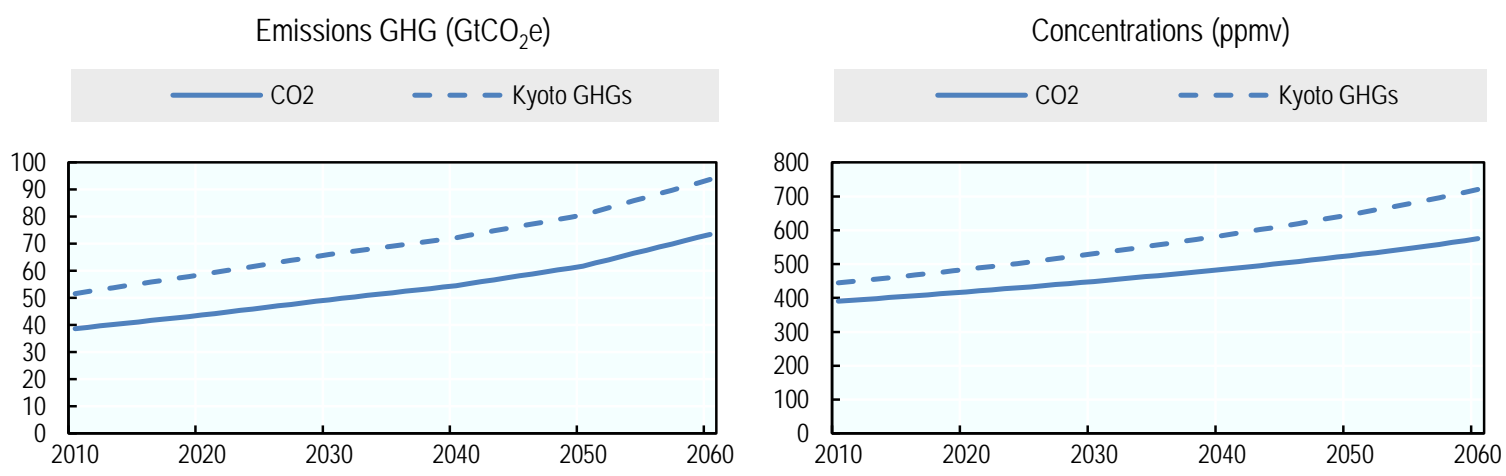

Anthrop. radiative forcing $\left(\mathrm{W} / \mathrm{m}^{2}\right)$
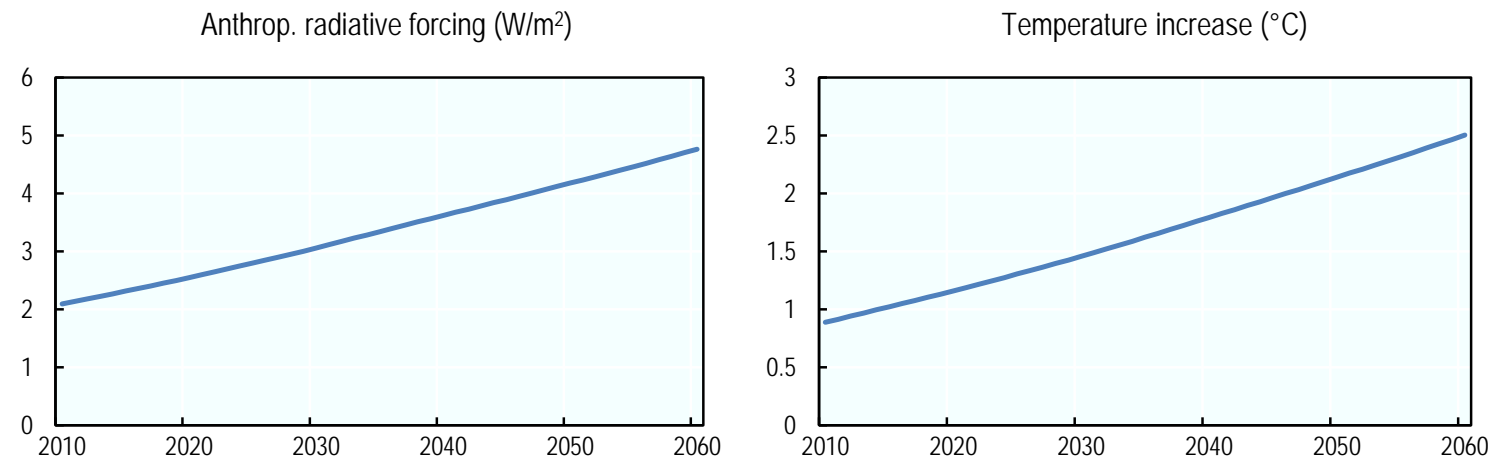

Source: ENV-Linkages model and MAGICC6.4 Model (Meinshausen et al., 2011).

\subsection{Evolution of international trade flows}

The projection of changes in international trade patterns is a core element of the ENV-Linkages model. A central assumption on the representation of international trade in the model is the so-called Armington assumption: domestic and foreign goods and services are considered to be imperfect substitutes. This approach, which is common in CGE models, can mimic plausible levels of bilateral trade by differentiating the price of each good across countries. The model abstracts from an explicit representation of international capital markets, and instead assumes specific pathways for regional current account balances. This latter assumption implies that regional trade balances follow an exogenous path and real exchange rates will adjust in each period to reproduce these balances, and thus maintain model closure. ${ }^{2}$

It is a common assumption in CGE models to decouple international capital markets from international goods markets. In this context current accounts are exogenously given. Hence, the real exchange rates are the "macro" variables that equilibrate trade balance constraints and there are no financial variables in the model. The baseline real exchanges rates of emerging and developing economies progressively increase relative to those of OECD, reflecting a BalassaSamuelson effect. This effect comes from high productivity growth in sectors that produce tradable goods, which will in turn drive wage increases in the slower growing non-tradable sectors. Hence, domestic price levels increase, and thus also relative prices vis-a-vis other countries, i.e. the real exchange rate. 
In line with the long-term economic projections presented in Chateau et al. (2015), growth in trade (gross exports of goods and services) is projected to continue to outpace GDP growth over the next 45 years. The projected global trade-to-GDP elasticity is assumed to be around 1.2 for all goods and services (1.35 for goods and 1.15 for services), over the whole period. Thus, although trade is projected to increase more rapidly than income, this assumption could be seen as low relative in comparison to the historical values of 1.6 for goods between 1950-2009 or the projected value of 1.4 for goods for 2012-2060 presented in the context of the OECD@100 project (Chateau et al., 2015). ${ }^{3}$ The more conservative approach adopted in this report is in line with the more pessimistic outlook for international trade in the Economic Outlook of November 2015.

In terms of geographical distribution, large shifts in trade patterns are projected, reflecting among other things uneven developments in income across the globe as well as changes in comparative advantage (Table 1). The People's Republic of China (hereafter China) and India are projected to gain market shares in world trade over the next half century. Likewise, Africa, Indonesia and other Asian economies are projected to experience sizeable increases in trade shares, especially after 2040, reflecting rapid growth leading to larger economic size combined with low production costs. These gains in trade shares of emerging and developing economies are mostly at the expense of European Union and OECD Asia, while some other OECD regions observe similar relative reductions in their trade shares. ${ }^{4}$ Contrarily, some other OECD economies, including the United States, Mexico and Australia \& New Zealand, are projected to see their trade shares relatively constant over the period.

Technically two assumptions done in the baseline construction explain our conservative view about the future trade to GDP elasticity: firstly in this report and contrarily to the OECD@100 projection no new trade policies and agreements are assumed after 2010, secondly the baseline assumes only small changes will occur in transaction costs for manufacturing goods in nonOECD countries.

$4 \quad$ These declining shares in exports follow a declining share of these regions in global GDP. They reflect a growth in exports that is slower than in other regions, rather than declining absolute export volumes over time. 
Table 1. Geographical distribution of trade in the no-damage baseline projection

(Regional gross exports as share of world exports)

\begin{tabular}{llll}
\hline & $\mathbf{2 0 1 5}$ & $\mathbf{2 0 4 0}$ & $\mathbf{2 0 6 0}$ \\
\hline European Union & $34 \%$ & $26 \%$ & $21 \%$ \\
\hline People's Republic of China & $13 \%$ & $19 \%$ & $18 \%$ \\
USA & $11 \%$ & $10 \%$ & $10 \%$ \\
OECD Asia & $8 \%$ & $6 \%$ & $5 \%$ \\
\hline Other ASEAN countries & $6 \%$ & $7 \%$ & $8 \%$ \\
Middle East \& North African & $5 \%$ & $5 \%$ & $5 \%$ \\
\hline Other OECD & $4 \%$ & $3 \%$ & $3 \%$ \\
\hline Other Asia & $3 \%$ & $4 \%$ & $5 \%$ \\
\hline Other Europe & $3 \%$ & $2 \%$ & $2 \%$ \\
\hline Canada & $3 \%$ & $2 \%$ & $2 \%$ \\
\hline Other Latin America & $2 \%$ & $2 \%$ & $3 \%$ \\
\hline Sub-Saharan Africa & $2 \%$ & $4 \%$ & $7 \%$ \\
\hline Mexico & $2 \%$ & $2 \%$ & $2 \%$ \\
\hline India & $1 \%$ & $3 \%$ & $4 \%$ \\
Australia \& New Zealand & $1 \%$ & $2 \%$ & $2 \%$ \\
Indonesia & $1 \%$ & $1 \%$ & $2 \%$ \\
\hline Brazil & $1 \%$ & $1 \%$ & $1 \%$ \\
Caspian region & $1 \%$ & $1 \%$ & $1 \%$ \\
\hline
\end{tabular}

Source: OECD ENV-Linkages model.

The changing geographical distribution of trade is also featured by changes in the relative importance of trading partners (Figure 3 ). The expected shift of wealth creation from OECD to non-OECD countries will have important implications for trade patterns. While currently about half of total trade flows in bilateral terms took place within the OECD area, the share of bilateral trade among OECD members is expected to nearly halve by 2060. Instead, by 2060 trade among non-OECD economies is projected to more than double, to account for approximately one-third of global trade. The growing share of non-OECD countries in world GDP is one driver for this, but it is also because non-OECD countries will progressively adopt more similar production structures to those in the OECD, so that they can trade between each other instead of trading with OECD partners. 
Figure 3. Bilateral trade between OECD and non-OECD countries in the no-damage baseline projection

(Regional gross exports at FOB prices as share of world exports)

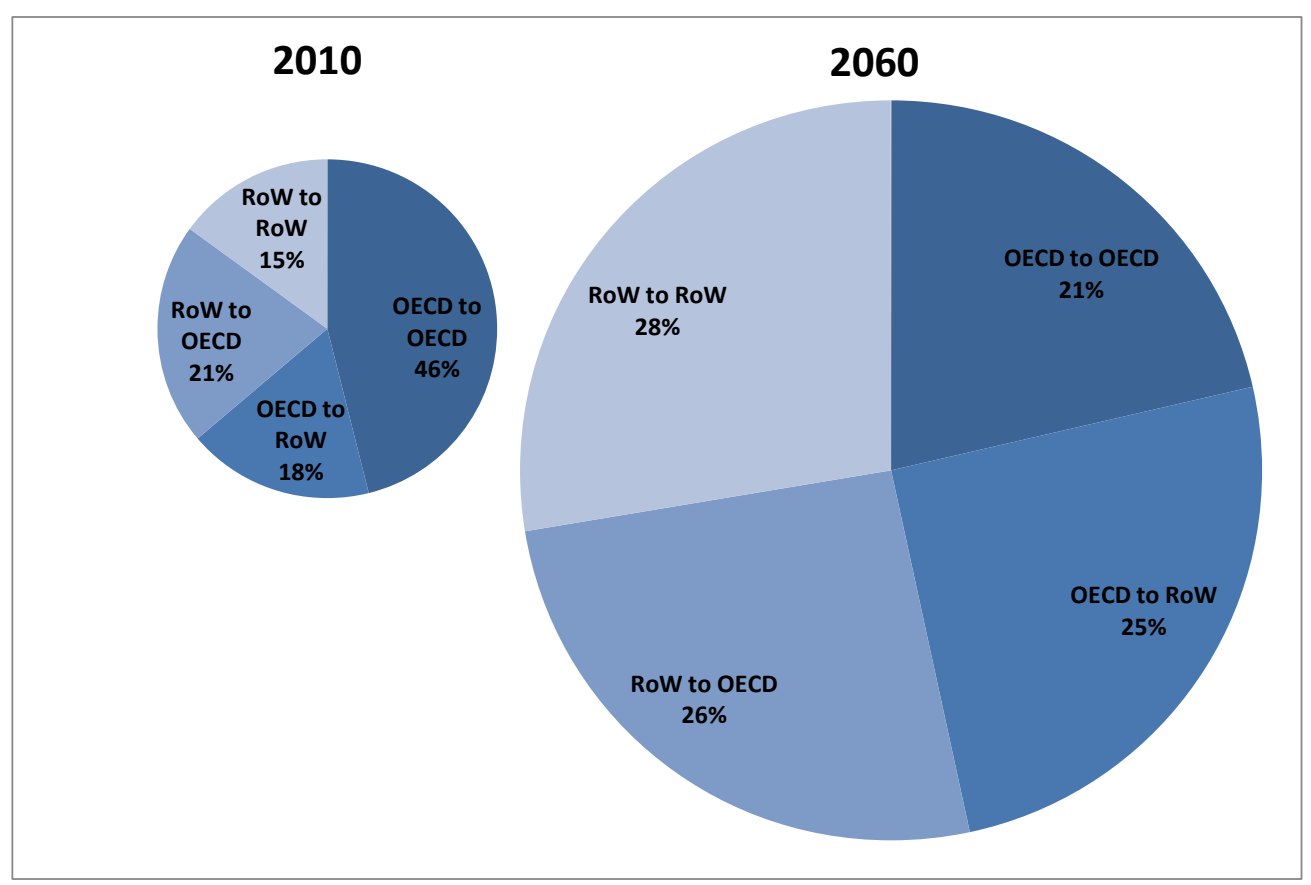

Source: OECD ENV-Linkages model.

Changes in sectoral trade patterns are driven by differences in income growth, but also by convergence in consumption patterns. As shown in Annex B, the baseline scenario will project a convergence in consumption patterns across countries that imply, among other things, a large shift away from consumption of food and necessary products towards services in emerging economies. Convergence in consumption patterns is projected to follow convergence in income levels. For production, there is more differentiation between countries in terms of access to technologies, factor endowments and productivity levels of production. Hence, production patterns evolve more slowly, and international trade patterns adjust to equate demand and supply in all regions. As a consequence, most OECD countries are projected to lose market shares for almost all goods (see also Figure B.4 in Annex B), while non-OECD East-Asian countries and African countries are projected to gain market shares in manufacturing goods and Latin American countries in textiles and food products (but not necessarily in raw agricultural goods). 


\title{
3. Impacts of Climate Change on Domestic Economies and International Trade
}

\begin{abstract}
The physical impacts of climate change will have direct as well as indirect consequences for trade. Direct effects encompass the effects of climate change on trade-relevant supply, transport and distribution chains, which could become manifest in damages to trade infrastructure such as ports from more frequent extreme weather events or rising sea level. Other impacts, such as retreat of polar ice under warmer temperatures can lead to opening up new trade routes in the Arctic. Indirect impacts for trade will primarily result from the impact of climate change on the production of goods and services through changes to the factors of production of economies, i.e. land, labour, and capital. Both direct and indirect effects of climate change on trade will likely lead to changes to the comparative advantage of economies, hence trade flows and patterns.
\end{abstract}

\subsection{The direct impacts of climate change on international trade}

Climate change will impact trade through a number of channels, not all of which can be easily quantified. This section outlines some of the main impacts, based on a brief review of the literature. One prominent explanation for the rise in international trade in the last decades was a decline in international transportation costs (Hummels, 2007). One key direct effect of climate change is that supply, transport and distribution chains might become more vulnerable to disruptions due to climate change, thereby affecting future international trade patterns. Extreme weather events, for instance, may lead to the temporary shutdown of ports and transport routes; they might also damage infrastructure critical to trade and thus have longer-lasting effects. These and other interruptions can lead to delays, increase the costs of international trade and could lead to a shift in trade patterns as companies involved in trade seek alternatives to increase reliability of shipping (WTO, 2009).

Although the literature on the link between climate change and trade is limited and mostly qualitative, there is high agreement among experts that climate change will on balance negatively affect transport infrastructure. According to reports surveyed by the IPCC (2014), climate change will affect all forms of transport relevant for international trade, including seaborne transportation, land-based transport modes, and aviation. There is only a small amount of research that points to the potential positive consequences of climate change on trade infrastructure, and supply, transport and distribution chains (Hansen et al. (2016), Heininen et al. (2015), Liu et al (2010), Maddocks et al. (2010)). ${ }^{5}$

Trade-relevant impacts to land-based transportation from climate change may become manifest in faster degradation of road and bridge infrastructure, and shorter

\footnotetext{
${ }^{5}$ All these literatures are on the Artic shipping.
} 
availability of transport routes through permafrost zones (IPCC, 2014). Bridges will be particularly prone to damage from sea level rise and changes in long-term flow regimes if authorities do not encourage necessary investments in adaptation. In the United States, for example, engineers typically design bridges to endure storms that have a historical probability of occurring only once or twice every 100 years. However, past climatic observations may no longer reliably predict future impacts due to climate change. Extreme weather events, including storms, may take place every 50 or even 20 years by the end of the century if global warming continues (IPCC, 2012). In addition, heat stress and a higher number of freeze thaw cycles may accelerate the degradation of paved roads. Higher temperatures will likely contribute to the melting of permafrost, shortening the availability of transportation routes through zones of cryotic soil (WTO, 2009; IPCC, 2014).

Airborne transport of goods for international trade might be impacted by climate change, for instance through damage to or impairment of the operations of airports. Research suggests that sea level rise, increased storminess, and extreme precipitation induced by climate change can affect the operations of airports, lead to more frequent disturbances, and affect infrastructures in weather-exposed or low-lying areas. Higher temperatures may also reduce aircraft lift, making airports adapt runways and air companies to change aircraft types or maximum payload with climate change. To address climate change from international flight emissions, which contributes about $2 \%$ of globally produced $\mathrm{CO} 2$ and accounts for $13 \%$ of fossil fuels consumed by transport (IPCC, 2007), the International Civil Aviation Organization (ICAO) ${ }^{6}$ has initiated movements toward strengthening technology standards and market-based instruments - such as a levy or a cap-and-trade scheme based on GHG emissions. ${ }^{7}$ It is expected that this may result in an additional financial burden on aviation transport.

Maritime shipping, which accounts for around $80 \%$ of global trade by volume and more than $70 \%$ of global trade by value (UNCTAD, 2014), could also experience some negative consequences from climate change. Increased storms, increased precipitation, and sea level rise may cause more frequent port closure, affect speed of passage, necessitate the use of alternative shipping routes or additional safety measures, and increase the maintenance costs for ships and ports (IPCC, 2014). Dependent on location, physical impacts from climate change might also affect future inland navigation.

\footnotetext{
${ }^{6}$ The ICAO is the primary UN body responsible for regulating civil aviation.

${ }^{7}$ www.icao.int/Pages/default.aspx 
Table 2. Potential direct impacts and consequences on trade infrastructures

\begin{tabular}{|c|c|c|c|}
\hline Climate change effect & Mode & Direct impact & Consequences on trade infrastructure \\
\hline \multirow[t]{3}{*}{$\begin{array}{l}\text { Increased temperature and } \\
\text { solar radiation }\end{array}$} & Land-based & $\begin{array}{l}\text { Road pavement cracking; Asphalt } \\
\text { rattling; Rail buckling; Loss of water seal } \\
\text { causing potholing }\end{array}$ & $\begin{array}{l}\text { Require more frequent maintenance }(-) \\
\text { Require track and road repairs or speed } \\
\text { restrictions to avoid derailments (-) } \\
\text { Higher maintenance and insurance costs }(-)\end{array}$ \\
\hline & Aviation & $\begin{array}{l}\text { Reduced life of asphalt on airport } \\
\text { tarmacs; } \\
\text { Reduced airlift capacity }\end{array}$ & $\begin{array}{l}\text { Need to construct longer runways to } \\
\text { compensate for reduced airlift (-); } \\
\text { Need for ground-cooling mechanisms (-) } \\
\text { Higher maintenance and insurance costs (-) }\end{array}$ \\
\hline & Sea-based & Reduced refrigeration storage period & Increase refrigeration costs (-) \\
\hline \multirow[t]{3}{*}{$\begin{array}{l}\text { Increased precipitation and } \\
\text { river floods }\end{array}$} & Land-based & $\begin{array}{l}\text { Flooding of land infrastructures; } \\
\text { River bridge scour; } \\
\text { Wet pavements and safety risks }\end{array}$ & $\begin{array}{l}\text { Need to re-route to avoid climate change- } \\
\text { affected roads (-); } \\
\text { Higher maintenance and insurance costs (-) }\end{array}$ \\
\hline & Aviation & $\begin{array}{l}\text { Flooding of runways and access roads; } \\
\text { Reduced visibility; Damage facilities } \\
\text { including airstrips; }\end{array}$ & $\begin{array}{l}\text { Higher maintenance costs and insurance } \\
\text { costs }(-)\end{array}$ \\
\hline & Sea-based & $\begin{array}{l}\text { Reduced capabilities in } \\
\text { loading/uploading of cargo at ports; } \\
\text { Increased rates of corrosion / oxidation } \\
\text { equipment }\end{array}$ & $\begin{array}{l}\text { Risk of delays (-); } \\
\text { Increased construction and maintenance } \\
\text { costs (-) }\end{array}$ \\
\hline \multirow[t]{3}{*}{$\begin{array}{l}\text { Sea level rise and sea storm } \\
\text { surges }\end{array}$} & Land-based & $\begin{array}{l}\text { Permanent or temporary inundation; } \\
\text { Submerge of bridges }\end{array}$ & $\begin{array}{l}\text { Risk of delays (-); } \\
\text { Higher maintenance and insurance costs (-) }\end{array}$ \\
\hline & Aviation & Submerge of terminals and villages & $\begin{array}{l}\text { Relocation and migration of people and } \\
\text { business (-) }\end{array}$ \\
\hline & Sea-based & $\begin{array}{l}\text { Lower clearance under waterway } \\
\text { bridges; } \\
\text { Damage to port infrastructure; Increased } \\
\text { rates of corrosion and oxidation } \\
\text { equipment }\end{array}$ & $\begin{array}{l}\text { Need for new ship design (-); } \\
\text { Need for reconfiguration of operational areas } \\
(-) \text {; } \\
\text { Higher maintenance costs and repair of port } \\
\text { facilities (-) }\end{array}$ \\
\hline \multirow[t]{3}{*}{ Extreme weather conditions } & Land-based & $\begin{array}{l}\text { Disturbance to transport electronic } \\
\text { infrastructures, signalling, etc. }\end{array}$ & $\begin{array}{l}\text { Disruption to operations (-); } \\
\text { Higher maintenance and insurance costs (-) }\end{array}$ \\
\hline & Aviation & $\begin{array}{l}\text { Disturbance to transport electronic } \\
\text { infrastructures, signalling, etc. }\end{array}$ & $\begin{array}{l}\text { Risk of delays; (-); } \\
\text { Higher maintenance and insurance costs (-) }\end{array}$ \\
\hline & Sea-based & $\begin{array}{l}\text { Temporary shutdown of ports; } \\
\text { Deterioration of sailing conditions; } \\
\text { Disturbance to transport electronic } \\
\text { infrastructures, signalling, etc. }\end{array}$ & $\begin{array}{l}\text { Risk of delays (-); } \\
\text { Higher maintenance and insurance costs (-) }\end{array}$ \\
\hline $\begin{array}{l}\text { Reduced Arctic sea ice } \\
\text { cover }\end{array}$ & Sea-based & Opening of Arctic shipping routes & $\begin{array}{l}\text { Reduced distances and time }(+) \\
\text { Need for additional navigation aids such as } \\
\text { ice-breakers for ships using the Arctic route } \\
(-) ; \\
\text { Higher insurance costs for ships using the } \\
\text { Arctic route }(-)\end{array}$ \\
\hline
\end{tabular}

Source: OECD based on Race (2015), UNCTAD (2014), Maddocks et al. (2010).

At the same time the loss of the Arctic ice cap will open up new possibilities for maritime transportation in the Arctic. One high-profile example is the potential further opening of Arctic shipping routes, including the Northeast Passage, the Northwest Passage, and the Transpolar Sea Route, for longer periods. Given that the Arctic ice is melting at a rapid rate, a growing number of papers find that reduced ice cover would permit ships with light icebreakers access to pretty much anywhere in the Arctic Ocean by $2040 .^{8}$ the Transpolar Sea Route (TSR). These are currently seasonal sea routes which has ice-free period only for summer. During summer, the North East Passage and North West Passage are easily navigable whereas the Transpolar Sea Route is navigable only with powerful icebreakers. 
This implies that the availability of Arctic shipping paths could lead to distance reduction for the relevant bilateral trade routes. Such distance reduction can have significant implications on international trade patterns. Shorter sailing distances allow for time savings and result in cost savings. Transportation cost is an important factor to determine the trade pattern, and in turn the transportation cost is determined by variables such as distance, time, trade volume and vessel size, competition, infrastructure, and piracy and other risk (OECD, 2011). Among such factors affecting the transportation costs, distance has been regarded as one of the most important determinants. Many studies and literature confirmed this "distance decay" - the volume of trade declines as the distance between two countries increases, reflecting transportation costs of increased freight costs and increased length of transit.

For trade between Europe and Asia, the conventional sea route is mainly the Suez Canal Route, which connects the Mediterranean and the Eastern Asia. The emerging alternative through the Arctic region is the Northern Sea Route (NSR), which is also called as Northeast Passage. Bekkers et al. (2015) analyses that the northern route would reduce the distance from Japan to northern European countries by 37\%, from Korea by 31\%, China 23\%, and Chinese Taipei 17\%. The countries in Europe that will gain most from the new sea route are those with access to ports on the North Sea and the Baltic. For South Asian countries and southern European countries, the conventional southern route will still be shorter. For trade between America and Asia, the traditional route is via the Panama Canal and the emerging alternative is the Northwest Passage (NWP). As an alternative to the traditional route, the distance savings achieved by navigating the NWP are close to $20 \%$ for most of the large ports located in North Eastern Asia (Hansen et al., 2016).

If the new sea route becomes a viable alternative for large portions of the year, world trade patterns may alter, benefiting northern countries, and potentially causing a reduction in revenues for the current main trade routes such as the Suez Canal. Bekkers et al. (2015) investigate the hypothetical extreme scenario in which the arctic route becomes fully operational all year around, and project that roughly $8 \%$ of world trade goes through the Suez Canal, and that two-thirds of this volume could potentially go via the shorter Arctic route if that becomes permanently available. The northern route would then become one of the busiest shipping lanes in the world, increasing the economic and political importance of the Arctic. At the same time, it will put economic pressure on countries that benefit from shipping that uses the southern route, but also some countries in eastern and southern Europe would experience a drop in trade because of the comparatively longer distances their exports and imports would need to travel. Over time, the opening of the Arctic route may have positive indirect effects on jobs and prosperity in all the countries concerned, but it is predicted that this will be a gradual rather than sudden process.

However, given that commercial use of Arctic shipping routes depends not only on distances but also on a number of other factors, distance advantage does not guarantee the fully viable commercial use of Arctic shipping routes in the near future. The shorter distances could attract time-sensitive cargoes, but on the other hand, other factors may outweigh the benefits.

There are a number of factors that caution against the hypothetical scenarios reviewed in the preceding paragraphs. Ships operating in the Arctic are exposed to unique risks. The most significant barrier is the transport logistic obstacles. These include underdeveloped communication systems, insufficient navigational aids, the need to use icebreakers, limited commercial weather forecasts, patchy search and 
rescue capabilities, scarcity of relief ports along the route, reduced sailing speeds, poorer fuel economy, detours, and damage to ships (Humpert and Raspotnik, 2012). These conditions increase the insurance premium and costs, thereby limiting the commercial viability of shipping operation.

At the same time, there has been an increasing concern about the vulnerability of Arctic ecosystems due to the potential further opening of Arctic shipping routes. Arctic shipping is among the greatest threats to biodiversity in the Arctic. Even if it is potentially beneficial for the economy, it may have detrimental effects on the environment. New opportunities for arctic shipping due to ice-melting present many threats for the regional environment and biodiversity, if not properly managed. First, it may increase emissions to air. Studies show that the increase of pollutants such as black carbon (BC), particulate matter, nitrogen oxide $\left(\mathrm{NO}_{\mathrm{x}}\right)$, carbon monoxide (CO) and sulphur oxide $\left(\mathrm{SO}_{\mathrm{x}}\right)$ may have significant regional effects potentially affecting human and environmental health in the Arctic Area (AMSA, 2009). BC emissions the result of incomplete combustion of fossil fuels and biomass - are of particular concern, in spite of their short atmospheric lifetimes, as they accelerate snowmelt and sea ice loss by reducing the albedo of snow and ice. ${ }^{9}$ Second, it may increase release of oil through spills or operational or illegal discharges. The release of oil into the Arctic environment could have short and long-term consequences on marine life, given that some Arctic animals are sensitive to oil (Arctic Yearbook, 2015). The Arctic environment is particularly vulnerable to the heavy fuel oil, which accounts for three-quarters of the fuel used in Arctic shipping (AMAP, 2013). ${ }^{10}$ Third, international shipping can also be an important vector in introducing invasive alien marine species, including through hull fouling and discharge of ballast water (Bax et al, 2003). These species are a major threat to Arctic ecosystems, both for flora and wildlife. Besides these significant challenges, increased waste, sound and noise disturbances, vessel collisions with marine mammals are also threats to Arctic environment and biodiversity.

Faced with growing concerns about the vulnerability of Arctic ecosystems to increasing traffic ${ }^{11}$, the International Maritime Organisation (IMO) formally adopted the new International Code of Safety for Ships Operating in Polar Waters (the Polar Code) by in May 2015. ${ }^{12}$ Reflecting the need for a high degree of environmental protection, the Polar Code includes much stricter regulations for Arctic shipping such as mandatory requirements for ship design, crew training, barriers to separate fuel tanks from ships' outer hulls, and a limit on discharge of sewage (ABS, 2016) ${ }^{13}$ These

According to the Arctic Council's Arctic Monitoring and Assessment Programme, although shipping is currently contributing only $5 \%$ of the black carbon load in the Arctic, this amount could quadruple by 2050 .

"It degrades slowly under Arctic conditions, the evaporation and dispersion rates are low compared to lighter, refined fuels, it may emulsify once released into the marine environment, and it is impossible to clean up in ice covered conditions and with a lack of nearby response resources and infrastructure. It has a devastating effect on marine life, particularly as Arctic marine food webs are so simple.” (Arctic Yearbook, 2015, p. 392).

In the Arctic, approximately 2,000 vessels currently operate, and the number is likely to grow as ice melts.

The code is expected to enter into force on 1 January 2017.

However, heavy fuel oil - which has been regarded as one of the biggest threats to the Arctic climate - is not banned under the Polar Code. 
new requirements would be another factor that may affect the net economic gains resulting from shortened transit route on Arctic shipping routes.

Several issues on direct impacts of climate change on trade require further clarification. With uncertainties on the pace and extent of the logistical barriers, the lack of infrastructure, harsh weather conditions, short winter days, and on how melting ice may affect the stability of the Arctic climate, it is difficult to predict how large an effect Arctic shipping may have on international trade. Furthermore, infrastructure in developing countries may become more climate-resilient in the future as a result of international development support, not least when donor mainstream climate considerations in their development assistance. These remain key areas for further analysis.

\subsection{The indirect consequences of climate change on international trade}

\subsubsection{The regional economic consequences of climate chang $e^{14}$}

The report The Economic Consequences of Climate Change (OECD, 2015a) provides a detailed global quantitative assessment of the costs of inaction on climate change. It presents the projected macroeconomic and sectoral economic consequences of climate change (i.e. climate damages) in absence of new climate policies, for a selected number of impacts: changes in crop yields, loss of land and capital due to sea level rise, changes in fisheries catches, capital damages from hurricanes, labour productivity changes and changes in healthcare expenditures from diseases and heat stress, changes in tourism flows, and changes in energy demand for cooling and heating. As mentioned above, due to a lack of data, this analysis does not include any of the direct impacts on trade and infrastructure discussed in Section 3.1, although qualitatively it is clear that e.g. increased freight costs from climate impacts will imply higher trade costs and therefore affects international trade patterns. A full discussion of the modelling assumptions is given in OECD (2015a); a summary is provided in Annex C. ${ }^{15}$ Here the main modelling results are summarised, to provide background for the analysis in the next section.

The modelling assessment suggests that market damages from the selected set of impacts are projected to gradually increase over time and rise faster than global economic activity. If no further climate change action will be undertaken, the combined effect of the selected impacts (in the climate damages scenario) on global annual GDP are projected to rise over time to likely levels of $1.0 \%$ to $3.3 \%$ by 2060 , with a central projection of $2 \%$ (Figure 4 ). ${ }^{16}$ This range reflects uncertainty in the equilibrium climate sensitivity (ECS) - a measure indicating how sensitive the earth's climate reacts to a doubling of atmospheric $\mathrm{CO}_{2}$ - using a likely range of $1.5^{\circ} \mathrm{C}$ to $4.5^{\circ} \mathrm{C}$ (see Box 1 in the next subsection) and a central projection of $3^{\circ} \mathrm{C}$. Assuming a wider range of $1^{\circ} \mathrm{C}$ to $6^{\circ} \mathrm{C}$ in the ECS, GDP losses could amount to $0.6 \%$ to $4.4 \%$ in 2060.

This section draws heavily on Chapter 2 of OECD (2015a).

OECD (2015a) also highlights that there are numerous important impacts of climate change which could not be included in the modelling analysis and provides the broader context that surrounds these simulations, and the logic for ambitious policy action.

Annex D presents some key results presented in this Section at the more disaggregated 25 region. 
The caveats on uncertainties in and incompleteness of these projections notwithstanding, the macroeconomic projections are well-aligned with the literature on quantified economic damages. ${ }^{17}$ The latest report of Working Group II of the Intergovernmental Panel on Climate Change (IPCC, 2014) surveyed the existing literature and found "global aggregate economic losses between 0.2 and $2.0 \%$ of income ("medium evidence, medium agreement", Ch. 10) for a temperature increase of $2.5^{\circ} \mathrm{C}$ (this is not linked to a specific date). In the central projection of ENVLinkages, this threshold is reached just before 2060. Given the relatively large variety of impacts included in this analysis, it is not surprising that the GDP losses projected here are at the higher end of the range provided by the IPCC.

Figure 4. Regional damages from selected climate change impacts in the climate damages scenario

(Percentage change in GDP w.r.t. no-damage baseline)

Panel A. Evolution over time

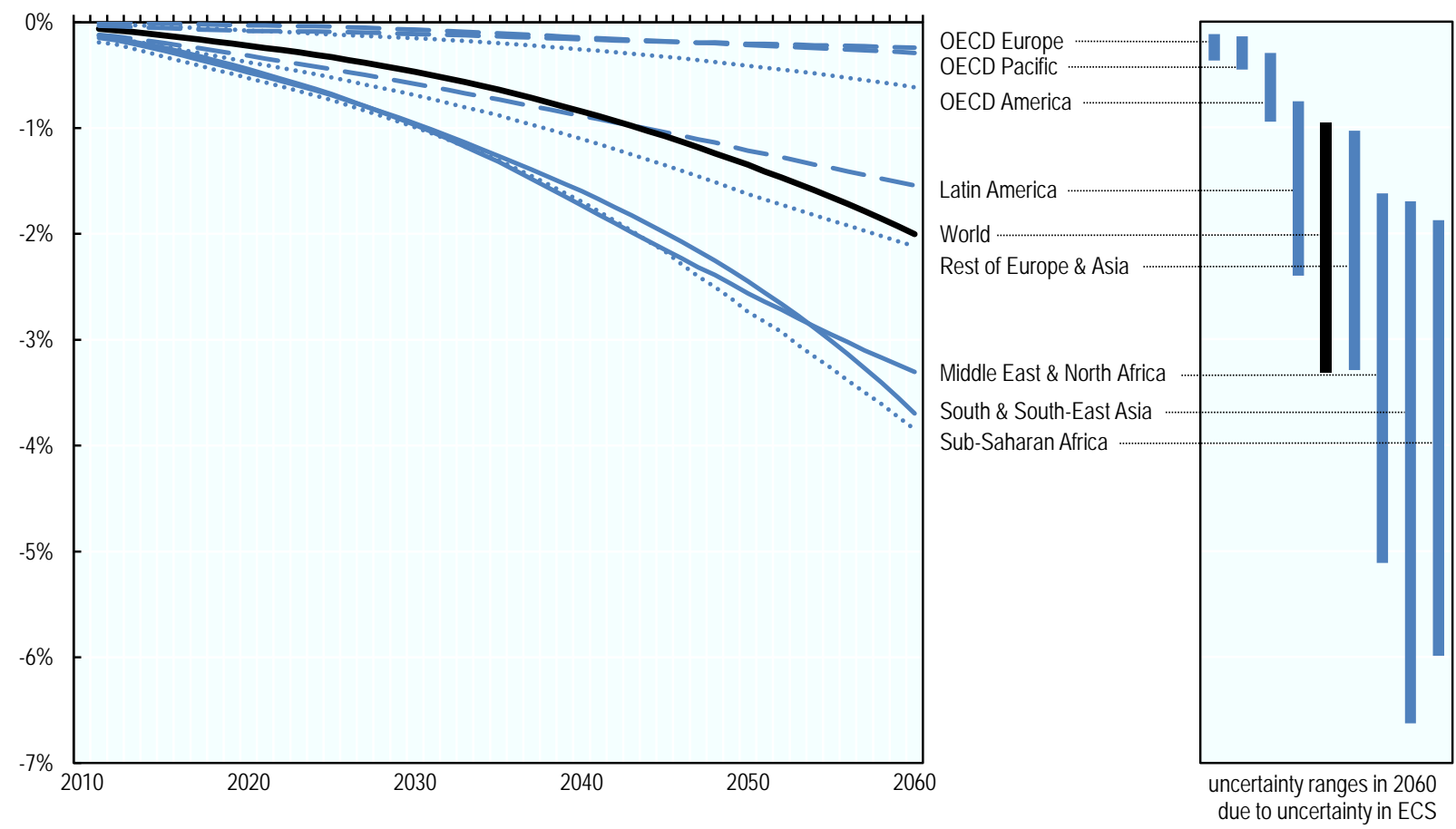

Although there are significant differences between the modelling approach and calibration used here and earlier economic studies of climate damages, similar patterns emerge in e.g. Nordhaus (2007; 2011), Eboli et al. (2010), Bosello et al. (2012), Roson and Van der Mensbrugghe (2012), Bosello and Parrado (2014) and Ciscar et al. (2014). In these studies, global impacts are increasing more than proportionately with temperature increases (and hence over time) and amount to reductions of several percent of GDP by the end of the century. Highest impacts are foreseen in emerging and developing countries, especially in South and South-East Asia and Africa, whereas countries at a high latitude in the Northern hemisphere, especially Russia, may be able to reap some economic benefits from the climatic changes. Studies that focus on a specific region tend to show larger negative impacts on the local economy, but by nature ignore the endogenous adjustment processes that take place within economies, and changes in international trade patterns. 
Panel B. Attribution of global damages to different impacts

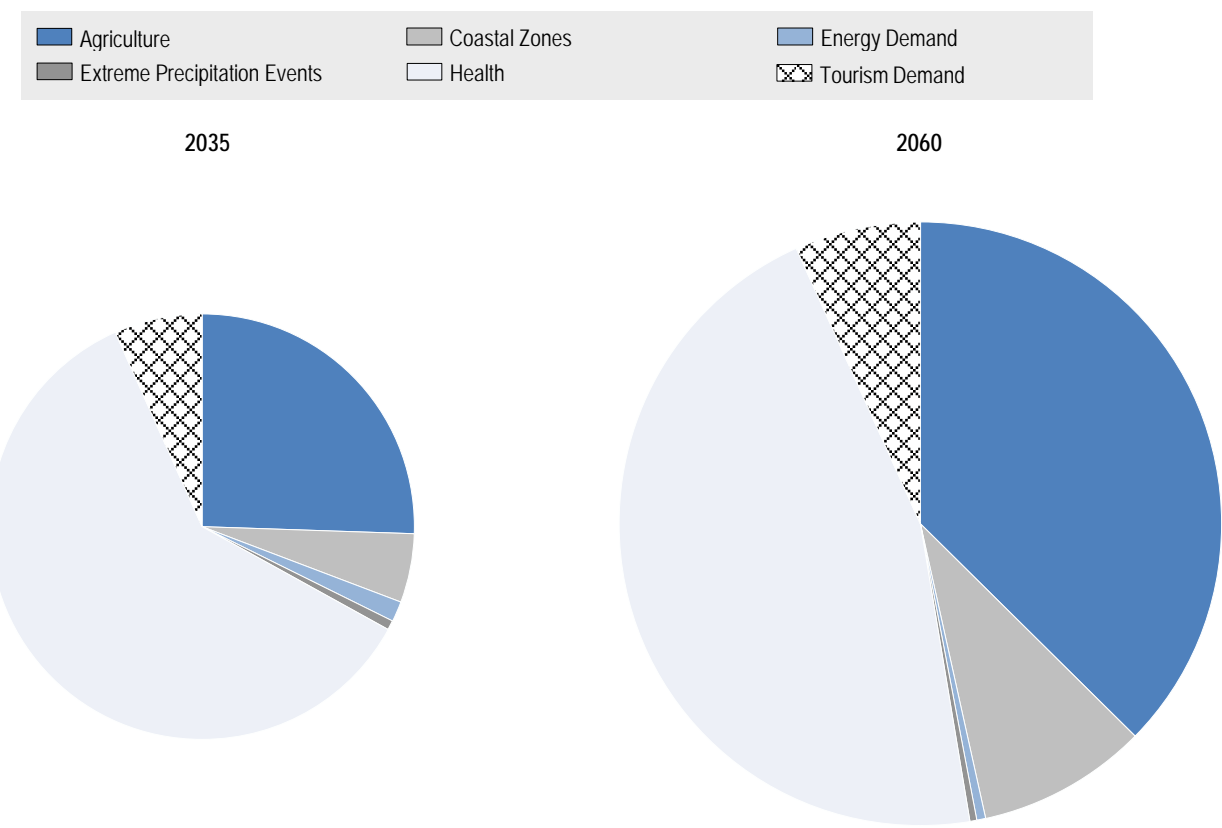

Source: OECD ENV-Linkages model.

Some sectors are directly impacted by specific climate impacts (e.g. services sectors are affected by health impacts, energy sectors by energy demand impacts). However, there are also substantial indirect effects that are induced by the full range of price changes that follow climate impacts. For example, impacts on the energy demands affect energy prices and thus induce changes in production in energyintensive industrial sectors. As another example, capital destruction from sea-level rise affects all sectors through changes in the marginal productivity of capital. Of the impacts modelled in the analysis, changes in crop yields and in health (labour productivity) are projected to have the largest negative consequences on the macro economy, causing loss to annual global GDP of $0.9 \%$ and $0.8 \%$, respectively, by 2060 for the central projection of the climate damages scenario (panel B). ${ }^{18}$

The GDP impacts of climate change damages as projected with the ENV-Linkages model can also be decomposed into changes in each specific primary factor of production. Climate impacts may directly affect labour, capital, land and natural resources. Figure 5 shows the decomposition of GDP losses according to production factor, with shading indicating the direct changes in value added of a production factor. These direct effects have been calculated by multiplying the percentage change in productivity with supply of these production factors at their no-damage baseline levels of use, i.e. before any endogenous market adaptation effects. The indirect effects (hatched in Figure 5) are then calculated as the difference between the total effect and the direct effect. by 2060 in Sub-Saharan Africa); see Section 4.2.1. Such effects are excluded from the analysis here. 


\section{Figure 5. Sources of damages from selected climate change impacts by production factor in the} climate damages scenario

(Percentage change in GDP in 2060 w.r.t. no-damage baseline)

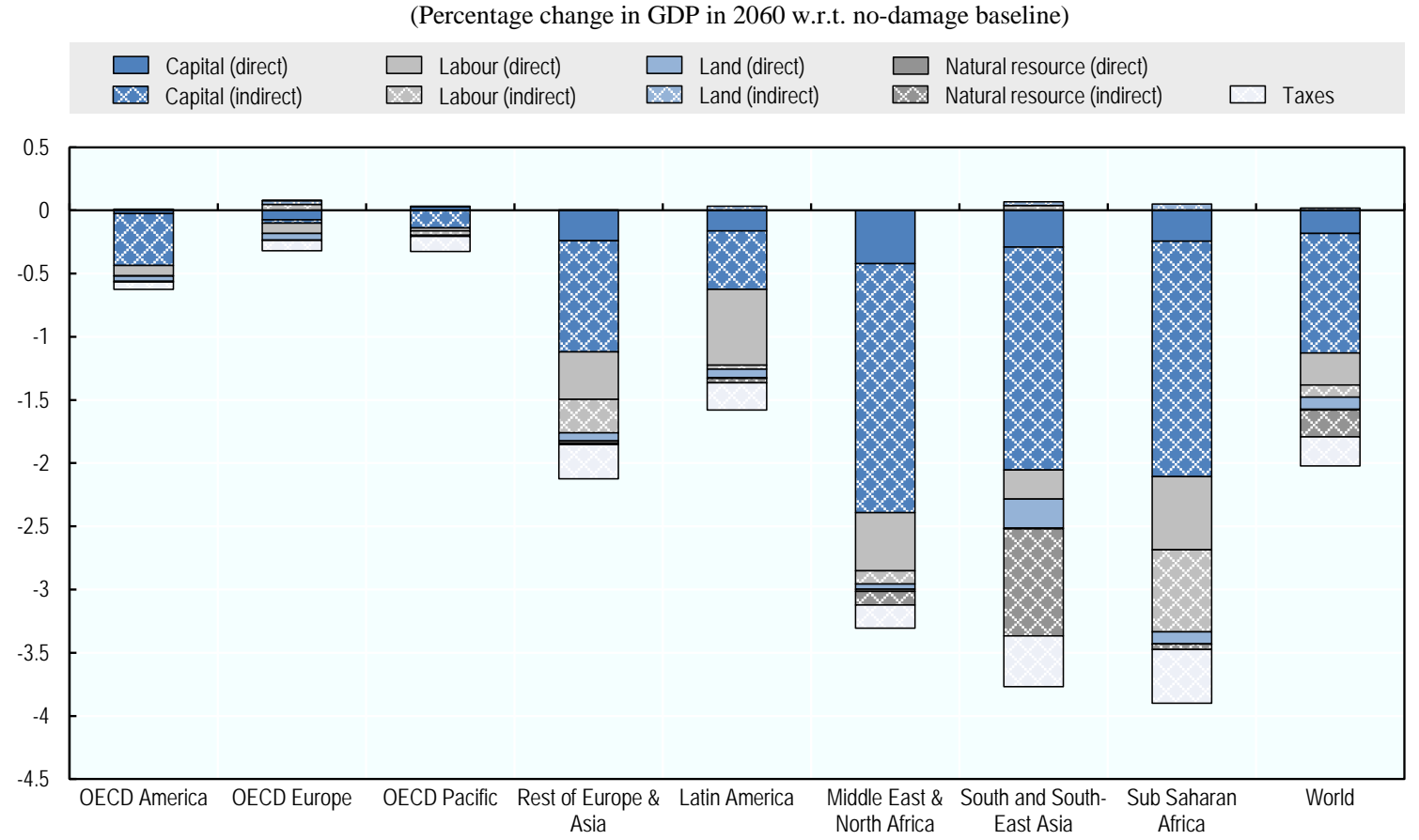

Note: Plain areas denote direct effects and hatched areas the associated indirect effects.

Source: OECD ENV-Linkages model.

In the model, total labour supply is assumed to be fixed, and total land supply is not very flexible and hence direct effects more or less directly translate into GDP loses, although sectoral reallocation can still affect their overall contribution to GDP. The reduction of value added from natural resources in South and South-East Asia is attributed to the decline in production of a number of resource-dependant sectors, which is induced by the changes elsewhere in the economy.

For capital, the situation is different, as its supply is flexible in the long run, since consumers can adjust their savings patterns in response to changes in the economic situation. Thus, there is an additional effect, as changes in income levels affect savings and hence future capital accumulation. Thus, the climate impacts not only affect the level of GDP, but also the growth rate, through reduced capital accumulation. As can be inferred from Figure 5, capital losses are substantially larger than the other factor losses, and this can be attributed to these indirect economic effects. At the global level, almost half of the projected GDP loss of $2 \%$ can be attributed to the indirect effects on capital, which may be interpreted as growth effects. In other words, by 2060 the projected economic consequences on GDP levels and on GDP growth are of similar size. This implies that logically, the longer-term consequences of climate change are substantially worse than the short- and medium-term consequences, unless new sources of economic growth can be found.

Adverse impacts of climate change will affect the production of all commodities of the economy, including those that are heavily traded internationally. Agricultural products may be particularly affected by climate change through increase in temperature and more frequent heat extremes. Further, changes in precipitation will in most regions likely lead to significant reductions in crop yields and hence, decreased crop output. For specific crops in specific regions, relatively small temperature 
increases, combined with increased rainfall, may benefit crop production. In order to examine the extent to which economies will be affected by the adverse impact of climate change on crop yields, Figure 6 illustrates the projected changes in yields in the climate damages scenario compared with the baseline scenario in $2060 .{ }^{19}$ The pure climate shocks on yields implemented in the model are calculated using the climate shocks of the IMPACT model for the AGMIP study (Von Lampe et al., 2014; Wiebe et al., 2015). ${ }^{20}$ Note that the effective change in crops yields tends to be smaller than the pure climate shocks: farmers can change their production process and to adapt to the pure climatic shocks on yields, and will do so in order to minimise their costs, i.e. market-driven adaptation is endogenously handled inside the economic modelling framework. These effects have been included in Figure 6. But the modelling framework excludes the possibility to increase the fraction of agricultural land that is irrigated. In regions with sufficient water supply for irrigation, this adaptation option can be an important part of the response to climate change (Ignaciuk and MasonD’Croz, 2014). Still, it is excluded here as markets forces alone are usually insufficient to achieve large-scale expansion of irrigated areas (Ignaciuk, 2015).

To avoid drastic changes in percentage terms when the baseline production level is very small, changes in yields are only shown for production volumes that exceed 1 percent of global production. are occasionally positive due to improved rainfall patterns and milder temperatures, such as for rice in the OECD Asian countries; see also Figure 1.2 in OECD (2015a). 
Figure 6. Impact of climate change on yields for selected crops in the climate damages scenario

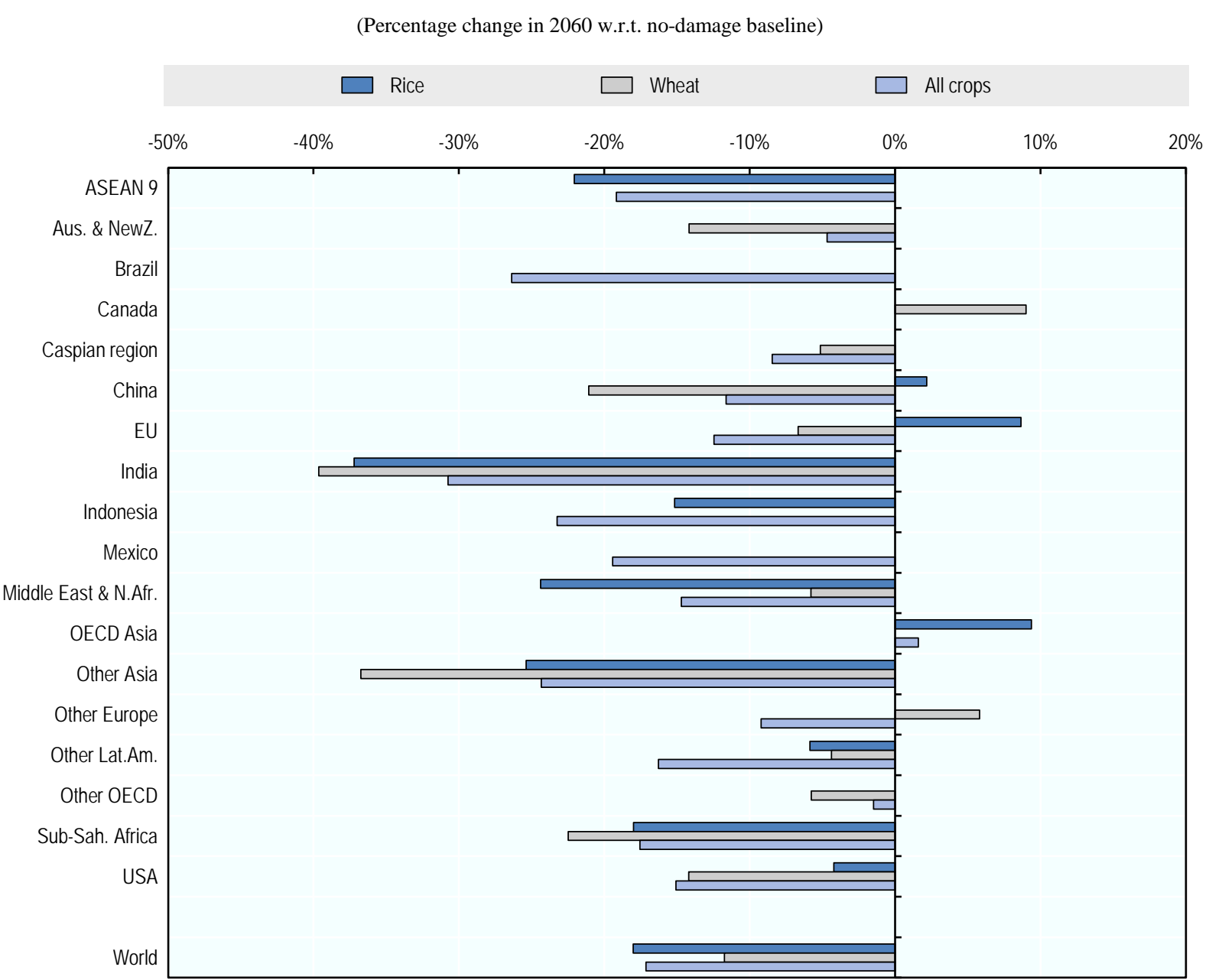

Source: OECD ENV-Linkages model.

\subsubsection{Changes in trade patterns due to climate change impacts}

The economy-wide and sectoral consequences of climate changes discussed in the previous section have important implications for trade and specialisation across countries. To highlight this, this section compares the baseline with no climate change impacts trade projection with the scenario with climate damages.

The volume of international trade is projected to be affected by climate change to more or less the same extent as global GDP. Figure 7 indicates that world exports may decrease by $1.8 \%$ in 2060 , relative to the baseline without climate damage, while global imports and GDP would be reduced by 1.6\% (expressed in 2010 USD using PPP exchange rates). At the global level, the decline in exports is larger than that of imports, as both are measured in different prices (FOB and CIF, respectively). ${ }^{21}$ In principle, one could expect that increased trade flows are necessary to compensate for production losses in the most affected economies. However, as indicated by the GDP losses, there is a global contraction of final demands (compared to the no-damage

21

In the model, volumes are expressed in constant 2010 USD; over time the price indexes for export and imports will deviate, as only flows in current dollars are balanced at the world level. 
baseline), and given the imperfect substitution between domestic and foreign goods and services, this will imply a reduction in both production and trade.

Regional shifts in trade patterns also differ: the African and Asian countries that are most affected by climate impacts (Figure 4) are also those that are projected to record growing importance in world trade over the next 50 years (see Table 1 and Figure 3). Exports contract more than imports especially in India and Sub-Saharan Africa, as their domestic production is severely hit by climate change. In contrast, Canada and the Other Europe region can increase their export volumes. The drivers for these changes are investigated in detail in Section 4.

Figure 7. Changes in trade volumes from climate impacts in the climate damages scenario (Percentage change in 2060 w.r.t. no-damage baseline)

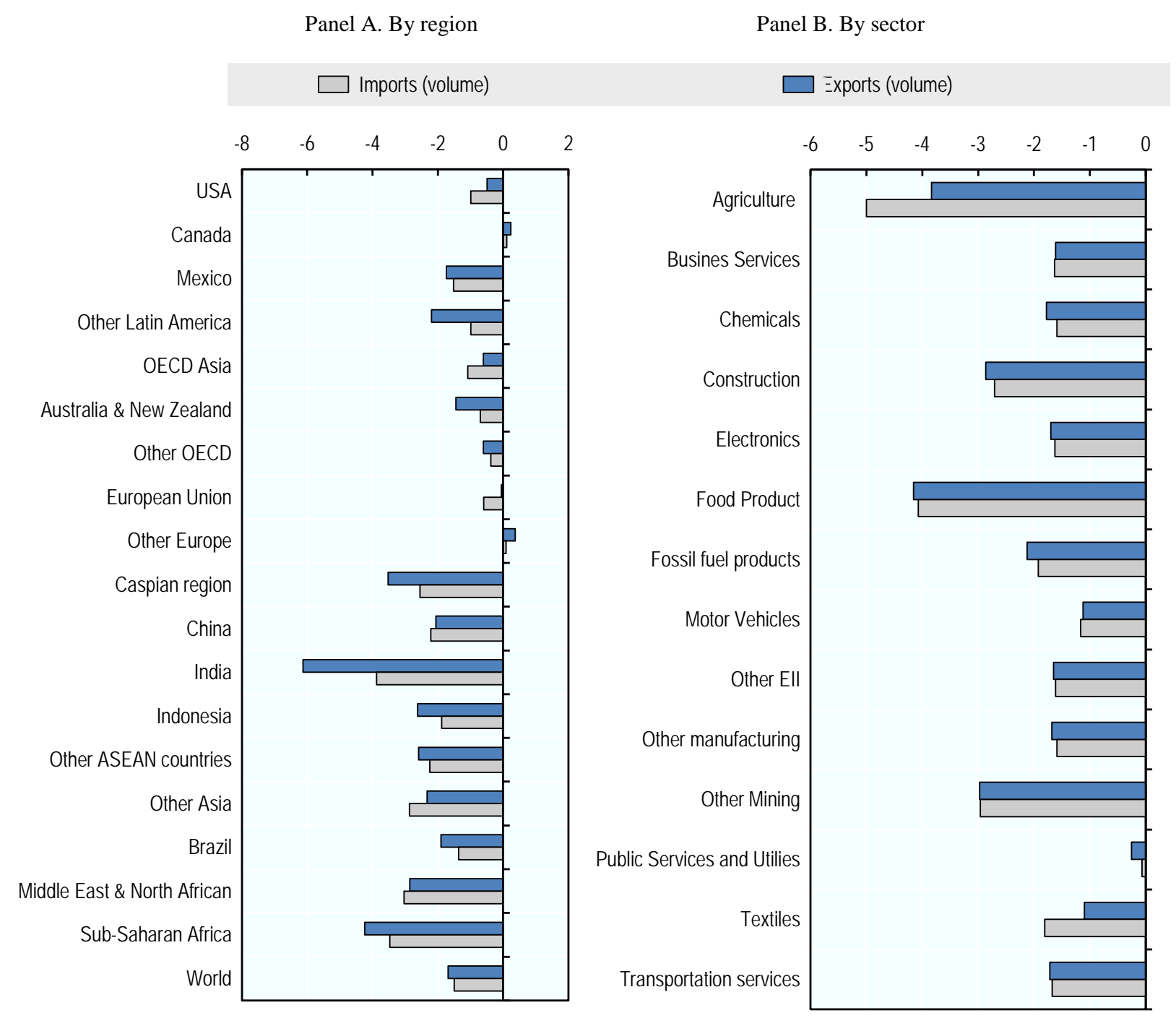

Source: OECD ENV-Linkages model.

GDP losses are not the only channel through which climate change would impact international trade. The differences in impacts of climate damage on economic sectors also translate in changes in the composition of trade. As indicated in Panel B of Figure 7, trade in agricultural commodities is projected to be relatively strongly OECD TRADE AND ENVIRONMENT WORKING PAPER 2017/01 @ OECD 2017 
impacted by the negative climate damages, not least through the direct impact on crop yields. This hides some major differences between various crops: the staple goods rice and wheat are projected to be more traded in response to climate change, while trade in other agricultural crops declines (see Section 4.2.1 for more details). Indirectly food product trade is also significantly affected as - at least in value terms - food is substantially more traded than its primary components, namely 'raw' agricultural products. $^{22}$

These sectoral and regional changes in trade flows are also reflected in changes in global export market shares. Figure 8 presents a country's potential export share under the baseline scenario as linked to the change in export share in 2060 under the climate change. Countries on the left-hand side are projected to lose export market share in 2060 without climate change, with in the case of Middle East \& North Africa climate change projected to lead to even further decline. Generally, those regions that increase their export share in the baseline see a reduction in export shares from climate damages. An explanation is that these regions depend strongly on trade as a source of economic growth, leaving them vulnerable to shocks that negatively affect trade opportunities.

Figure 8. Change in export shares in the no-damage baseline projection and in the climate damages scenario

Change in export share (Percentage change)

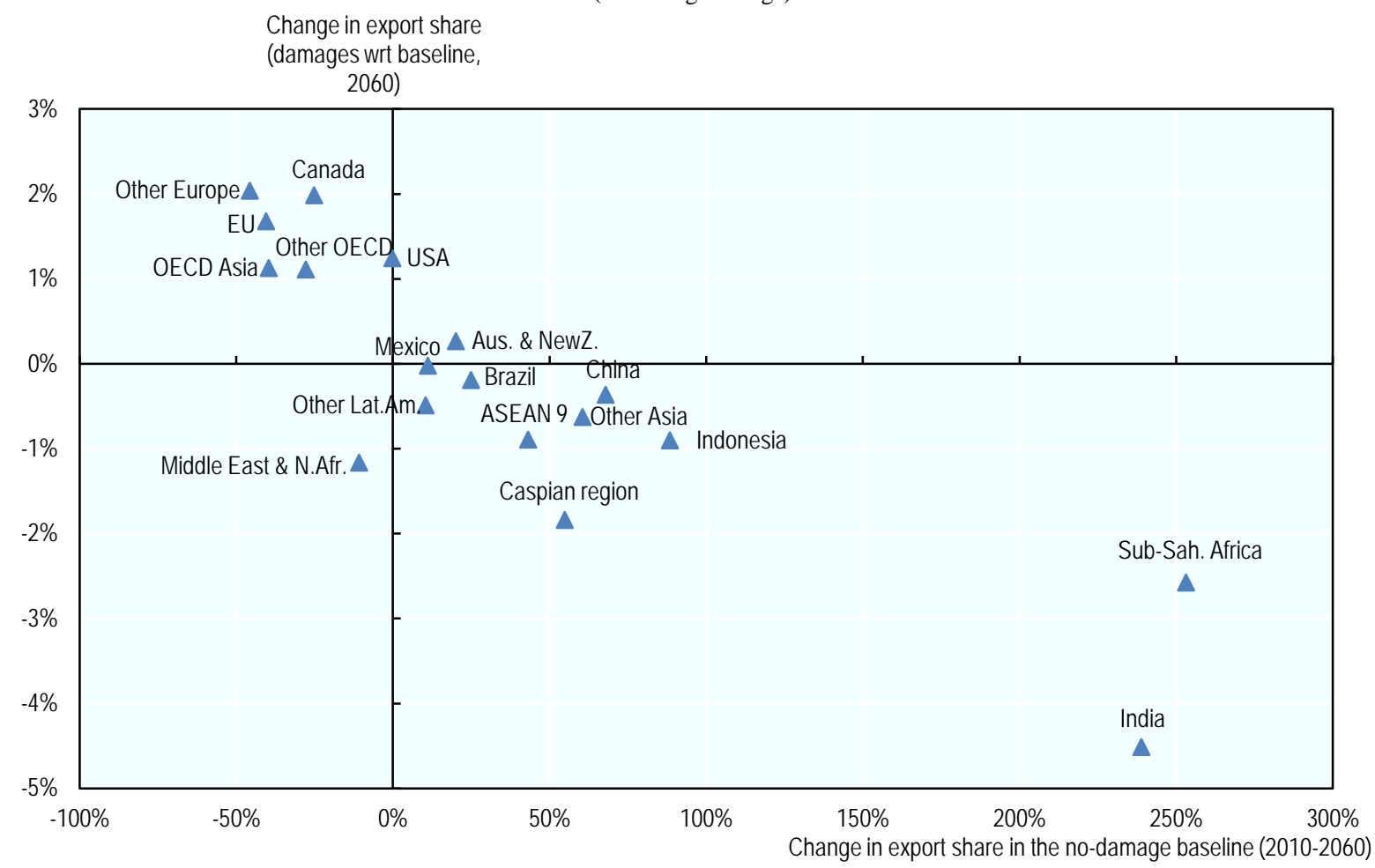

Source: OECD ENV-Linkages model. products category includes meat, milk, vegetable oils, processed rice, sugar, other food, beverages and tobacco products. 


\section{Box 1. Uncertainty on the projections}

The numerical results presented in this report are surrounded by significant uncertainties. The equilibrium climate sensitivity (ECS) reflects the equilibrium climate response, i.e. the long-run global average temperature increase, from a doubling in carbon concentrations, and is often used to represent the major uncertainties in the climate system in a stylised way. In Figure 9, the ECS is varied between $1.5^{\circ} \mathrm{C}$ and $4.5^{\circ} \mathrm{C}$ in the likely uncertainty range, and between $1{ }^{\circ} \mathrm{C}$ and $6^{\circ} \mathrm{C}$ in the wider uncertainty range, in line with the 5th Assessment Report of the Intergovernmental Panel on Climate Change (IPCC) (Rogelj et al., 2012; IPCC, 2013). The global temperature increase by 2060 that is associated with the likely uncertainty range on the ECS equals 1.6 to $3.6^{\circ} \mathrm{C}$, while the larger range is 1.1 to $4.3^{\circ} \mathrm{C}$.

Figure 9. Change in trade volumes and in GDP for a range of climate damages scenarios

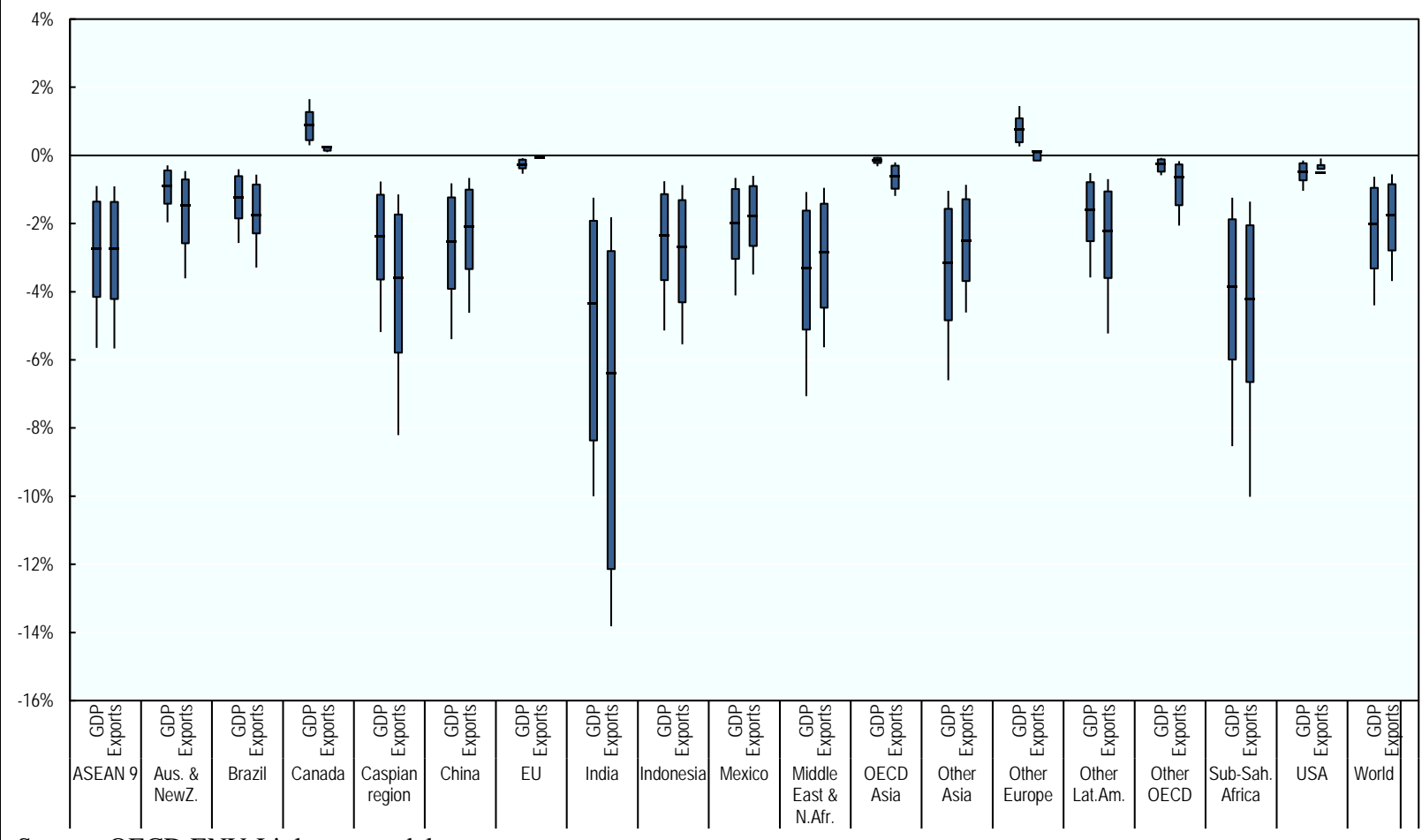

Source: OECD ENV-Linkages model.

The blue bars in Figure 9 indicate how much regional damages may fluctuate in the likely range, while the thin black lines highlight that the impacts may be considerably larger (or smaller) when the wider uncertainty range is considered. Thus, by 2060, global annual GDP losses for the likely ECS range are $1.0 \%$ to $3.3 \%$, but the possibility that global losses from the selected impacts covered in the model are as low as $0.6 \%$ or as high as $4.4 \%$ cannot be excluded. Changes in export levels follow a similar pattern for most regions, but the downside uncertainties tend to be amplified. A key difference is that a potential increase in GDP hardly translates into a similar increase in exports; given the global loss in international trade volumes, this is not surprising.

The panel clearly shows that the regional differences in GDP losses in the central projection are relatively small when compared to the uncertainties within a region related to different climate sensitivities. Perhaps equally importantly, the model analysis shows that even at low levels of climate sensitivity there will be significant (albeit smaller) GDP and export losses in many countries.

A more detailed analysis of how uncertainty on the ECS affects the assessment of the macroeconomic consequences of climate change is given in OECD (2015a). The approach to measuring the uncertainties surrounding the numerical results is too crude to reliable present uncertainty margins on the more detailed sectoral results. Nonetheless, these uncertainties should be kept in mind when interpreting the results of the analysis of the central projection in Section 4. 


\section{Understanding the Indirect Impacts of Climate Change on International Trade}

As mentioned above, the indirect consequences of climate change on international trade patterns can be understood by looking at 4 key channels: (i) changes in transportation costs; (ii) changes in macroeconomic competitiveness (the macroeconomic channel); (iii) changes in comparative advantage at the sectoral level (the sectoral channel); and (iv) changes in policies.

This section focuses on two of these main channels of trade impacts: the macroeconomic channel of the income effect, and the sectoral channels of the compositional effects. Changes in international transportation costs were reviewed separately in Section 3.1, but are not included in the modelling exercise. On balance, Section 3.1 and the wider literature suggest that by 2060 the quantitative effects of direct trade impacts are relatively minor, especially in comparison with the significant indirect trade impacts of climate change, although for specific climate events in specific regions, temporary trade disruptions can be very significant.

Changes in policies, as an endogenous response to the projected macroeconomic and trade consequences of climate change, are explicitly excluded in the analysis. While it may well be the case that countries react to large changes in trade flows and losses to their domestic economies by revising their trade and other policies, these are not easily predicted. An analysis of the role of trade flexibility in responding to climate change impacts, and the interactions between trade policies (incl. trade liberalisation) and climate policies deserves a separate study. ${ }^{23}$ By excluding an endogenous policy response, the analysis here boils down to an assessment of the costs of inaction. This can then serve as a basis for assessing the benefits of policy action.

There are no direct measures of competitiveness and comparative advantage. For a macroeconomic analysis, changes in trade flows can be linked to a range of macroeconomic variables, including GDP and exchange rates. At the sectoral level, Revealed Comparative Advantage (RCA) is a common technique for providing information on the relative advantage or disadvantage of a country in the supply of certain goods or services on international markets (Box 2). Linkages baseline projection. No new trade policies or trade agreements are implemented after 2010: tariff rates as well as export tax rates are assumed to stay constant over the horizon. In similar spirit, support to production (in agriculture and energy) that could be seen as indirect subsidies to domestic production are also kept constant, relative to the tax-basis. The only change in policies that is implemented in the baseline are energy and carbon policies as covered by the IEA in its "Current Policies Scenarios" presented in the World Energy Outlook 2013 (IEA, 2013). 


\section{Box 2. The Revealed Comparative Advantage (RCA)}

An RCA indicator can be used to show more clearly how changes to factors of production (induced by climate change damages in this case) affect gains and losses from trade that countries derive from domestic factor endowments. RCA is defined as the share of a region's exports of a set of commodities in the region's total exports relative to the share of the world's exports of these commodities in global exports. Technically,

$$
R C A \equiv \frac{\mathrm{X}_{\mathrm{i}, \mathrm{j}} / \mathrm{X}_{\text {'all', } \mathrm{j}}}{\mathrm{X}_{\mathrm{i}, \text { all' }} / \mathrm{X}_{\text {'all','all' }}} \equiv \frac{x_{i j} / \sum_{i} x_{i j}}{\sum_{j} x_{i j} / \sum_{i j} x_{i j}}
$$

where $\mathrm{x}_{\mathrm{ij}}$ denotes exports of product $i$ by country $j$ and 'all' refers to the relevant group of all products (i.e. all those that are exported) or all regions (i.e. all those that are exporting product $i$ ).

\subsection{Income effect: changes in macroeconomic competitiveness of countries}

Figure 10 shows that changes in GDP are generally well-aligned with the overall volume changes in trade at the macro level: countries whose national income deteriorates from climate impacts will scale down not only domestic economic activity, but also the volume of trade, both for imports and exports. ${ }^{24}$

For the regions most affected by climate damages, not least India and Sub-Saharan Africa, exports are projected to contract more than GDP. Given the strong impacts of climate change on these regions (cf. Section 3), their production costs increase much more than those of their trading partners such that their macroeconomic competitiveness will decline. ${ }^{25}$ As import changes are essentially driven by income change, import reductions in these regions are very close to GDP reduction. In these countries the large drop in domestic production is partially compensated through increasing the import share, in order to keep domestic consumption as little affected as possible.

In contrast, regions whose macroeconomy is less affected by climate change (in this case regions with GDP losses of less than 1\% in 2060), can increase their competitive position on their domestic market, i.e. import shares decline and imports fall more than GDP. At the same time, these regions have lower losses (or higher gains) for exports than for imports, which is indicative of their increased competitive position on the international market.

\footnotetext{
$24 \quad$ Annex D presents some key results presented in this Section at the more disaggregated 25 region.

$25 \quad$ Two other regions that are substantially affected by climate change, Other Asia and the Middle East, defy this trend and have relatively small impacts on exports. These two regions are characterised by very particular specialisation patterns which partially shelters them against trade impacts.
} 
Figure 10. Change in trade volumes and in GDP in the climate damages scenario

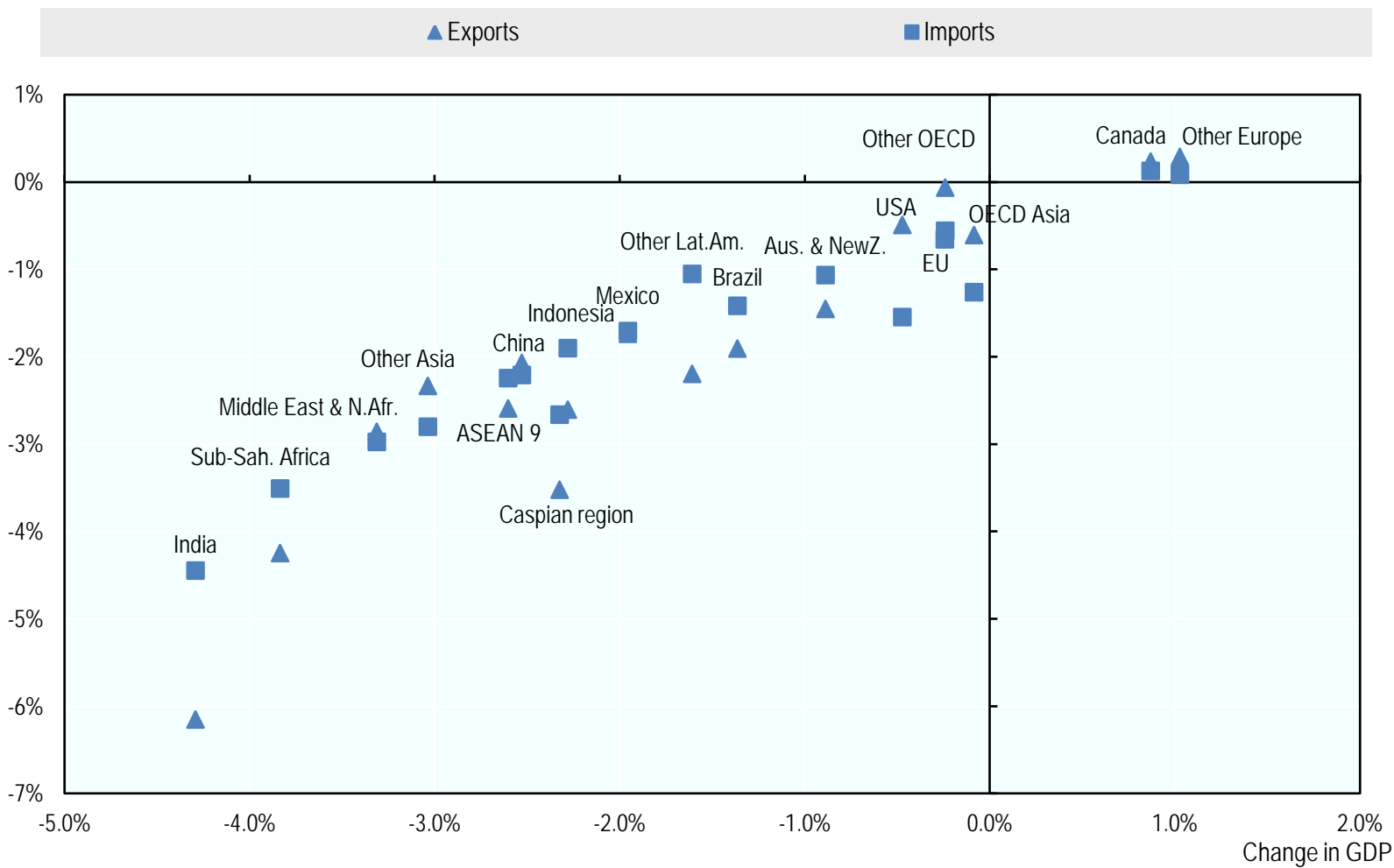

Note: y-axis presents percentage change in exports and imports, respectively w.r.t. no-damage baseline.

Source: OECD ENV-Linkages model.

Given the assumption of exogenous trade balances in the model, changes in trade flows alone cannot show all the mechanisms at work. ${ }^{26}$ An important role in adapting to the climate impacts is through adjustments of the real exchange rate, which adjust endogenously to correct any imbalance in trade flows relative to the reference projection. Figure 11 highlights that in general large GDP losses are associated with strong increases in the real exchange rate vis-a-vis the United States. Increases in the real exchange rate in the worst affected countries imply a degradation of their competiveness, or in other words that their exports become more expensive relative to international prices. These results confirm the insights from Figure 8 in Section 3.2: those regions that have strong increases in export volumes in the no-damage baseline (India, Sub-Saharan Africa), have relatively strong degradation of their competitiveness, both in terms of export volumes and exchange rates; countries at the other side of the spectrum, and especially Other Europe, have contracting export shares in the no-damage baseline projection, and much smaller effects of climate damages. adjusting exchange rates, may influence the quantitative results but would not reverse the general insights. 
Figure 11. Change in real exchange rates in the climate damages scenario

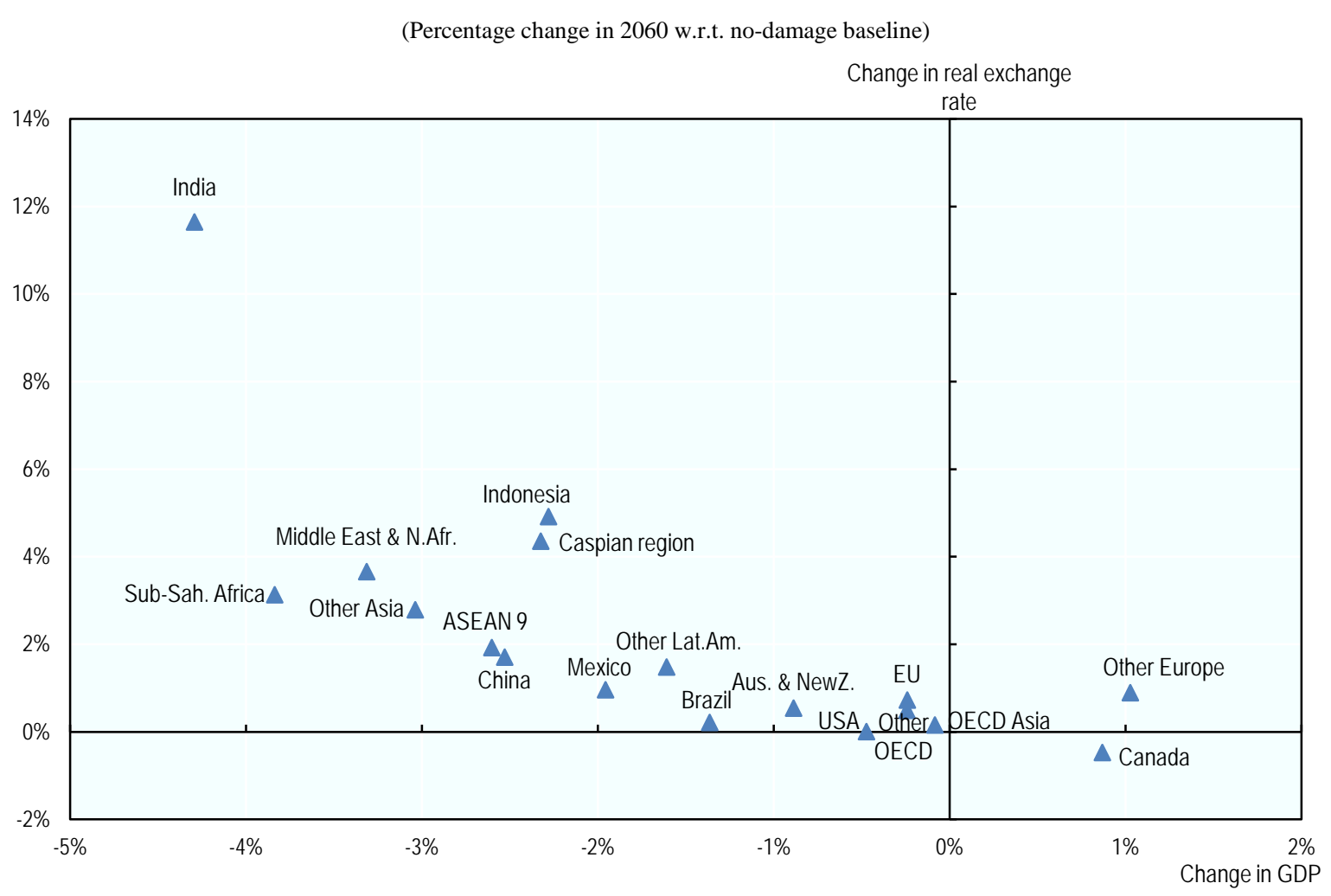

Source: OECD ENV-Linkages model.

Changes in sectoral import patterns are determined by a combination of macroeconomic and sectoral effects. As illustrated in Figure 12, the total change in sectoral imports could be decomposed in three components. First, sectoral imports depend on the size of the economy; this income effect is calculated as the change in imports due to changes in GDP. Second, total imports in volume as a share of real GDP may adjust to the new equilibrium; this macro trade effect is defined as the change in total imports minus the change in GDP. Finally, sector-specific effects will lead to adjustments of the sectoral composition of imports. In volumes, for each region these sectoral effects add up to zero across sectors.

With the exception of Canada, OECD Asia and the EU, total import volumes follow GDP, and the income effect is larger than the macro trade effect. In most cases, the macro trade effect is of the opposite sign as the income effect, reflecting the mechanism outlined above that regions adjust their imports to compensate for changes in domestic production costs. Given that agricultural trade is a relatively small share of overall imports, a large percentage change in the sectoral effect for agriculture combined with relatively minor opposite changes in the other sectors imply small changes in GDP.

For the aggregate agricultural sector, the sectoral component dominates in almost all regions: changes in agricultural imports are predominantly determined by climate change impacts on the sector itself, not by changes in the macro economy. It is striking to see that the sign of the sectoral effects varies widely across regions. Several regions import more to compensate for the smaller domestic production, including Australia and New Zealand, Brazil, Sub-Saharan Africa and, most prominently, the Middle East 
and North Africa region (where the agricultural sector effect amounts to 6.6 percent, but from a relatively small baseline level). In these regions, the increase in imports for some crops is larger than the decrease in imports for other crops.

Figure 12. Change in sectoral imports in the climate damages scenario

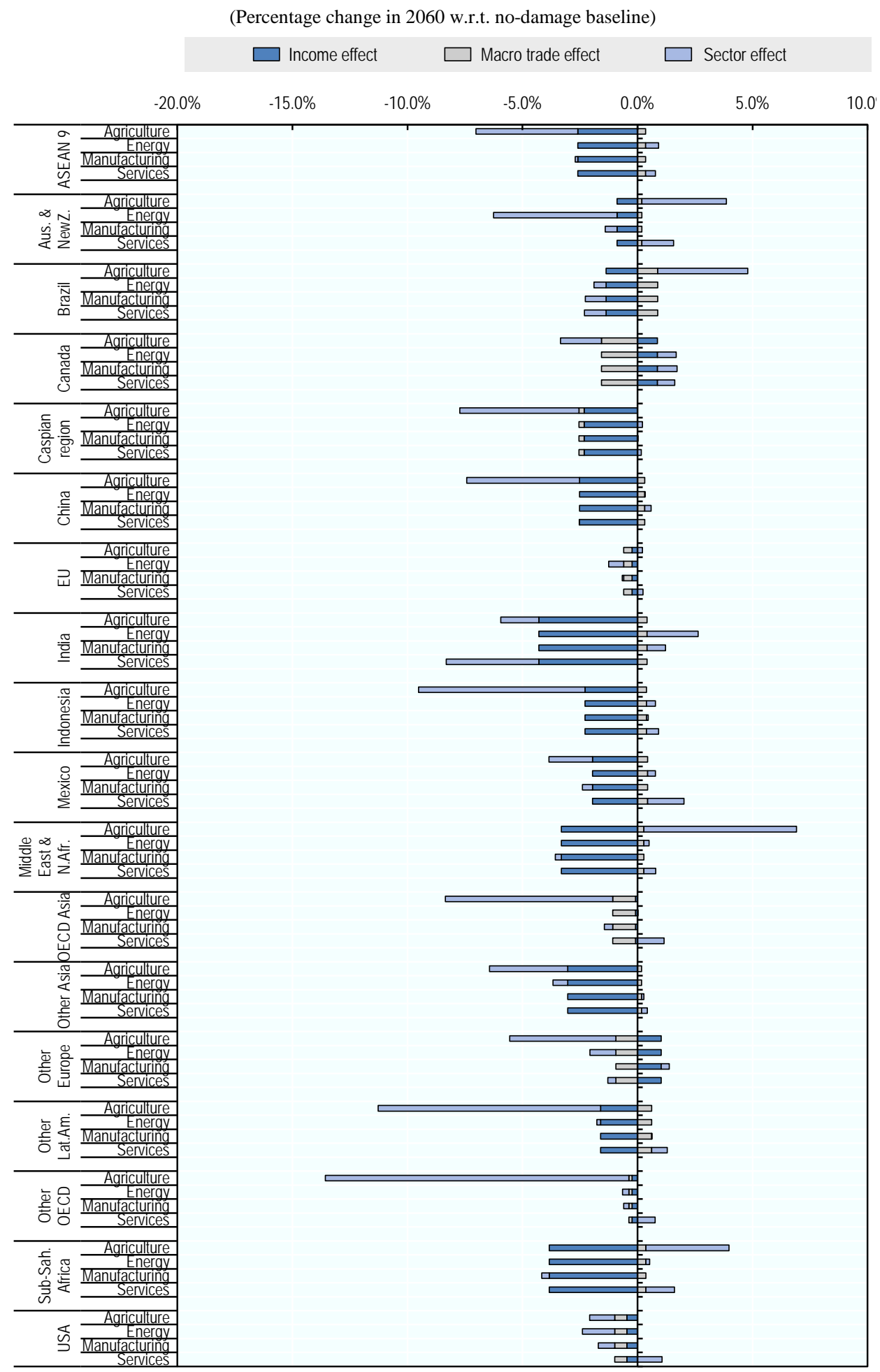

Source: OECD ENV-Linkages model. 
A similar pattern of less imports of some crops and more imports of others occurs in almost all regions, but in most cases overall agricultural imports decline compared to the baseline. All countries balance the increased domestic production costs (from reduced yields) with the increased world price for agricultural commodities. In order to minimise the consequences of the climate change impacts on welfare, countries change their specialisation in crop production to accommodate the changes in relative comparative advantage, revise their domestic consumption levels to reflect changes in relative prices between all consumption goods, and adjust their imports accordingly. ${ }^{27}$ This signifies that a detailed sectoral and regional analysis is warranted to explain what happens to sectoral trade flows. The next section will investigate these sectoral effects in more detail, with a focus on how agricultural trade is affected by agricultural impacts of climate change (while Figure 12 shows the consequences from the whole set of climate impacts, including those on agriculture, labour productivity and others).

\subsection{Compositional effects: changes in comparative advantage in agriculture and food}

The previous section has illustrated the main macroeconomic effects of climate change on trade. This section instead focuses on sectoral and compositional effects by studying changes in comparative advantage. Many effects interact in the model both in terms of sectoral changes and consequences of the different impacts. This makes it hard to analyse the impacts on all sectors and from all climate damages together. As a case study, this section therefore focuses on climate change impacts on crop yields and their impacts on trade in food products. Throughout this section, "agriculture" refers to the land-based production of crops and livestock, while "food" refers to the processed commodities derived from these. Thus, the former includes e.g. wheat and cows, the latter bread, meat and dairy products. The food processing sector depends crucially in the inputs of the agricultural sectors; while it is not directly severely affected by climate change, the indirect effects from the impacts on agriculture are very significant.

\subsubsection{Macroeconomic consequences of agricultural impacts}

The analysis in this section focuses on changes in agricultural exports, and specifically food products (which includes all processed foods, as noted above). In order to clarify the main mechanisms at work, this analysis is carried out with a simulation in which only agricultural impacts from climate change are included, and the other impacts, such as those on labour productivity, are excluded.

The macroeconomic consequences from considering agricultural impacts only are logically more modest than those of the full set of market damages. In terms of yield shocks, the largest losses are projected to be in Brazil and the Asian regions, especially India (cf. x-axis in Panel A of Figure 13) ${ }^{28}$ Especially in Asia and Africa, the yield losses translate into reductions in GDP (y-axis in panel A of Figure 13). These results are fairly similar to the macroeconomic consequences of the full set of market damages, as discussed in Section 3.2. In particular, macroeconomic consequences are only very loosely related to the yield shocks imposed on the regional economies.

\footnotetext{
27 Furthermore, given the modelling assumption of fixed regional trade balances, countries balance total imports and total exports. region. 
Panel B highlights that there are large differences in the consequences of agricultural damages for the volume of trade of selected commodities. ${ }^{29}$ Especially trade in rice is projected to increase significantly, as some of the main rice consumers are severely hit by climate change. In contrast, some of the other agricultural commodities get less traded internationally; consequently, aggregate trade of agricultural commodities slightly reduces below the no-damage baseline level. Trade in food products declines by 3\%, more than the decline in overall trade (which amounts to around $0.6 \%$ ). The reduction in aggregate trade of agricultural commodities can be explained by a mixture of factors, including the relatively strong reduction in yields compared to the no-damage baseline projection, reduced demand for crops by the food sector, the general contraction of the economy (also implying lower incomes), and the need to meet domestic food demands.

Figure 13. Change in aggregate crop yields and GDP in the agricultural damages scenario

(Percentage change in 2060 w.r.t. no-damage baseline)

Panel A. Aggregate crop yields versus GDP at the regional level

Changes in GDP

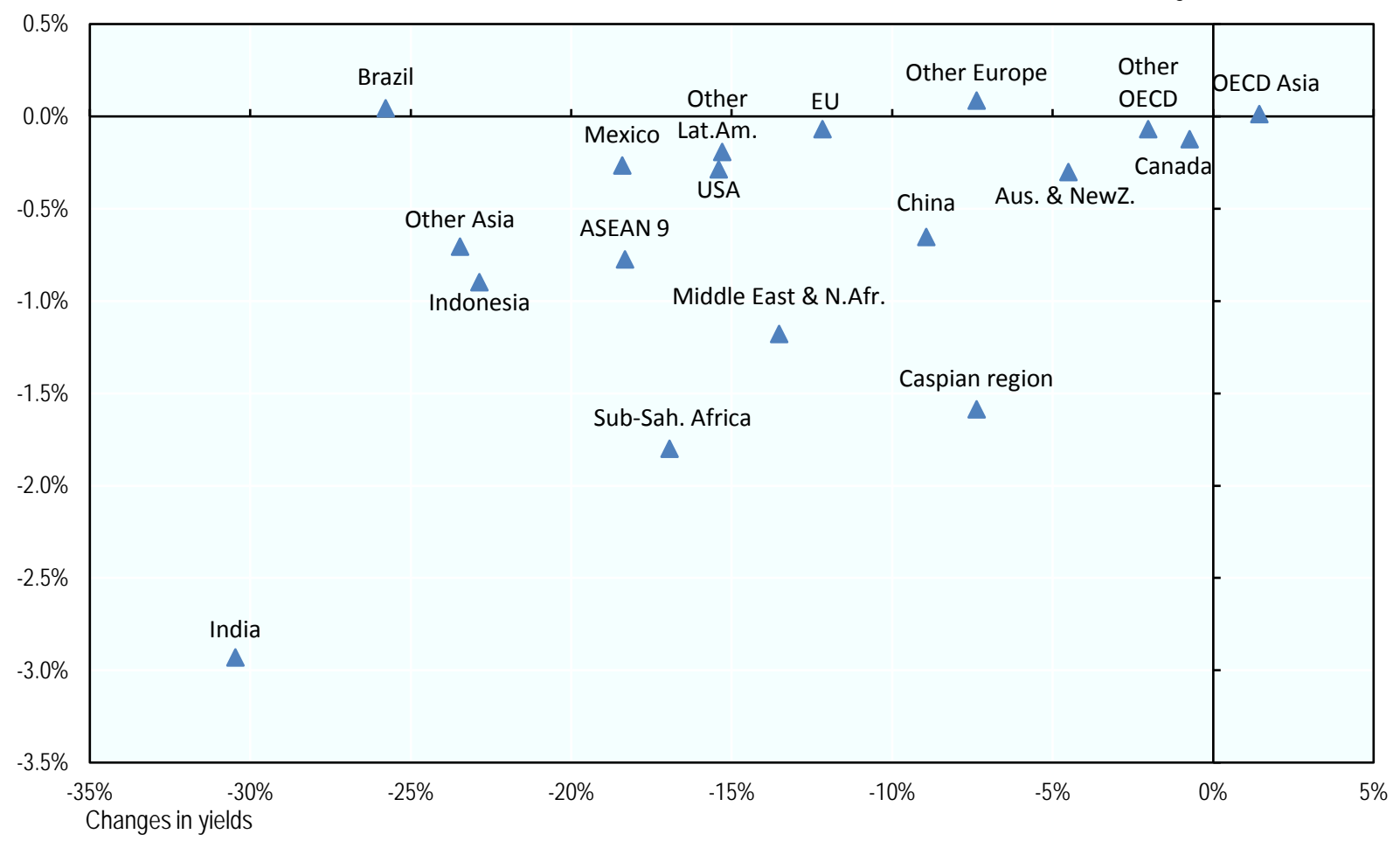

29

These changes in trade flows are measured in terms of monetary export volumes. Changes in aggregate monetary import volumes differ somewhat from these, as import prices differ between regions and changes across regions are hence differently weighed. 


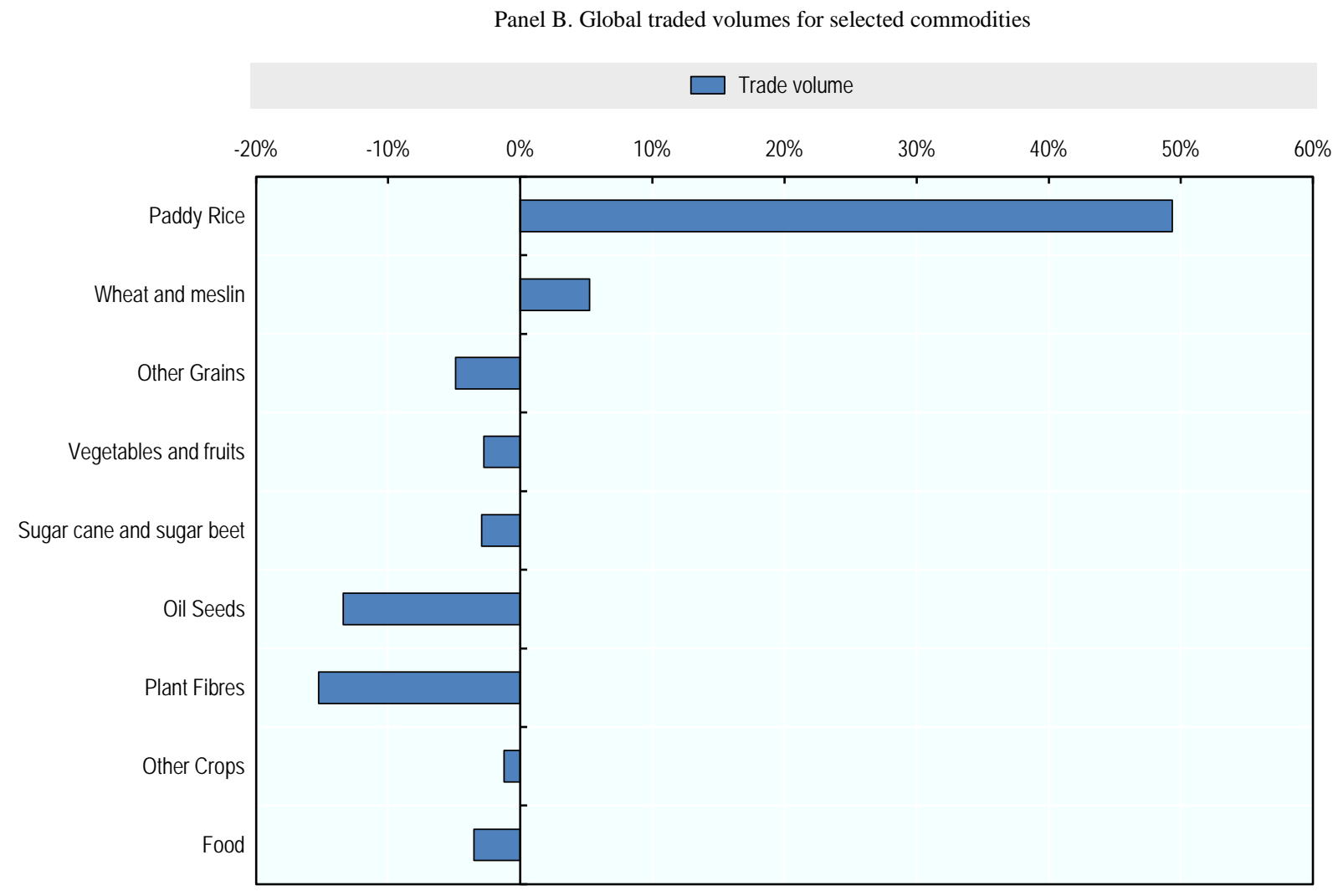

Source: OECD ENV-Linkages model.

It is worthwhile to highlight that this central projection represents only one scenario, and different assumptions on e.g. the regional climate impacts (especially precipitation) would lead to different numerical results. Figure 14, reproduced from OECD (2015a), shows the full range of possible macroeconomic consequences from agricultural damages from varying the underlying climate model, underlying crop model, and the assumption on the effect of increased carbon concentrations on crop growth (the carbon fertilisation effect). ${ }^{30}$ These alternative specifications are not further explored in this report, as the analysis serves mostly as a case study to highlight the key mechanisms at work, not as a prediction of changes in agricultural and food trade. the potential gains for specific scenarios that are projected in specific countries, such as Brazil, Chile and Russia in 2060, and more widespread potential gains in earlier decades for some scenarios. 
Figure 14. Change in regional GDP in different agricultural damages scenarios

(Percentage change in 2060 w.r.t. no-damage baseline)

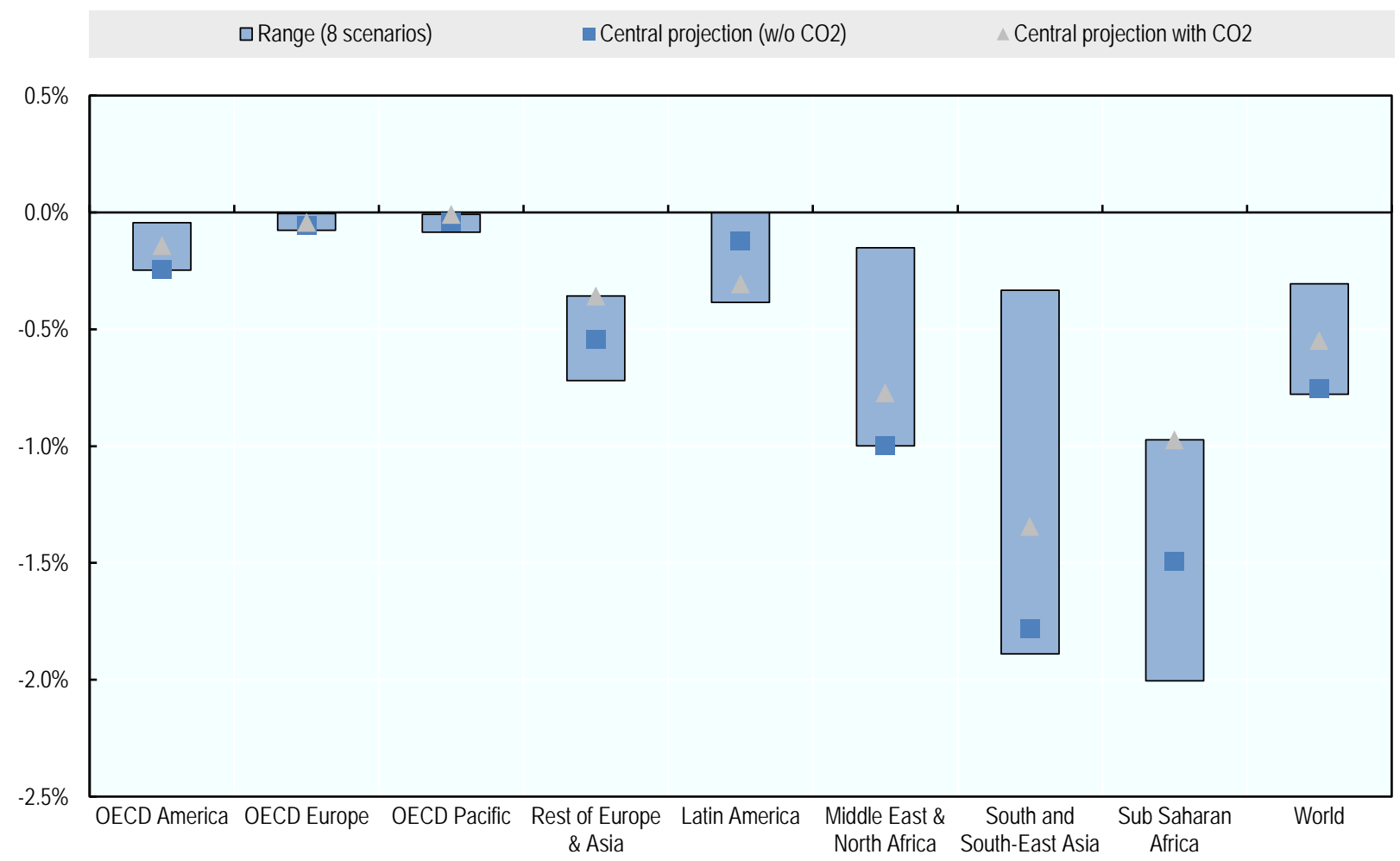

Source: OECD ENV-Linkages model.

\subsubsection{Revealed Comparative Advantage (RCA) in food products}

Figure 15 shows the change in Revealed Comparative Advantage (RCA) for the baseline and the "agricultural damages" scenarios. It also shows the change in RCA between the two scenarios (diamonds in the figure). This figure shows, first of all, which regions have a strong specialisation and comparative advantage in food products. Brazil has the highest comparative advantage in both scenarios. A group of other regions, including the Other Latin America region, Indonesia, the Other Europe region, the ASEAN 9 region and Sub-Saharan Africa also have high comparative advantage in food products. Regions with smaller comparative advantage include Australia and New Zealand, Canada, Mexico, Middle East and North Africa, the EU, India and Other OECD countries. Finally some regions, namely the USA, other OECD and non-OECD Asian regions, China and the Caspian regions, do not specialise in trade of food products. ${ }^{31}$

This distribution of comparative advantage is largely unchanged by climate change damages to the agricultural sector. However, climate change damages lead to changes in RCA for several regions and for some of the most specialised in the sector. Brazil remains the country with highest RCA and actually increases its comparative advantage with the highest increase among all regions. Smaller increases also take products, as specialisation is about the share of a specific sector (in this case food products) in total exports. 
place in most other regions, and particularly in Europe, Australia and New Zealand and in North America. The South and South East Asia region is most damaged in its comparative advantage, especially Indonesia and India. The Middle East and North Africa region also loses comparative advantage in food products.

Figure 15. RCA levels for food products and changes due to agricultural damages

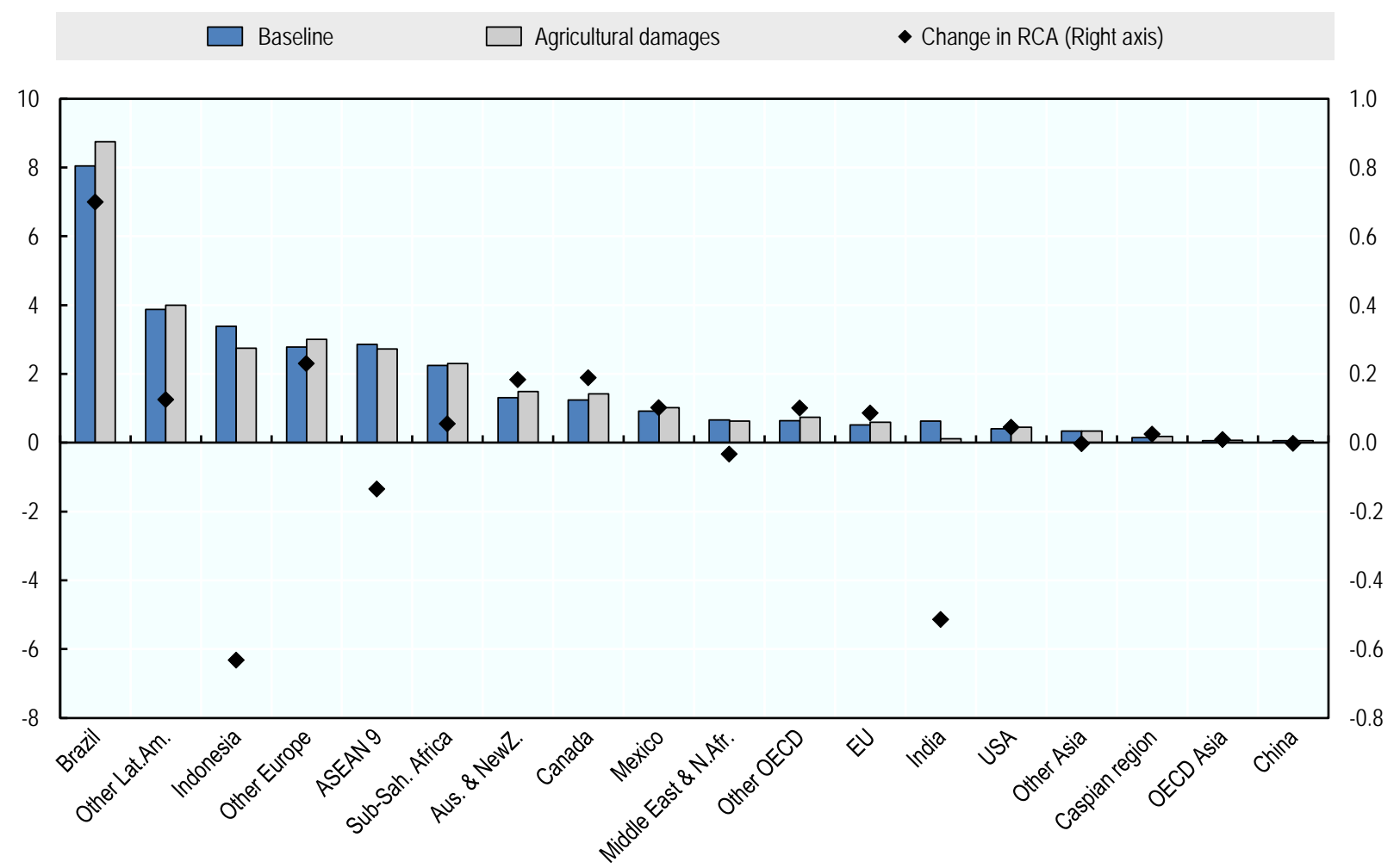

Source: OECD ENV-Linkages model.

Changes in crop yields due to climate change are one of the drivers for these changes in comparative advantage. However, as all sectors and regions are linked with each other, a complex set of interactions and endogenous changes is triggered by the yield shocks, leading to adjustments in all sectors of all economies. Considering the correlation between RCA and crop yield changes, as illustrated in Figure 16, panel A, it is clear that crop yield changes alone cannot explain the changes in RCA. For instance, although Brazil and Indonesia have a similar loss in crop yields, Brazil gains in competitiveness, while Indonesia loses part of its competitiveness.

Panel B related the changes in RCAs to changes in the prices and volumes of exports. Those countries that have the largest increase in export prices see the largest drop in export volumes. As expected, the combined effect of these, i.e. changes in food export revenues, does show a clear link with the change in RCA: for those countries where the negative volume effect dominates, the RCA goes down, while for those where the volume effect is positive, the change in RCA is positive. But at the level of individual regions, more complex interactions play a role, and the regional changes in RCAs and export revenues cannot be fully explained at this aggregation level. 
In order to better understand the interaction between trade flow changes, RCAs and competitiveness, it is therefore necessary to look more specifically at trade markets and competition amongst regions for a specific market. This is done in the next section.

Figure 16. Changes in RCAs for food products and agricultural damages

(Percentage change in 2060 w.r.t. no-damage baseline)

Panel A. Changes in RCAs and crop yields

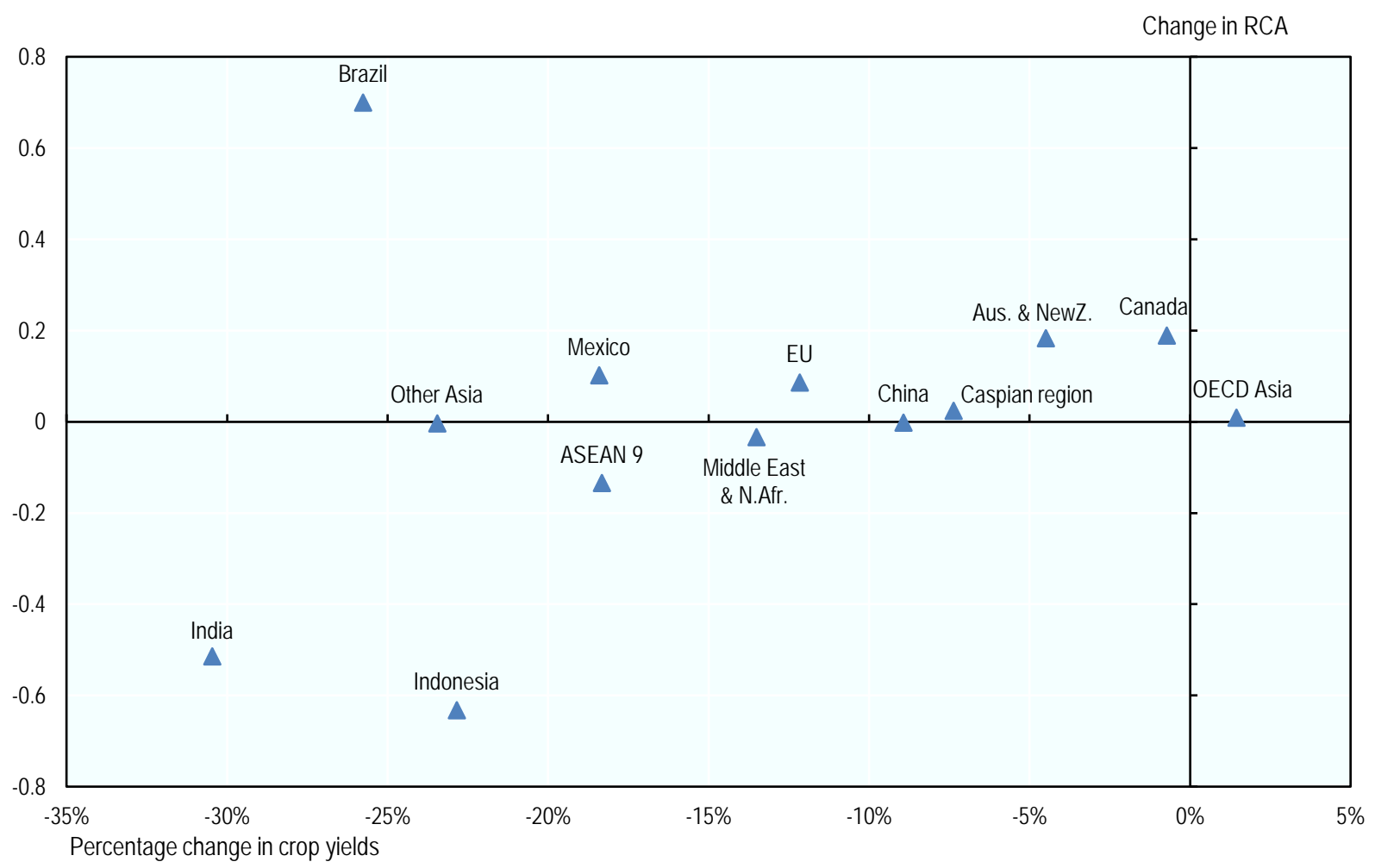


Panel B. Changes in RCAs, export prices and volumes

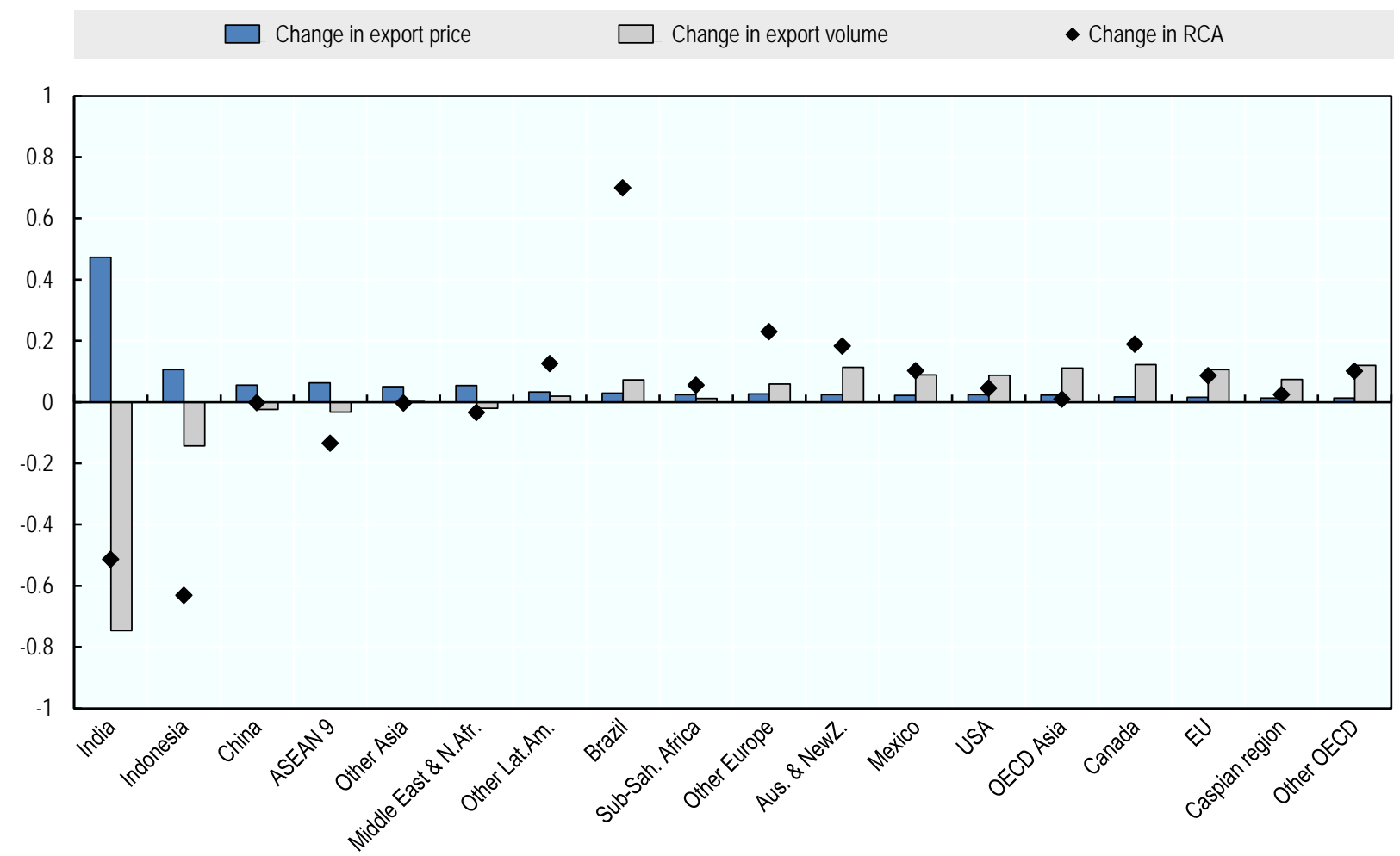

Source: OECD ENV-Linkages model.

\subsubsection{A deeper look at RCAs: food exports to the EU}

Given that many complex linkages between the trade flows of regions exist, and there are multiple drivers of trade changes, the overall changes in RCA do not say much. Rather, in order to shed further light on the linkages between GDP losses, changes in trade flows and comparative advantage, one must dive deeper into the model and focus on changes in more specific trade flows. Therefore, this subsection looks at the exports of food products (i.e. not raw agricultural commodities, but the output of the food industry) to the EU, and tries to shed light on the mechanisms at work. This specific case is chosen because Europe is one of the main importers and its main partners are regions that will be confronted with large changes in their RCA.

Figure 17, panel A presents the projected size of exports of food products to the EU by region of origin. The most important trading partner is projected to be SubSaharan Africa: 21\% in 2060, up from 13\% in 2010 (not shown in the figure), to a large extent at the expense of imports from other OECD countries. The growth in exports from Sub-Saharan Africa to the EU is stronger in absence of climate impacts on agricultural production in Sub-Saharan Africa, but even when agricultural damages are accounted for, these exports increase significantly. This is primarily driven by the projected strong increases in agricultural productivity in Sub-Saharan Africa in the baseline (in line with the larger literature, cf. Alexandratos and Bruinsma, 2012, Ignaciuk and Mason-D'Croz, 2014 and Sulser et al., 2015), and the fact that extensive trade links already exist between Europe and many African countries. This implies that the region can simultaneously increase crop production for domestic consumption (to improve food security) and increase food exports. The baseline improvement in yields outweighs the negative impact of climate change, so Sub-Saharan Africa can 
significantly improve its yields compared to 2015 levels even in the agricultural damages scenario; this effect is stronger than in other regions. Furthermore, given the relative abundance of land in many Sub-Saharan African countries, the continent has relatively large possibilities to partially absorb yield shocks by increasing the cultivated area. Finally, one should remember that this analysis is done for the combined group of Sub-Saharan African countries. Within this group, there will be significant heterogeneity, where some countries will struggle with food security, while others export large amounts of food to the European market.

According the modelling projections, Brazil and to a lesser extent other Latin American countries roughly maintain their large export shares in the coming decades. Climate change will have a small negative impact on overall food product imports in the EU, and hence for most countries exports to the EU will be reduced compared to the baseline (but not compared to 2010). Given the relatively small macroeconomic consequences of agricultural impacts from climate change on Europe, total imports by EU hardly change; changes in exports of specific regions to the EU are therefore driven primarily by changes in the region's comparative advantage.

Panel B presents changes in export flows of food product to EU. It portrays how changes in export prices (or more precisely, the prices that EU must pay for imports from this region) drive a wedge between the changes in export volumes and values (export revenues). Panel A already shows that climate damages to agriculture almost completely wipe out exports of food from India to the EU. Therefore, the percentage changes in exports are extremely large and not presented in panel $\mathrm{B}$. The general picture that emerges from panel B is that the stronger the increase in regional prices, not least related to increases in exchange rates, the bigger the reduction in export volumes. And as it is relative comparative advantage that matters, those regions whose export price levels change least can gain in terms of export volumes. The second clear trend is that the export volume effect clearly dominates the price effect: those regions that see their export volumes decline also see a reduction in export revenues. Putting both mechanisms together implies that stronger price increases imply lower revenues and larger wedges between revenues and volumes. 
Figure 17. Change in food exports to the EU in the agricultural damages scenario

Panel A. Volumes of exports of food products to the EU by region of origin

(Percentage change in 2060 w.r.t. no-damage baseline)

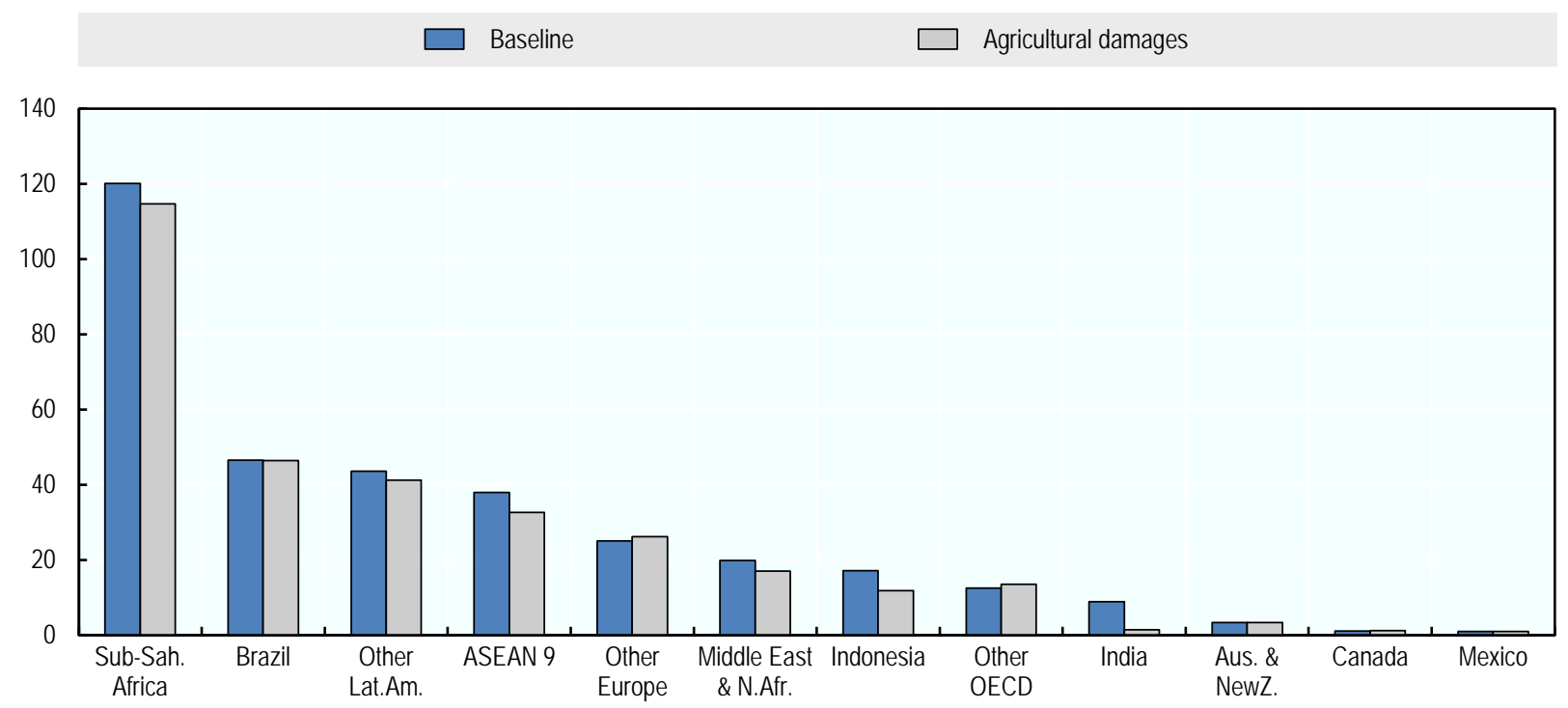

Panel B. Changes in volume and value of exports of food products to the EU

$\Delta$ Change in export revenues

Change in export volumes

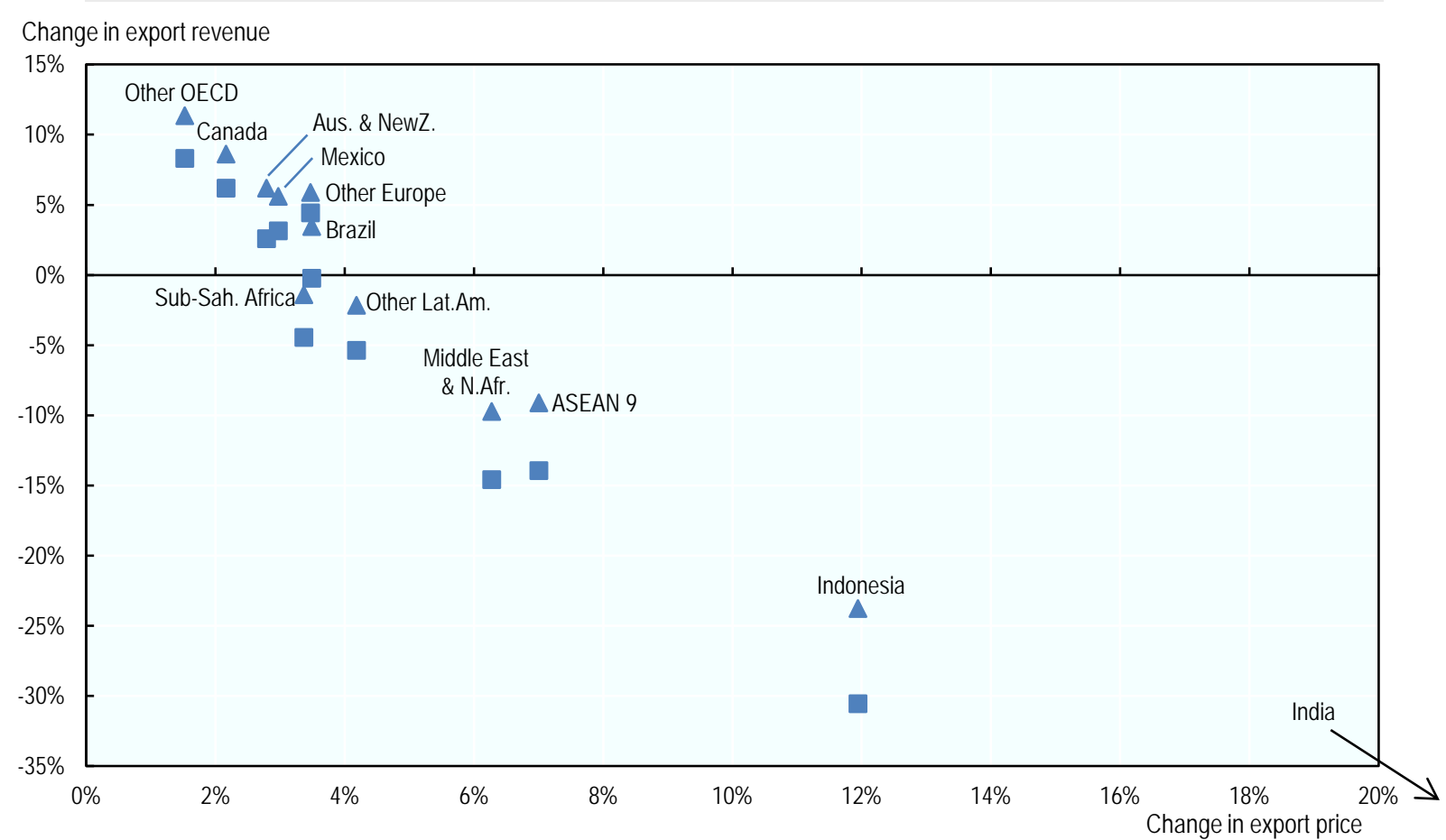

Note: In panel B, the percentage changes in India are too large to be meaningfully shown on the graph.

Source: OECD ENV-Linkages model. 
The changes in regional comparative advantage are shown in Figure 18, which shows the projected RCA for exports to the EU (i.e. not based on global exports like in Figure 15, but specifically for exports to the EU only). From comparing Figure 18 to Figure 15 it is clear that the change in RCA for exports to the EU closely resembles the change in the global RCA. It is the same set of countries which are projected to have the strongest change in their RCA, and strong reductions in RCA correlates with strong macroeconomic losses in these countries.

Figure 18. Levels and change in RCA of food exports to the EU in the agricultural damages scenario

(Percentage change in 2060 w.r.t. no-damage baseline)

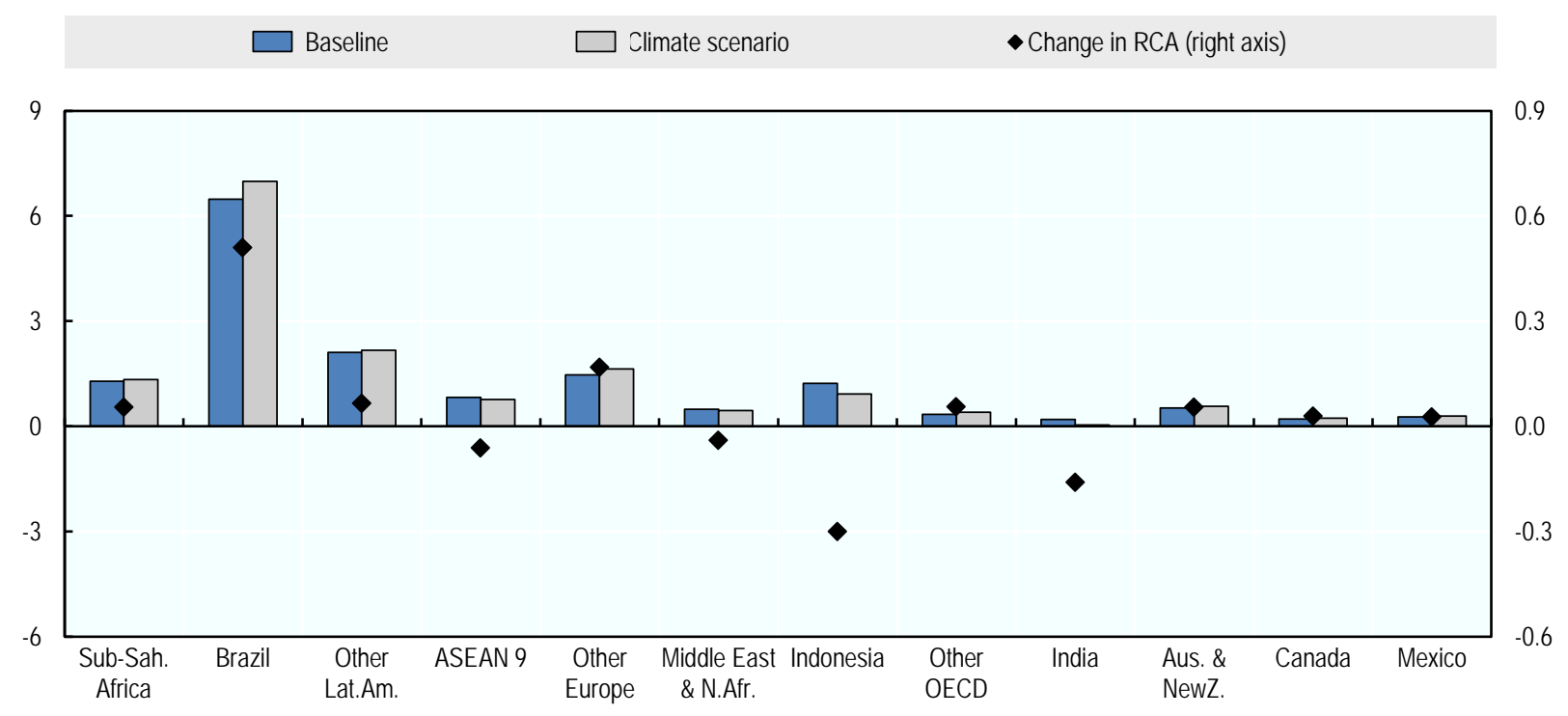

Source: OECD ENV-Linkages model.

For Brazil, food products are projected to make up almost half of total exports to the EU, according to the baseline projection for 2060. Hence, Brazil's RCA is very high, and it increases further in the climate scenario (Figure 18), not because it will export more to the EU, but rather because the other trading partners will export less (Figure 16). Furthermore, the domestic market in Brazil is less dependent on agriculture than those of the other major trading partners of the EU: agriculture is projected to make up a relatively smaller share of overall output of the Brazilian economy. As a consequence, the macroeconomic consequences are smaller in Brazil than in the other regions, despite very similar yield shocks (cf. Section 4.2.1).

By contrast, a country like Indonesia, which has relatively smaller yield shocks but given the stronger dependency on agriculture, larger macroeconomic consequences, is projected to see its exports to the EU decline. The price that the EU for food imports increases substantially for imports from Indonesia and e.g. India and the Middle Eastern countries. This implies a shift of competitive position for exporting to the EU from counties like Indonesia towards countries like Brazil.

This case study is an illustration of some of the specific effects that drive changes in trade in the different regions. The numerous interactions that exist between regions and sectors make it impossible to establish a rule of thumb that shows for instance that 
crop yield decreases will lead to a decrease in competitiveness. As illustrated, there may be an increase in competitiveness if other competitors for a certain market are more severely damaged or decide to specialise in the production of other goods. This highlights the need for each region to understand the direct impacts of climate change on their sectoral production and on their trade flows, but also the possible impacts of climate change on regions they are competing with for specific markets. This will help maintain comparative advantage, if possible, and decisions regarding what goods to specialise in the future.

\subsection{Sensitivity of domestic consequences to international spillovers}

The projections above show how economic consequences of climate change damages in one region affect other regions, and how trade plays a central role in these cross-country linkages. If impacts were identical across countries, all regions would maintain their international competitive position. Simultaneously, they would be negatively affected by the reduced demand for exports following the slowdown in the economies of trading partners that are affected by climate change. However, heterogeneity in impacts means that relative competitive positions start to shift. Further, if climate change is beneficial (or less negative) for other countries, whereas the domestic damages are (more) negative, the competitive position may be worsened by climate change. Thus, there are two key international spillovers between the countries in determining the domestic economic consequences of climate change: (i) damages from climate impacts in other countries; and (ii) changes in international trade patterns due to shifts in competitive positions.

This Section aims to shed further light on the importance of these international linkages, by decomposing the macroeconomic costs of climate change. The point of the exercise is to illuminate to what extent international linkages determine the costs of climate change, but cannot be interpreted as a policy analysis. The decomposition uses two hypothetical alternative cases:

1. damages only affect domestic economies, and other countries are not damaged by climate change; hence, there are no spillovers from damages in other economies; this is labelled "no international damage spillovers".

2. adjustments of import patterns to adapt to the climate shocks are not allowed, labelled "no import flexibility spillovers". 


\section{Box 3. Modelling assumptions used for the decomposition}

For the first type of spillover, "International damage spillovers", the central projection is compared to a specific simulation which is carried out for each country separately with damages affecting that region only. Damages in all other regions are excluded. Since climate change has consequences on all regions across the world, it is clear that this is just a hypothetical scenario used for analytical purposes. In a modelling setting, when damages are implemented in all regions, it is impossible to single out specific effects. Applying climate damages individually to each region considered, allows instead isolating the effect of domestic damages on the economy, by cancelling the spillovers from climate damages in other regions. In this scenario, world market prices are hardly affected; in contrast, in the central scenario the climate damages, which are applied to all world regions, affect international trade patterns.

For the second type, "Import flexibility spillovers", simulations are compared where the import volumes of the country under scrutiny are fixed at the baseline levels or can adjust freely. Fixed imports imply that countries cannot respond to lower productivity of domestic production and lower domestic demand by changing their import levels. As production in certain sectors and regions becomes more costly, in the central projection economies adapt through changing their production and trade patterns. In other words, some resources will be reallocated across sectors in order to alleviate the burden in other sectors. ${ }^{32}$ In absence of this flexibility, the adjustment of trade patterns is no longer possible, although total imports can still scale with domestic production. ${ }^{33}$ Fixed import patterns can be imposed at the local level (i.e. only the country under investigation has fixed import flows), or globally (i.e. import patterns are fixed for all countries). Again, this is a hypothetical set-up that allows decomposing the trade spillover effects by comparing the results with those of the central projection in which trade is not constrained.

Box 3 describes the underlying modelling assumptions in more detail. Together, these two alternative specifications allow decomposing the costs into the domestic costs from domestic impacts, spillovers from foreign damages and spillovers from adjusting trade flows. Because these spillovers are region-specific, this illustrative analysis focuses on the USA, European Union, China, India and Sub-Saharan Africa.

This decomposition is meant only as a theoretical exercise, and does not reflect specific recommendations on climate or trade policies. They may highlight the potential benefits of adjusting trade patterns, but do not reflect any specific policy and cannot be interpreted to imply costs or benefits of policy actions. Any policy change that would aim at achieving a change in international trade patterns along the lines as presented in this decomposition would by definition have more complex economic reactions that are - by construction - absent in this decomposition analysis. Assessing the role of specific trade or trade-related policies would require a much more detailed analysis, and simulations of specific policy instruments. This is left for future analysis.

32

For instance, if agricultural yields drastically decrease due to climate change for a certain crop, the gap in domestic production can be replaced with imports from abroad. The decision whether to import more will also depend on other factors, such as the changes in import and export prices, the changes in domestic prices, and the possibilities to substitute with other goods.

For this analysis, import-to-production ratios and import shares across countries are assumed to be the same than in the baseline without climate feedbacks, and the trade balance is fixed at the baseline level as well. But the volume of imports and trade flows themselves will adjust to take into account changes in income resulting from climate damages, i.e. they scale with domestic production. In order to reproduce the trade structure of the baseline with no climate impacts, this scenario with "fixed import patterns" will assume that the parameters driving these import shares will adjust. Alternative ways of removing import flexibility have been tested, such as changing the responsiveness of trade flows to changes in relative prices. The results of these alternative scenarios are similar to those presented here. 
Figure 19 shows to what extent the international spillovers dominate the costs of climate change. For both types of spillovers, the effects can be positive or negative, depending on the circumstances of the country under investigation. For the international damage spillovers, damages in other regions will, on the one hand, negatively affect the domestic economy, especially because countries cannot protect their consumption levels by importing more (cheaply) from unaffected regions. On the other hand, countries maintain their regional competitive position better when other regions are also affected, at least when the major trading partners are affected in a similar way. For the import flexibility spillovers, the adjustments to import levels can limit shocks to domestic production. But one country's import flexibility implies changes in exports by another country.

Figure 19. Decomposition of changes in real GDP in 2060 in the climate damages scenario (Shares in change of GDP in 2060 in the central projection)

Domestic import flexibility spillovers $\square$ International import flexibility spillovers $\square$ International damage spillovers $\square$ Domestic damages

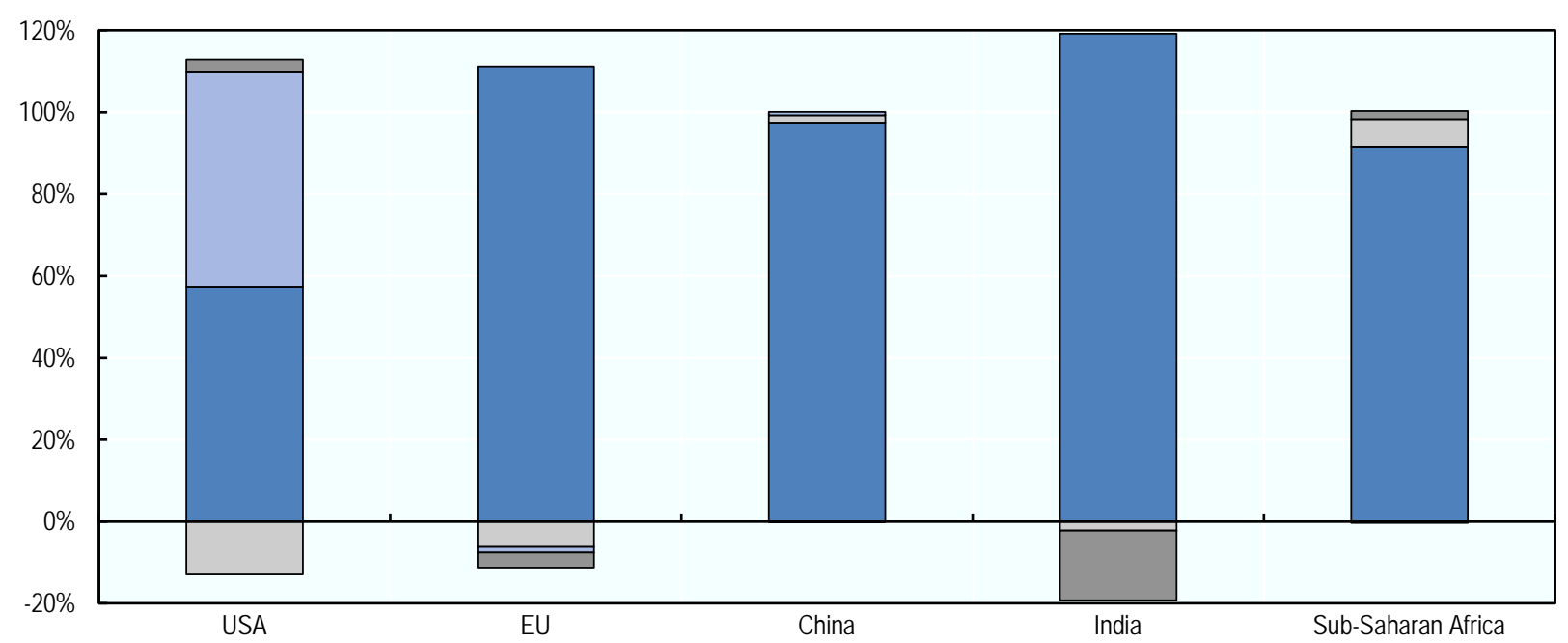

Note: Shares add up to $100 \%$, which reflects the change in GDP in the central projection.

Source: OECD ENV-Linkages model.

The regional results show remarkable differences in the extent to which the two international spillovers affect the costs of climate change. For the United States, a pattern emerges where international import flexibility spillovers contribute a significant portion of the total damages. This reflects a vulnerability of the US economy to changes in its export market: when other countries can adjust their imports, they will reduce imports from the US. Similarly, the contribution of international damage spillovers to the total costs in the USA is negative, as long as there is no import flexibility. In this case, the global level of imports does not contract, and the share of the USA in world trade is larger due to relatively larger impacts in some of its trading partners. But the US economy is hurt by the loss of exports to other countries that is induced by damages in other countries when import patterns are flexible. Domestic import flexibility is much less important for the US economy. ${ }^{34}$

The small additional costs from domestic import flexibility depend on the modelling assumption that the current account is fixed and exchange rates adjust. Thus, reducing imports will have to be compensated by also reducing exports, which hurts the domestic economy. The Armington assumption on flexibility to change international trade also excludes the OECD TRADE AND ENVIRONMENT WORKING PAPER 2017/01 @ OECD 2017 
The results for the European Union and India reflect a different story: local damages with fixed imports are the worst situation; these regions have lower costs to their economy when damages also affect other regions and when imports are flexible, either locally or globally. The reason is that when damages affect all economies in the world, they tend to 'level the playing field'. A lack of international damage spillovers instead implies a larger shock to the domestic competitive position. The positive effect of adjusting domestic import flows is especially strong in India. The country is projected to have very severe damages from climate change, and international trade plays a major role. As domestic production costs rise due to the lower productivity, the economic consequences can only be limited by relying more on relatively cheap imports. This loss of comparative advantage of the Indian economy is clear from the analysis in Section 4. Whether only India or all countries have their import patterns fixed does not matter, as the additional costs stem from the inability to adjust imports, not from changes in India's exports.

For China and Sub-Saharan Africa, the spillovers work in the opposite way. Damages in other countries and import flexibility both constitute a positive part of the total damages in these regions, due to the negative consequences on their exports. Damages to the Chinese economy are, however, largely driven by domestic impacts, and international linkages play a very minor role. ${ }^{35}$ The additional costs from international damage spillovers are more substantial in Sub-Saharan Africa, at least in terms of share of total costs in the central projection. International damage spillovers imply an additional burden for the Sub-Saharan economies as on the one hand their import costs rise due to higher production costs abroad, and secondly their export position weakens as the impacts in Africa are projected to be relatively higher than in most of its trading partners.

These results illustrate that international linkages through world trade markets may significantly differ across countries: an international spillover channel that is positive for one region can be negative to another. In fact, the only result that is robust across all countries is that when damages are local, fixing imports leads to higher costs (not shown in the figure). But in all situations where there are some international linkages, the results are very specific and determined by a region-specific mixture of trade openness, import dependency, relative competitive position, and - last but not least the relative impacts of climate change vis-à-vis the trading partners.

Finally, it should be re-iterated that this decomposition analysis does not imply a trade policy recommendation. At the global level, adjustments of international trade patterns can keep the costs of climate change limited, but it does pose additional costs for some regions. Without import flexibility, the global costs of climate change are projected to be higher, especially in some of the regions which are most severely affected by climate damages, not least India. This points to the importance of the general principle that various policy domains need to be properly aligned, and that specific policies in one domain can provides significant barriers to accomplishing objectives in other domains (OECD, 2015b).

possibilities that new bilateral trade patterns emerge. Alternative modelling assumptions may lead to different results in this respect. However, this effect is very small.

Restricting changes in exports may affect the Chinese economy more. The ENV-Linkages model assumes perfect substitutability in exports. Furthermore, in principle countries cannot control exports as easily as imports. Thus, country-specific export restrictions cannot be simulated without going into detailed trade policy scenarios. This is left for future research. 


\section{Concluding Remarks}

Providing a plausible projection of bilateral trade flows across many world regions for decades into the future is a daunting task, and then overlaying that with information on the economic consequences of climate change further complicates matters. The uncertainties surrounding these projections are large. Will Brazil by the middle of the century really be able to gain competitive advantage over Indonesia in exporting food to the EU? No-one knows. This paper limits itself to presenting one plausible scenario of future developments, to shed light on the mechanisms at work in explaining how climate change will affect trade. More robust quantitative insights require more elaborate modelling analysis, using multiple scenarios on the major modelling assumptions, and ideally comparing different models and using a risk-based framework. That is beyond the reach of this paper. Nonetheless, a number of general insights that are less sensitive to the exact model specification emerge that are worth highlighting.

First, international trade flows are projected to increase substantially in the coming decades, with increased focus on trade outside the OECD region. But by-and-large the direct impacts of climate change on international trade and infrastructure are negative, implying some of these projected increases in trade will be hampered by climate change. Furthermore, climate damages will put negative pressure on the economies of almost all regions, and trade flows are smaller when considering climate damages than in the naïve baseline that ignores feedbacks from climate change on the economy. These effects are especially strong in Africa and Asia, where the projections show high economic growth rates combined with increased trade dependency and large damages from climate change. In terms of economic sectors, the impacts on agriculture are projected to be relatively strong, and as agricultural goods and food products are heavily internationally traded, changes in agricultural trade flows are projected to be stronger than changes in trade flows for most other commodities.

Secondly, policy makers will need to understand not only the impacts of climate change on their domestic sectoral production patterns, but also the projected impacts on the economies of the regions they compete with on international markets. A national climate change assessment without attention to changes in international trade can lead to misleading conclusions on the effects of climate change on domestic competitiveness. Despite being negatively affected by climate damages, a region may increase its competitiveness if other competitors for a certain market are more severely damaged or decide to specialise in the production of other goods. In the most affected countries exports decline more than imports and GDP. In contrast, producers in the least affected countries can improve their competitive position on both domestic and export markets. "Least affected" in this case is a relative term: what matters more are the domestic damages compared with those of the main trading partners, rather than absolute damage levels.

Thirdly, the mechanisms driving changes in trade patterns are very complex, with mutually reinforcing and dampening effects. Generally, countries that have larger domestic markets and more diversified trade patterns can absorb climate shocks better than countries that are more specialised. Comparative advantage tends to decline in countries where climate damages lead to relatively large reductions in export volumes, while those regions whose export price levels change least can gain in terms of export volumes. 
Fourthly, adjusting trade patterns can help alleviate the burden of climate change impacts on the domestic economy, for instance higher domestic production costs can be compensated through increased imports when these are becoming relatively cheaper. A decomposition analysis reveals that a lack of international damage spillovers, i.e. when damages affect only the domestic economy, implies a larger shock to the domestic competitive position, as damages occurring in all countries 'levels the playing field', although exports are hurt more with global damages due to a contraction of the global economy. Similarly, import flexibility can help accommodate relatively severe domestic impacts and thus reduce costs, but at the same time they provide a threat to the exports of other regions.

In this report, it was impossible to include any direct impacts of climate change on international trade in the modelling analysis. However, this could be pursued further if reliable information becomes available on e.g. the change in overall costs from climate impacts on international sea, air and land transport, or more specifically on the changes in transportation costs from opening up of the Arctic shipping route. Especially the latter would ideally be pursued in close collaboration with the International Transport Forum (ITF).

An analysis of the trade policy response to climate change is beyond the scope of this paper. ${ }^{36}$ Future work can build on preliminary analysis in Chateau et al. (2015), who show that a "partial multilateral scenario" will benefit all countries, but especially the same less-developed economies which are most threatened by climate change. Many of the countries that are most severely affected, and that have the strongest reduction in revealed comparative advantage, are also those that are rapidly growing economies in the baseline, with significantly increasing world market shares in the major commodities. Future modelling work could therefore potentially look at how differences in regional impacts from climate change can be partially compensated by re-aligning trade agreements to improve the competitive position of the countries that are most negatively affected; similarly, future work could also investigate the sectoral dimensions in more detail, exploring how differences in climate impacts between sectors can be exploited to alleviate the largest climate and economic risks. More indepth analysis is also warranted on changes in trade in clean technology, as induced by ambitious climate policies.

Even if trade policies are not actively used to reduce the pressure on the climate system, harmful barriers to climate change adaptation can imply significant costs and worsen climate damages and risks. Therefore, it is important that policies are not diametrically opposed on certain aspects, to ensure that least-cost adjustment mechanisms are facilitated (OECD, 2015b). Climate policies and trade policies could therefore be aligned in order to avoid unnecessary barriers in the pursuit of various policy options, offset some of the worst climate damages and alleviate the burden on the most vulnerable economies. technology and other mitigation actions. Lanzi et al. (2013) highlight the potential for reducing economic impacts by linking carbon markets. 


\section{Annex A. Description of the ENV-Linkages Modelling Tool}

The OECD's in-house dynamic computable general equilibrium (CGE) model ENV-Linkages - is used as the basis for the assessment of the economic consequences of climate impacts until 2060. The advantage of using a CGE framework to model climate impacts is that the sectoral details of the model can be exploited. Contrary to aggregated Integrated Assessment Models, where monetised impacts are directly subtracted from GDP, in a CGE model the various types of climate damages can be modelled as directly linked to the relevant sectors and economic activities.

ENV-Linkages is a multi-sectoral, multi-regional model that links economic activities to energy and environmental issues; Chateau et al. (2014) provide a description of the model. The model is calibrated for the period 2013 - 2060 using the macroeconomic trends of the baseline scenario of the OECD@100 project. The ENVLinkages model is the successor to the OECD GREEN model for environmental studies (Burniaux, et al. 1992).

Production in ENV-Linkages is assumed to operate under cost minimisation with perfect markets and constant return to scale technology. The production technology is specified as nested Constant Elasticity of Substitution (CES) production functions in a branching hierarchy (cf. Figure A.1). This structure is replicated for each output, while the parameterisation of the CES functions may differ across sectors. The nesting of the production function for the agricultural sectors is further re-arranged to reflect substitution between intensification (e.g. more fertiliser use) and extensification (more land use) of crop production; or between intensive and extensive livestock production. The structure of electricity production assumes that a representative electricity producer maximizes its profit by using the different available technologies to generate electricity using a CES specification with a large degree of substitution. The structure of non-fossil electricity technologies is similar to that of other sectors, except for a top nest combining a sector-specific resource with a sub-nest of all other inputs. This specification acts as a capacity constraint on the supply of the electricity technologies.

The model adopts a putty/semi-putty technology specification, where substitution possibilities among factors are assumed to be higher with new vintage capital than with old vintage capital. In the short run this ensures inertia in the economic system, with limited possibilities to substitute away from more expensive inputs, but in the longer run this implies relatively smooth adjustment of quantities to price changes. Capital accumulation is modelled as in the traditional Solow/Swan neo-classical growth model.

The energy bundle is of particular interest for analysis of climate change issues. Energy is a composite of fossil fuels and electricity. In turn, fossil fuel is a composite of coal and a bundle of the "other fossil fuels". At the lowest nest, the composite "other fossil fuels" commodity consists of crude oil, refined oil products and natural gas. The value of the substitution elasticities are chosen as to imply a higher degree of substitution among the other fuels than with electricity and coal. 
Figure A.1. Production structure of a generic sector in ENV-Linkages

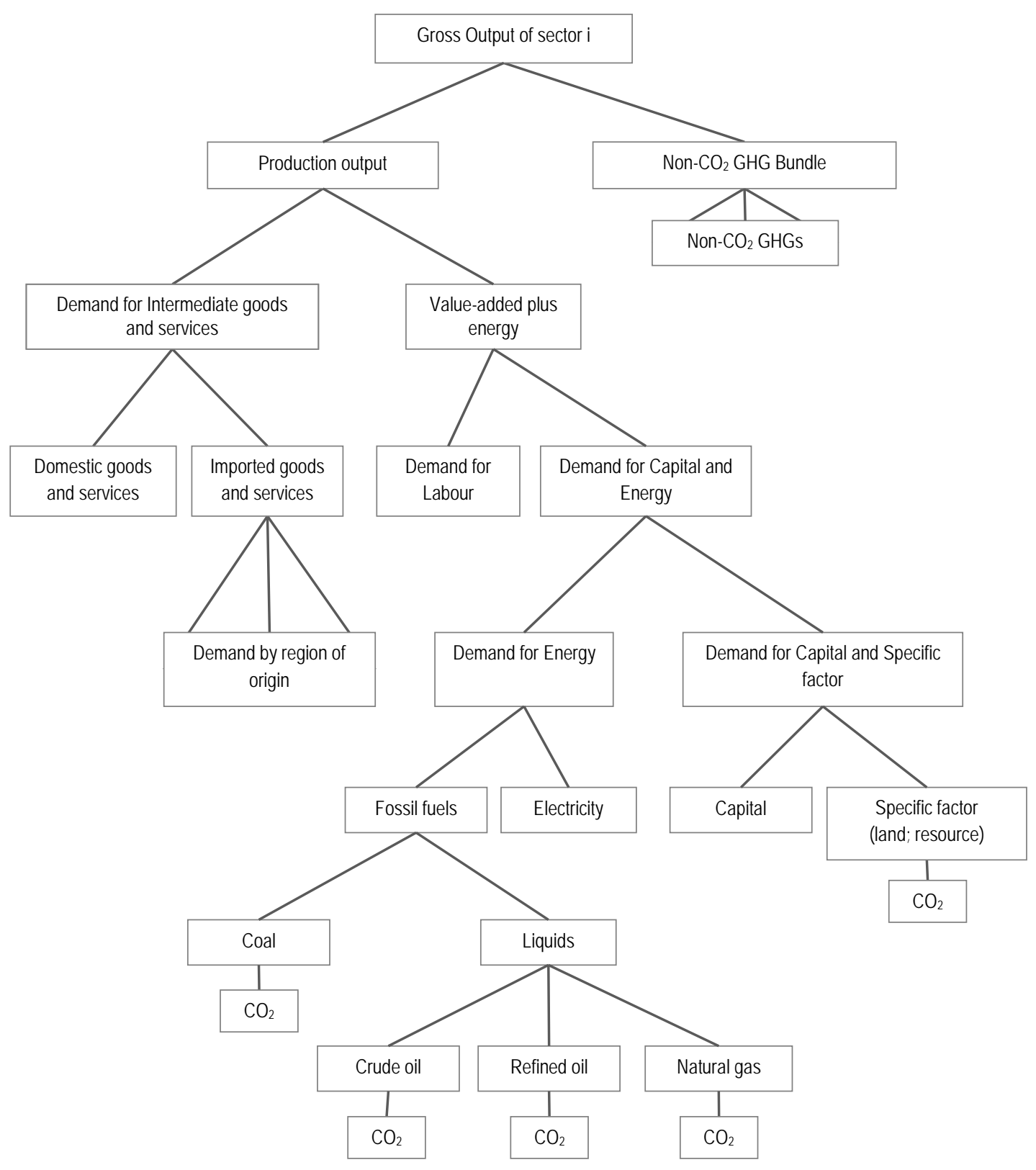

Source: OECD ENV-Linkages model.

Household consumption demand is the result of static maximization behaviour which is formally implemented as an "Extended Linear Expenditure System". A representative consumer in each region optimally allocates disposal income among the full set of consumption commodities and savings. Saving is considered as a standard good in the utility function and does not rely on forward-looking behaviour by the consumer. The government in each region collects various kinds of taxes in order to finance government expenditures. Assuming fixed public savings (or deficits), the government budget is balanced through the adjustment of the income tax on consumer income. In each period, investment net-of-economic depreciation is equal to the sum of government savings, consumer savings and net capital flows from abroad. 
International trade is based on a set of regional bilateral flows. The model adopts the Armington specification, assuming that domestic and imported products are not perfectly substitutable. Moreover, total imports are also imperfectly substitutable between regions of origin. Allocation of trade between partners then responds to relative prices at the equilibrium.

Market goods equilibria imply that, on the one side, the total production of any good or service is equal to the demand addressed to domestic producers plus exports; and, on the other side, the total demand is allocated between the demands (both final and intermediary) addressed to domestic producers and the import demand.

$\mathrm{CO}_{2}$ emissions from combustion of energy are directly linked to the use of different fuels in production. Other greenhouse gas (GHG) emissions are linked to output in a way similar to Hyman et al. (2002). The following non- $\mathrm{CO}_{2} \mathrm{emission}$ sources are considered: i) methane from rice cultivation, livestock production (enteric fermentation and manure management), fugitive methane emissions from coal mining, crude oil extraction, natural gas and services (landfills and water sewage); ii) nitrous oxide from crops (nitrogenous fertilizers), livestock (manure management), chemicals (non-combustion industrial processes) and services (landfills); iii) industrial gases (SF6, PFCs and HFCs) from chemicals industry (foams, adipic acid, solvents), aluminium, magnesium and semi-conductors production. Over time, there is, however, some relative decoupling of emissions from the underlying economic activity through autonomous technical progress, implying that emissions grow less rapidly than economic activity.

Emissions can be abated through three channels: (i) reductions in emission intensity of economic activity; (ii) changes in structure of the associated sectors away from the 'dirty' input to cleaner inputs, and (iii) changes in economic structure away from relatively emission-intensive sectors to cleaner sectors. The first channel, which is not available for emissions from combustion of fossil fuels, entails end-of-pipe measures that reduce emissions per unit of the relevant input. The second channel includes for instance substitution from fossil fuels to renewable in electricity production, or investing in more energy-efficient machinery (which is represented through higher capital inputs but lower energy inputs in production). An example of the third channel is a substitution from consumption of energy-intensive industrial goods to services. In the model, the choice between these three channels is endogenous and driven by the price on emissions.

ENV-Linkages is fully homogeneous in prices and only relative prices matter. All prices are expressed relative to the numéraire of the price system that is arbitrarily chosen as the index of OECD manufacturing exports prices. Each region runs a current account balance, which is fixed in terms of the numéraire. One important implication from this assumption in the context of this report is that real exchange rates immediately adjust to restore current account balance when countries start exporting/importing emission permits.

As ENV-Linkages is recursive-dynamic and does not incorporate forward-looking behaviour, price-induced changes in innovation patterns are not represented in the model. The model does, however, entail technological progress through an annual adjustment of the various productivity parameters in the model, including e.g. autonomous energy efficiency and labour productivity improvements. Furthermore, as production with new capital has a relatively large degree of flexibility in choice of inputs, existing technologies can diffuse to other firms. Thus, within the CGE framework, firms choose the least-cost combination of inputs, given the existing state 
of technology. The capital vintage structure also ensures that such flexibilities are larger in the long run than in the short run.

The sectoral and regional aggregation of the model, as used in the analysis for this report, are given in Tables A.1. and A.2., respectively.

Table A.1. Sectoral aggregation of ENV-Linkages

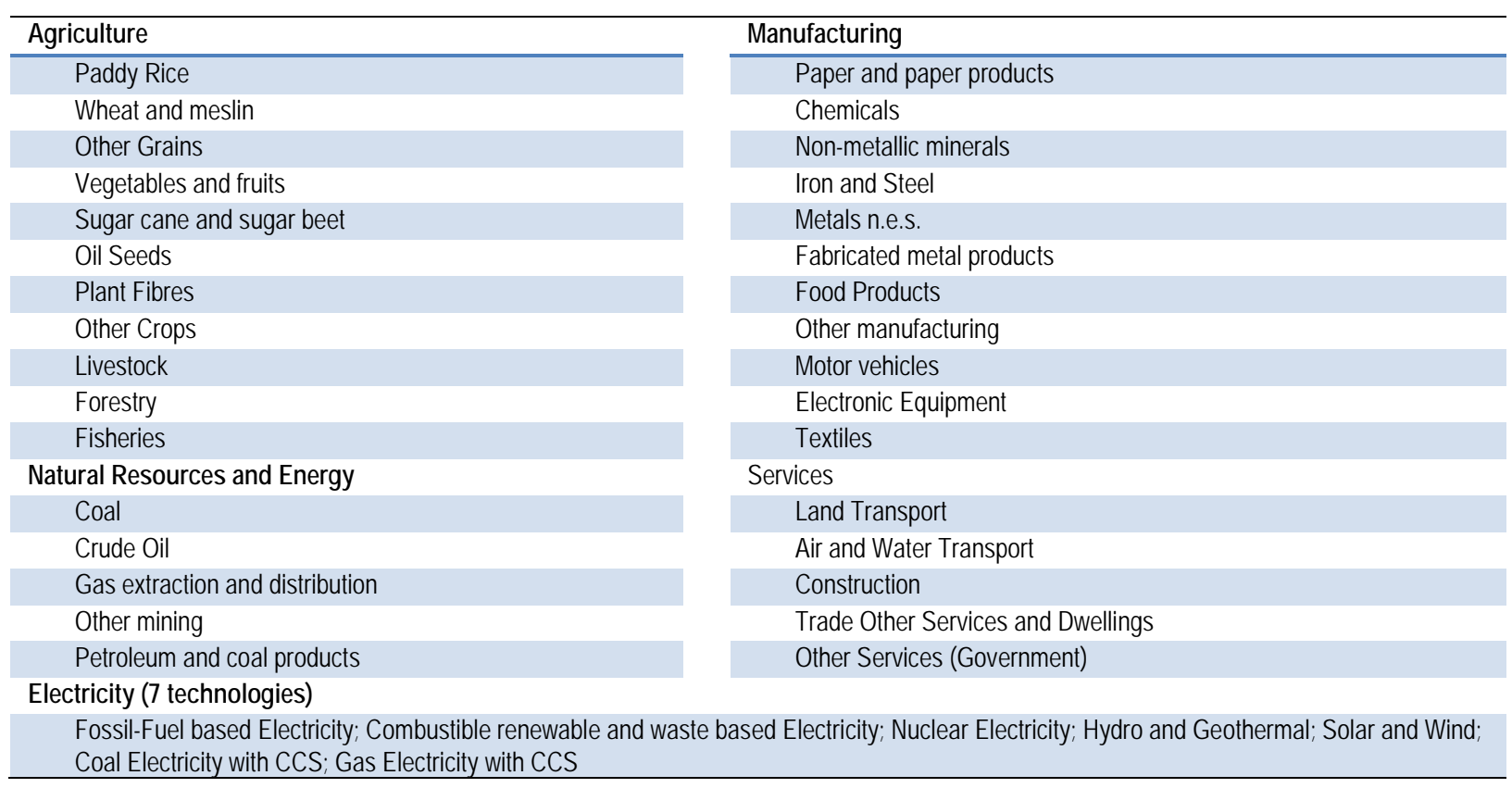


Table A.2. Regional aggregation of ENV-Linkages

\begin{tabular}{ll}
\hline Macro regions & ENV-Linkages countries and regions \\
\hline OECD America & Canada \\
& Chile \\
& Mexico \\
& United States \\
OECD Europe & EU large 4 (France, Germany, Italy, United Kingdom) \\
& Other OECD EU (other OECD EU countries) \\
& Other OECD (Iceland, Norway, Switzerland, Turkey, Israel) \\
OECD Pacific & Oceania (Australia, New Zealand) \\
& Japan \\
Rest of Europe and Asia & Korea \\
& People's Republic of China (abbr. China) \\
& Non-OECD EU (non-OECD EU countries) \\
& Russian Federation (abbr. Russia) \\
& Caspian region \\
Latin America & Other Europe (non-OECD, non-EU European countries) \\
& Brazil \\
Middle East \& North Africa & Other Lat.Am. (other Latin-American countries) \\
South and South-East Asia & Middle-East \\
& North Africa \\
\hline Sub-Saharan Africa & India \\
& Indonesia \\
& ASEAN9 (other ASEAN countries) \\
& Other Asia (other developing Asian countries) \\
\hline & South Africa \\
& Other Africa (other African countries) \\
\hline
\end{tabular}

In the presentation of the results, some smaller regions, and the EU regions, have been regrouped to avoid a false sense of accuracy. Specifically, Chile has been grouped with Other Latin America; Russia has been grouped with Other Europe; Japan and Korea have been aggregated in OECD Asia; EU large 4, Other OECD EU and non-OECD EU have been aggregated in EU; and South Africa and Other Africa have been aggregated in Sub-Saharan Africa. 


\section{Annex B. Details on the Evolution of International Trade in the No-damage Baseline Projection}

Trade specialisation patterns or the relative importance of different countries and regions in markets for each good and service markets will change over time, driven by the same four drivers of international trade, but more precisely by the differences across countries in relative productivity (or production costs) changes and by the convergence in consumption patterns.

\section{Changes in consumption patterns}

The baseline scenario for the world economy will project convergence in consumption patterns and this for two reasons. Firstly as standards of living are growing the consumption of all kind of services is increasing, as a percentage of total income, while the share of consumption of necessity goods is decreasing. These changes in consumption patterns are more pronounced in fast growing economy than in OECD countries where some levels of satiation would occur. Secondly, the projection also assumes that household's preferences themselves will converge towards OECD standards. As a result the composition of demand will change over time (Figure B.1).

Figure B.1. Changes in sectoral composition of world trade

Panel A. gross exports by aggregate industries as percentage of total exports)

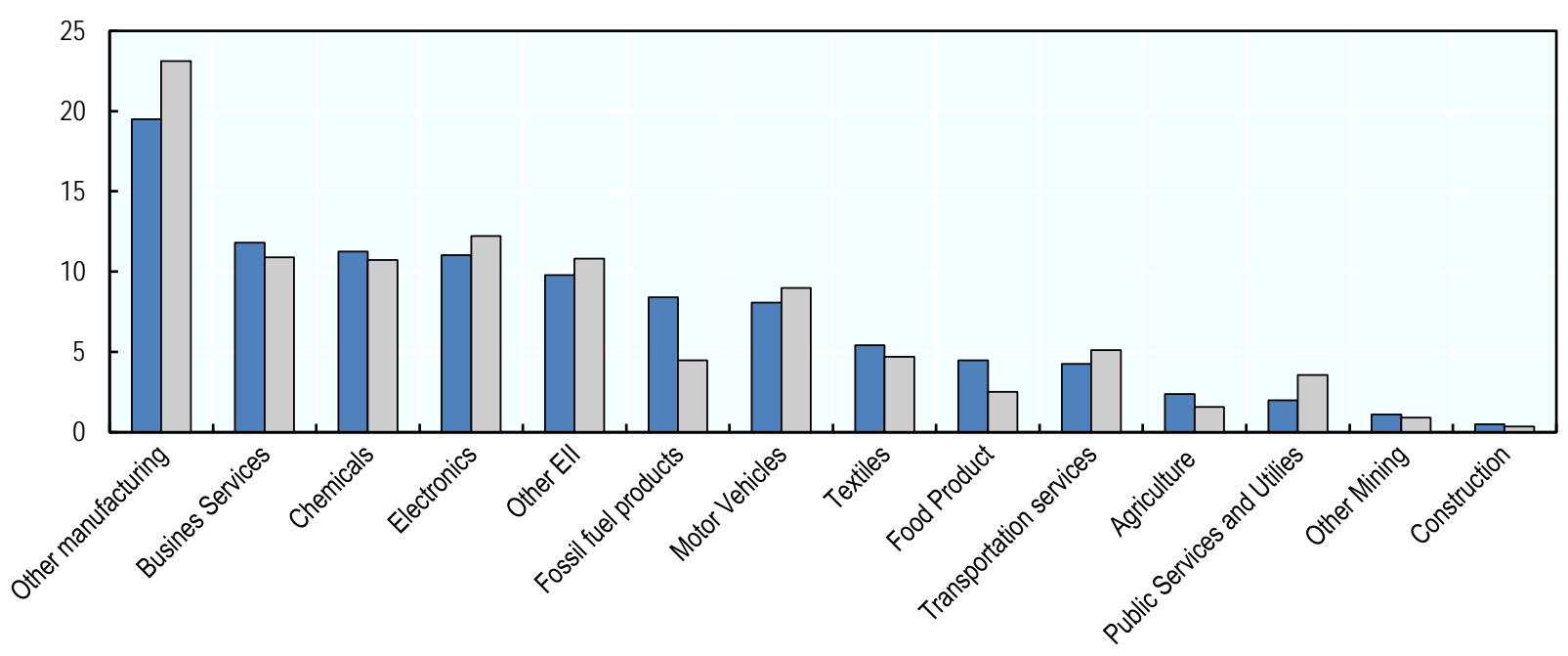


Panel B. Growth of value-added and Exports by aggregate activities 2015-2060 (average rate)

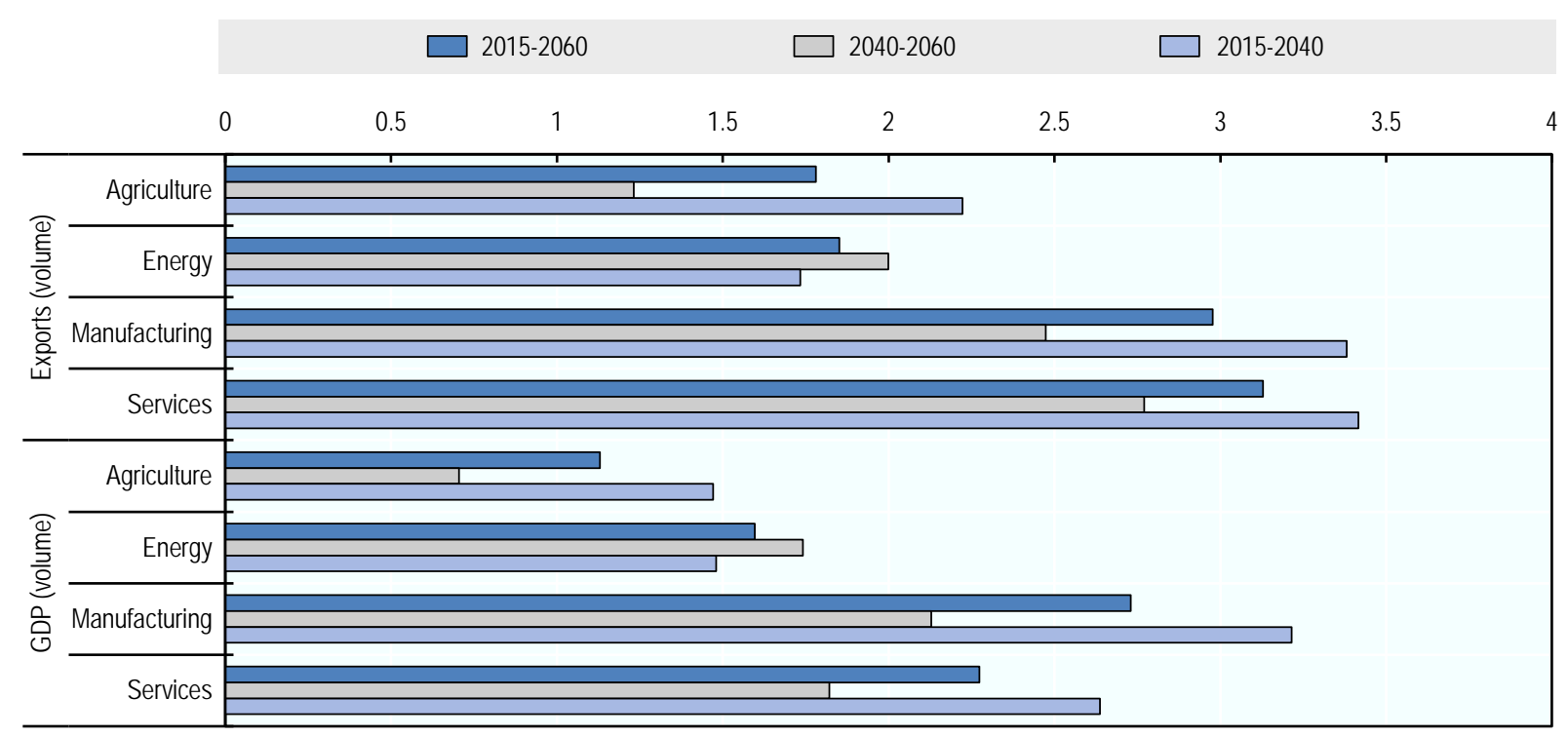

Source: OECD ENV-Linkages model.

\section{Changes in production patterns}

A second force is that production structures also change over time: some sectors in some countries will take advantage of some comparative advantage, associated with the change in endowments of production factor inputs or in their efficiency use relative to other factors. This explains that the changes in production patterns will not necessarily correspond to the changes in demand and follow some changes in trade specialisation patterns (Figure B.2 and B.3). 
Figure B.2. Changes in consumption patterns, selected countries

(Demand shares as percentage of total demand, 2010-2060)

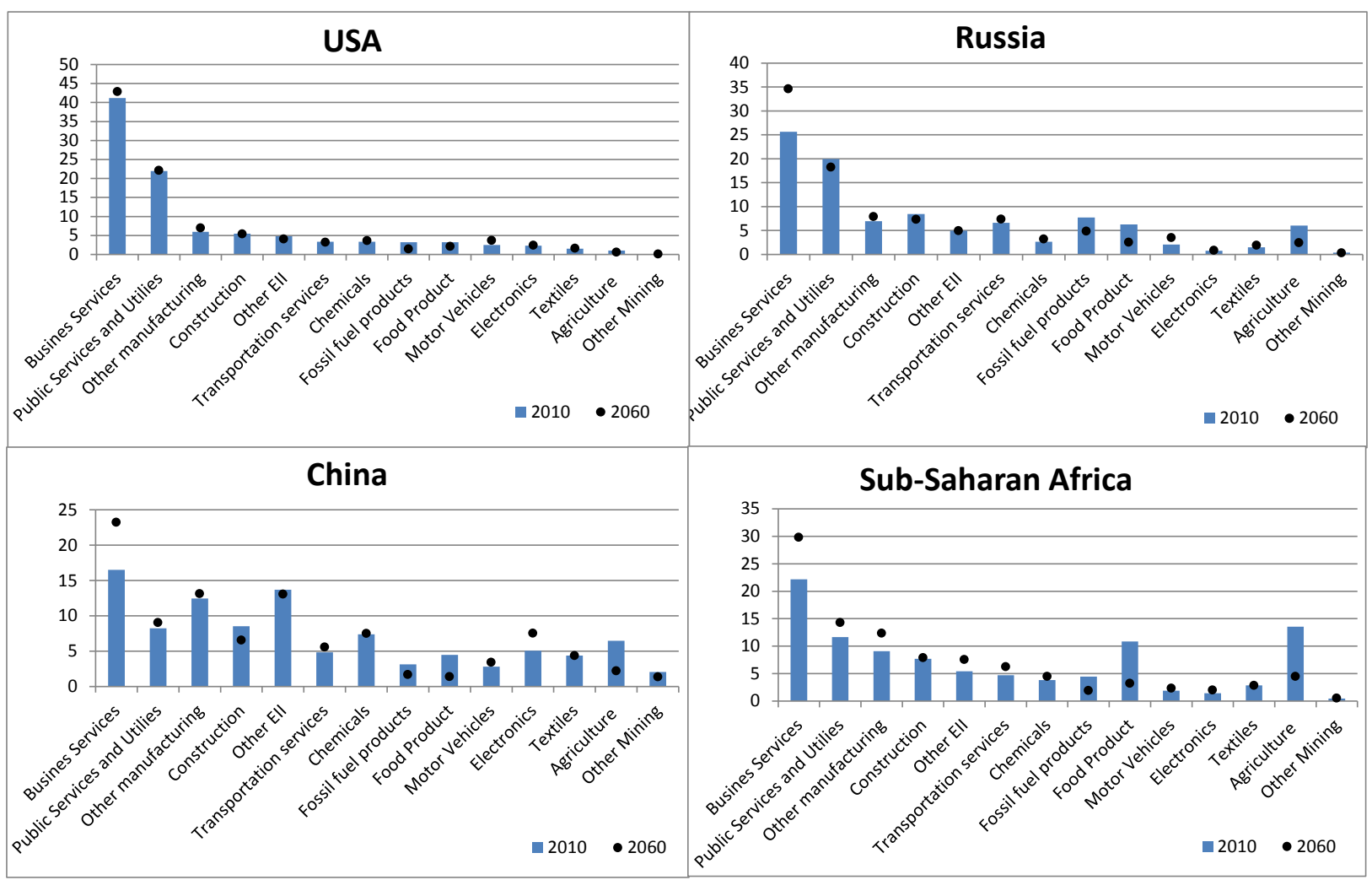

Source: OECD ENV-Linkages model. 
Figure B.3. Changes in industrial structure, selected countries

(Value added shares in total GDP, 2010-2060)

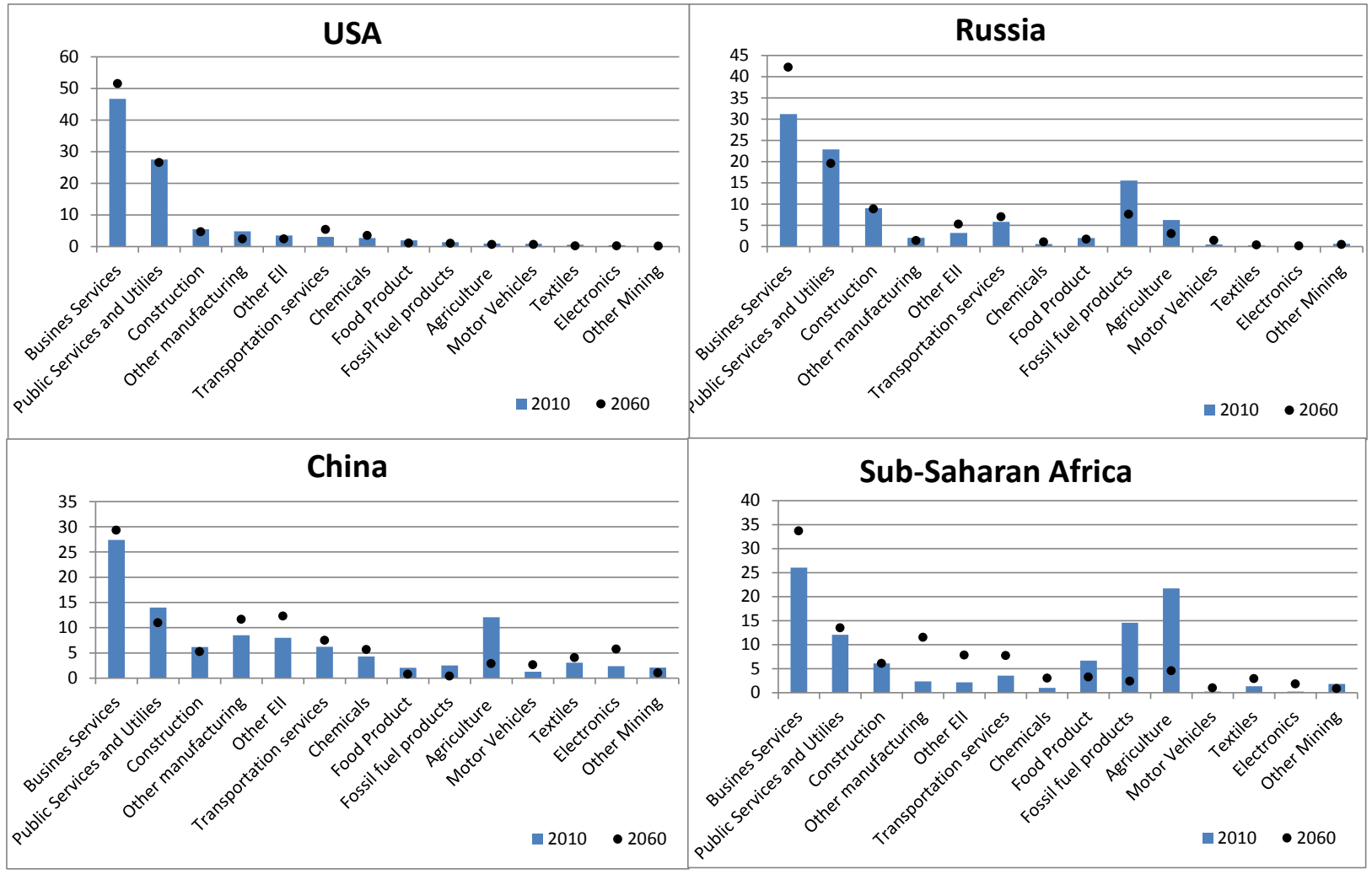

Source: OECD ENV-Linkages model. 


\section{Changes in trade specialisation}

Figure B.4. Changes in trade specialisation patterns in selected aggregate industries (Trade shares as percentage of global trade, 2010-2060)

Panel A. Transformed Good and Services

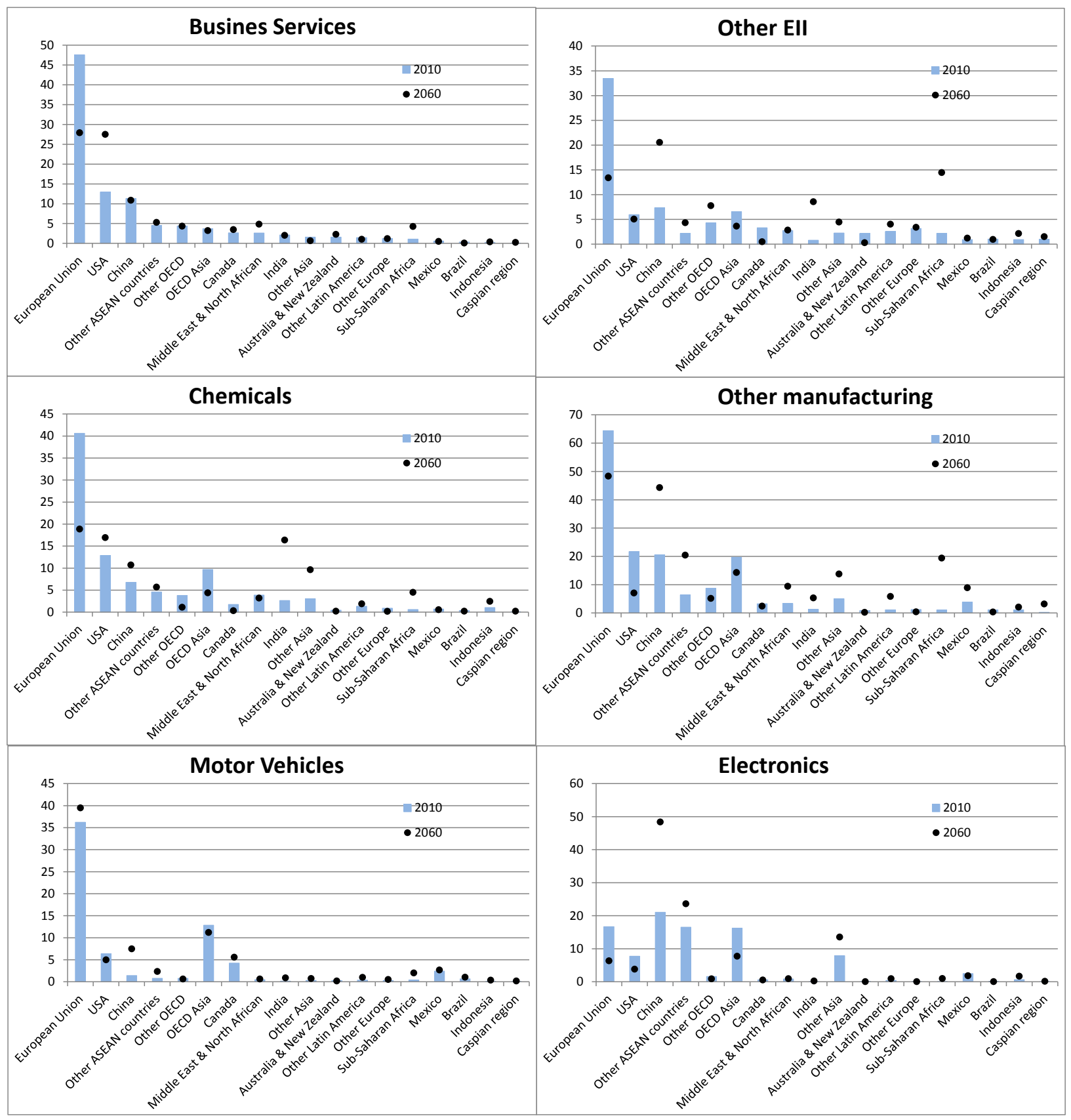


Panel B. Raw Product and Transformed raw products

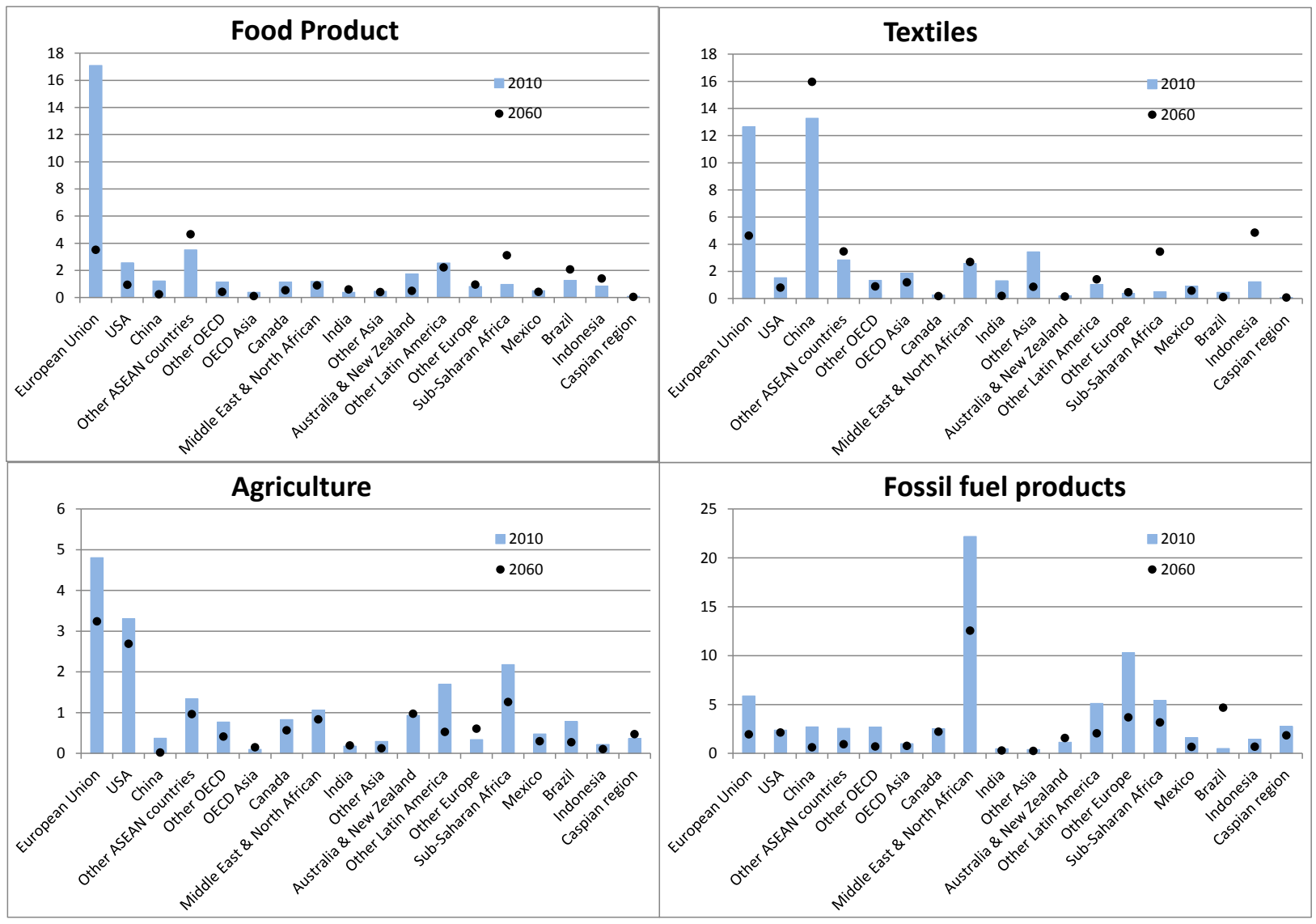

Source: OECD ENV-Linkages model.

Two kinds of goods deserve a closer examination. Energy and Agricultural goods, as they ultimately depend strictly on very unevenly distributed primary factors: natural resources and land factors. Notice also that a large part of the efficiency of these factors are also regional (extraction costs of fossil fuel are function of the quality of the land surface while land yields are function of the climate and geographical position) (Figure B.4). 


\section{Annex C. Summary of the Approach to Represent Damages from Climate Change in the Model}

A key challenge in modelling the link between climate change impacts and economic activities is to adequately capture the heterogeneity of climate change impacts. These vary in character and magnitude across regions and translate into shocks to the economy with some activities and sectors being more severely affected than others, through the channels of different economic variables.

One way to study this complex system in an economic framework is to link each climate impact to different variables in the production function that represents the activity of a specific industry or group of industries in the basic structure of the model. In a production function, output is produced from distinct inputs (e.g. labour and capital), intermediate commodity inputs and primary resources.

By modelling climate change impacts with a production function approach, it is possible to obtain, as for integrated assessment models, the total economic costs of the selected impacts of climate change on GDP. The overall GDP costs are in turn an indicator of the extent to which climate change has an impact on future economic growth; as in this approach damages can also affect capital stocks, it includes a potential direct effect on the growth rate of the economy. Compared to integrated assessment models in which climate damages are subtracted as a total from GDP, the production function approach can also explain how the composition of GDP is affected over time by climate change: what sectors are most affected (for the impacts that have been assessed) and what changes in production factors mostly contribute to changes in GDP.

Explicitly linking climate impacts to the sectoral economic variable works well for those impacts that are directly affecting economic markets. For non-market impacts, such a direct link with a part of the production function does not exist, and the damages need to be evaluated separately. Modelling climate damages in CGE models also means that a certain level of market-driven, reactive autonomous adaptation to the damages is inherently modelled. In models with sectoral details and a complex production and trade structure, a change in the productivity of a particular input will trigger substitution responses by producers that alter the use of the various inputs. Substitution is a powerful form of market adaptation once the level of the economy at which impacts manifest themselves is reached. The presence of market adaptation in the model also means that the final estimated costs of climate change impacts can be expected to be lower (or higher) than those estimated if adaptation is not considered (or considered to be optimal), as is often the case in IAMs. This feature also allows modellers to study both the direct effects of climate change and the indirect ones, such as the impacts that take place after trade effects.

The quantification of climate change impacts in ENV-Linkages relies on available information on how climate impacts affect different economic sectors. The information sources are mostly derived from bottom-up partial-equilibrium models, 
climate impact models and econometric studies. ${ }^{37}$ Table C.1 provides a summary of the impacts considered and their respective sources from the literature. They refer to the consequences of climate-related changes in agriculture and fisheries, coastal zones, health, and changes in the demand for tourism services and for energy for heating and cooling. Most impacts used are assessed for the specific Representative Concentration Pathway (RCP) 8.5 scenario, which describes a pathway of climate change resulting from a fast increase in global emissions. This scenario is, at least until 2060, similar to the ENV-Linkages model baseline with respect to GHG concentrations. Wherever possible, the central projection uses results from the HadGEM3 model from the Hadley Center of the UK Met Office, for the specification of the climate system variables. However, for certain climate impacts the data was only available from other climate models.

Table C.1. Climate impact categories included in ENV-Linkages

\begin{tabular}{|c|c|c|c|}
\hline Climate Impacts & Impacts modelled & Source & Time frame \\
\hline \multirow[t]{2}{*}{ Agriculture } & Changes in crop yields & IMPACT model - Nelson et al. (2014) & 2050 \\
\hline & Changes in fisheries catches & Cheung et al. (2010) & 2060 \\
\hline Coastal zones & Loss of land and capital from sea level rise & DIVA model - Vafeidis et al. (2008) & 2100 \\
\hline Extreme events & Capital damages from hurricanes & Mendelsohn et al. (2012) & 2100 \\
\hline \multirow[t]{2}{*}{ Health } & $\begin{array}{l}\text { Mortality and morbidity from infectious diseases, } \\
\text { cardiovascular and respiratory diseases }\end{array}$ & Tol (2002) & 2060 \\
\hline & Morbidity from heat and cold exposure & $\begin{array}{l}\text { Roson and Van der Mensbrugghe } \\
\text { (2012) and Ciscar et al. (2014) for } \\
\text { Europe }\end{array}$ & 2060 \\
\hline Energy demand & $\begin{array}{l}\text { Changes in energy demand for cooling and } \\
\text { heating }\end{array}$ & IEA (2013) & 2050 \\
\hline Tourism demand & Changes in tourism flows and services & HTM - Bigano et al. (2007) & 2100 \\
\hline Ecosystems & \multicolumn{3}{|c|}{ No additional impacts covered in the modelling exercise } \\
\hline Water stress & \multicolumn{3}{|l|}{ No additional impacts covered in the modelling exercise } \\
\hline Tipping points & \multicolumn{3}{|c|}{ Not covered in the modelling exercise } \\
\hline
\end{tabular}

Source: Own compilation.

Two broad categories of climate change impacts can be distinguished. The first affects the supply-side of the economic system, namely the quantity or productivity of primary factors. Land and capital destruction from sea level rise, crop productivity impacts in agriculture, and labour productivity impacts on human health belong to this category. The second category of climate change impacts affects the demand side. Impacts on health expenditures ${ }^{38}$ and on energy consumption are of this kind.

Much of the information used is an elaboration of data provided by recently concluded and ongoing research projects, including both EU Sixth and Seventh Framework Programs (FP6 and FP7) such as ClimateCost, SESAME and Global-IQ and model inter-comparison exercises such as AgMIP. These data have been kindly provided by the researchers involved in these projects. other costs to society. A valuation of full welfare costs would imply higher values. 


\section{Annex D. Key Simulation Results for 25 Regions}

The results presented in this paper have been aggregated to avoid an impression of false accuracy of the analysis for particular small economies and for intra-EU trade. However, in line with OECD (2015a), the underlying analysis is carried out at the 25 region level. Some of the key results for the simulation of all climate damages, as reported in Section 4.1, are reproduced in Table D.1; Similarly, Table D.2 provides the more disaggregated results for the analysis of agricultural damages presented in Section 4.2.

Table D.1. Regional results for the climate damages scenario

(Percentage change in 2060 w.r.t. no-damage baseline)

\begin{tabular}{|c|c|c|c|c|}
\hline & GDP & $\begin{array}{l}\text { Exports } \\
\text { (volume) }\end{array}$ & $\begin{array}{l}\text { Imports } \\
\text { (volume) }\end{array}$ & Real exchange rate \\
\hline ASEAN 9 & $-2.6 \%$ & $-3 \%$ & $-2 \%$ & $2 \%$ \\
\hline Brazil & $-1.4 \%$ & $-2 \%$ & $-1 \%$ & $0 \%$ \\
\hline Canada & $0.9 \%$ & $0 \%$ & $0 \%$ & $0 \%$ \\
\hline Chile & $-0.6 \%$ & $-1 \%$ & $0 \%$ & $2 \%$ \\
\hline China & $-2.5 \%$ & $-2 \%$ & $-2 \%$ & $2 \%$ \\
\hline Other OECD EU & $-0.4 \%$ & $0 \%$ & $-1 \%$ & $0 \%$ \\
\hline EU large 4 & $-0.1 \%$ & $0 \%$ & $-1 \%$ & $0 \%$ \\
\hline Non-OECD EU & $-0.8 \%$ & $-1 \%$ & $0 \%$ & $2 \%$ \\
\hline Indonesia & $-2.3 \%$ & $-3 \%$ & $-2 \%$ & $5 \%$ \\
\hline India & $-4.3 \%$ & $-6 \%$ & $-4 \%$ & $12 \%$ \\
\hline Japan & $0.0 \%$ & $0 \%$ & $-1 \%$ & $0 \%$ \\
\hline Korea & $-0.4 \%$ & $-1 \%$ & $-1 \%$ & $0 \%$ \\
\hline Middle East & $-3.2 \%$ & $-3 \%$ & $-3 \%$ & $3 \%$ \\
\hline Mexico & $-2.0 \%$ & $-2 \%$ & $-2 \%$ & $1 \%$ \\
\hline North Africa & $-3.5 \%$ & $-3 \%$ & $-3 \%$ & $5 \%$ \\
\hline Other Africa & $-4.1 \%$ & $-4 \%$ & $-4 \%$ & $6 \%$ \\
\hline Aus. \& NewZ. & $-0.9 \%$ & $-1 \%$ & $-1 \%$ & $1 \%$ \\
\hline Other Asia & $-3.0 \%$ & $-2 \%$ & $-3 \%$ & $3 \%$ \\
\hline Other OECD & $-0.2 \%$ & $-1 \%$ & $-1 \%$ & $0 \%$ \\
\hline Other Europe & $-0.7 \%$ & $-1 \%$ & $0 \%$ & $1 \%$ \\
\hline Other Lat.Am. & $-1.7 \%$ & $-2 \%$ & $-1 \%$ & $1 \%$ \\
\hline Russia & $1.4 \%$ & $1 \%$ & $0 \%$ & $1 \%$ \\
\hline Caspian region & $-2.3 \%$ & $-4 \%$ & $-3 \%$ & $4 \%$ \\
\hline USA & $-0.5 \%$ & $0 \%$ & $-2 \%$ & $0 \%$ \\
\hline South Africa & $-2.3 \%$ & $-3 \%$ & $-3 \%$ & $1 \%$ \\
\hline
\end{tabular}

Source: OECD ENV-Linkages model. 
Table D.2. Regional results for the agricultural damages scenario

(Change in 2060 w.r.t. no-damage baseline)

\begin{tabular}{|c|c|c|c|c|c|}
\hline & GDP & crop yields & RCA Food & Food export volume & Food export price \\
\hline ASEAN 9 & $-0.7 \%$ & $-18 \%$ & -0.13 & $-3 \%$ & $6 \%$ \\
\hline Brazil & $0.0 \%$ & $-26 \%$ & 0.70 & $7 \%$ & $3 \%$ \\
\hline Canada & $-0.1 \%$ & $-1 \%$ & 0.19 & $12 \%$ & $2 \%$ \\
\hline Chile & $0.3 \%$ & $12 \%$ & 0.47 & $9 \%$ & $2 \%$ \\
\hline China & $-0.6 \%$ & $-9 \%$ & 0.00 & $-2 \%$ & $6 \%$ \\
\hline Other OECD EU & $-0.1 \%$ & $-12 \%$ & 0.09 & $9 \%$ & $2 \%$ \\
\hline EU large 4 & $0.0 \%$ & $-11 \%$ & 0.08 & $13 \%$ & $1 \%$ \\
\hline Non-OECD EU & $-0.4 \%$ & $-13 \%$ & 0.06 & $8 \%$ & $2 \%$ \\
\hline Indonesia & $-0.7 \%$ & $-23 \%$ & -0.63 & $-14 \%$ & $11 \%$ \\
\hline India & $-2.6 \%$ & $-30 \%$ & -0.51 & $-75 \%$ & $47 \%$ \\
\hline Japan & $0.0 \%$ & $2 \%$ & 0.01 & $19 \%$ & $1 \%$ \\
\hline Korea & $0.0 \%$ & $0 \%$ & 0.01 & $7 \%$ & $4 \%$ \\
\hline Middle East & $-0.7 \%$ & $-13 \%$ & 0.02 & $4 \%$ & $4 \%$ \\
\hline Mexico & $-0.2 \%$ & $-18 \%$ & 0.10 & $9 \%$ & $2 \%$ \\
\hline North Africa & $-1.6 \%$ & $-15 \%$ & -0.16 & $-10 \%$ & $7 \%$ \\
\hline Other Africa & $-1.7 \%$ & $-18 \%$ & 0.05 & $0 \%$ & $4 \%$ \\
\hline Aus. \& NewZ. & $-0.3 \%$ & $-4 \%$ & 0.18 & $11 \%$ & $2 \%$ \\
\hline Other Asia & $-0.5 \%$ & $-23 \%$ & 0.00 & $0 \%$ & $5 \%$ \\
\hline Other OECD & $-0.1 \%$ & $-2 \%$ & 0.10 & $12 \%$ & $1 \%$ \\
\hline Other Europe & $-0.2 \%$ & $-11 \%$ & 0.63 & $7 \%$ & $2 \%$ \\
\hline Other Lat.Am. & $-0.2 \%$ & $-16 \%$ & 0.09 & $1 \%$ & $4 \%$ \\
\hline Russia & $0.3 \%$ & $-8 \%$ & 0.02 & $2 \%$ & $3 \%$ \\
\hline Caspian region & $-1.4 \%$ & $-7 \%$ & 0.02 & $7 \%$ & $1 \%$ \\
\hline USA & $-0.3 \%$ & $-15 \%$ & 0.04 & $9 \%$ & $2 \%$ \\
\hline South Africa & $-0.2 \%$ & $1 \%$ & 0.08 & $12 \%$ & $2 \%$ \\
\hline
\end{tabular}

Source: OECD ENV-Linkages model. 


\section{References}

ABS (2016), “IMO Polar Code Advisory”, American Bureau of Shipping, Houston.

Alexandratos, N. and J. Bruinsma (2012), "World agriculture towards 2030/2050: the 2012 revision”, FAO-ESA Working paper No. 12-03, Rome, www.fao.org/docrep/016/ap106e/ap106e.pdf.

AMAP (2013), "Arctic Ocean Acidification Assessment: Summary for Policymakers”, Arctic Monitoring and Assessment Programme (AMAP), Oslo, Norway, www.amap.no/documents/doc/amap-arctic-ocean-acidification-assessmentsummary-for-policy-makers/808.

Arctic Council (2009), Arctic Marine Shipping Assessment 2009 Report, April 2009, second printing.

Bax, N. et al. (2003), "Marine invasive alien species: a threat to global biodiversity", Marine Policy, Vol. 27, pp. 313-323.

Bekkers, E. et al. (2015), "Melting Ice Caps and the Economic Impact of Opening the Northern Sea Route”, CPB Netherlands Bureau for Economic Policy Analysis.

Bigano, A., J.M. Hamilton and R.S.J. Tol (2007), "The Impact of Climate Change on Domestic and International Tourism: A Simulation Study”, Integrated Assessment Journal, Vol. 7, pp. 25-49.

Bosello, F., F. Eboli and R. Pierfederici (2012), “Assessing the Economic Impacts of Climate Change. An Updated CGE Point of View”, FEEM Working Paper, No. 2.

Bosello, F. and R. Parrado (2014), "Climate change impacts and market driven adaptation: the costs of inaction including market rigidities", Nota di Lavoro 64.2014, Fondazione Eni Enrico Mattei, Milan, Italy.

Chateau, J., et al. (2015), "Trade patterns in the 2060 world economy", OECD Journal: Economic Studies, Vol. 2015/1, http://dx.doi.org/10.1787/eco_studies2015-5jrs63llqgjl.

Chateau, J., R. Dellink and E. Lanzi (2014), "An Overview of the OECD ENVLinkages Model: Version 3", OECD Environment Working Papers, No. 65, OECD Publishing, Paris, http://dx.doi.org/10.1787/5jz2qck2b2vd-en.

Cheung, W.W.L., et al. (2010), "Large-scale redistribution of maximum fisheries catch potential in the global ocean under climate change”, Global Change Biology, Vol. 16, pp. 24-35.

Ciscar. J.C. et al. (2014), “Climate impacts in Europe. The JRC PESETA II project”, JRC Scientific and Policy Reports, No. EUR 26586EN, Luxembourg: Publications Office of the European Union.

Copeland, B.R. and M.S. Taylor (2004), “Trade, Growth and the Environment”, Journal of Economic Literature, Vol. 42/1, pp. 7-71.

Cosbey, A. and R. Tarasofsky (2007), “Climate change, competitiveness and trade”, A Chatham House Report, Chatham House, London. 
Eboli, F., R. Parrado and R. Roson (2010), "Climate-change feedback on economic growth: explorations with a dynamic general equilibrium model”, Environment and Development Economics, Vol. 15, pp. 515-533.

Feenstra, R. C. (1998), "Integration of Trade and Disintegration of Production in the Global Economy", Journal of Economic Perspectives, Vol. 12/4, pp. 31-50.

Hansen, C.Ø. et al. (2016), Arctic Shipping-Commerical Opportunities and Challenges, CBS Maritime, Copenhagen.

Heininen, L., H. Exner-Pirot and J. Plouffe (eds.) (2015), Artic Yearbook 2015, Northern Research Forum, Akureyri, Iceland.

Huang, H.,M. van Lampe and F. van Tongeren (2011), "Climate change and trade in agriculture”, Food Policy, $\quad$ Vol. 36/1, pp. S9-S13, http://dx.doi.org/10.1016/j.foodpol.2010.10.008.

Hummels, D. (2007), "Transportation Costs and International Trade in the Second Era of Globalization", Journal of Economic Perspectives, Vol. 21/3, pp. 131-154.

IEA (2013), Redrawing the energy climate map, IEA, Paris.

Ignaciuk, A. (2015), "Adapting Agriculture to Climate Change: A Role for Public Policies", OECD Food, Agriculture and Fisheries Papers, No. 85, OECD Publishing, Paris, http://dx.doi.org/10.1787/5js08hwvfnr4-en.

Ignaciuk, A. and D. Mason-D'Croz (2014), "Modelling Adaptation to Climate Change in Agriculture", OECD Food, Agriculture and Fisheries Papers, No. 70, OECD Publishing, Paris, http://dx.doi.org/10.1787/5jxrclljnbxq-en.

IPCC (2014), Climate Change 2014: Impacts, Adaptation, and Vulnerability. Part A: Global and Sectoral Aspects, Contribution of Working Group II to the Fifth Assessment Report of the Intergovernmental Panel on Climate Change, Field, C.B. et al. (eds.), Cambridge University Press, Cambridge, United Kingdom and New York, NY, USA, 1132 pp.

IPCC (2013), "Summary for Policymakers", in Climate Change 2013: The Physical Science Basis, Contribution of Working Group I to the Fifth Assessment Report of the Intergovernmental Panel on Climate Change, Stocker, T.F. et al. (eds.), Cambridge University Press, Cambridge, United Kingdom and New York, NY, USA.

IPCC (2012), Managing the Risks of Extreme Events and Disasters to Advance Climate Change Adaptation, A Special Report of Working Groups I and II of the Intergovernmental Panel on Climate Change, Field, C.B. et al. (eds.), Cambridge University Press, Cambridge, UK, and New York, NY, USA.

IPCC (2007), Climate Change 2007: The Physical Science Basis. Contribution of Working Group I to the Fourth Assessment Report of the Intergovernmental Panel on Climate Change Solomon, S. et al. (eds.), Cambridge University Press, Cambridge, United Kingdom and New York, NY, USA.

Korinek, J. (2011), “Clarifying Trade Costs in Maritime Transport”, OECD Trade and Agriculture Directorate, TAD/TC/WP(2008)10/FINAL, OECD, Paris.

Liu et al. (2014), International trade buffers the impact of future irrigation shortfalls, Global Environmental Change, Vol. 29, pp. 22-3. 
Liu et al. (2010), "The Potential Economic Viability of Using the Northern Sea Route (NSR) as an Alternative Route Between Asia and Europe," Journal of Transport Geography, Vol. 18, pp. 434-444.

Maddocks, Hassell and Hyder (2010), “Climate Change and the Transport Sector: Are we travelling in the right direction?” Maddocks Australia, www.maddocks.com.au/app/uploads/articles/climate-change-and-the-transportsector-are-we-travelling-in-the-right-direction-update-november-2010.pdf.

Meinshausen, M., S.C.B. Raper and T.M.L. Wigley (2011), "Emulating coupled atmosphere-ocean and carbon cycle models with a simpler model, MAGICC6: Part I - Model Description and Calibration”, Atmospheric Chemistry and Physics, Vol. 11, pp. 1417-1456.

Mendelsohn, R. et al. (2012), "The Impact of Climate Change on Global Tropical Cyclone Damage”, Nature Climate Change, Vol. 2, pp. 205-209.

Nelson, G.C. et al. (2014), "Climate change effects on agriculture: Economic responses to biophysical shocks", Proceedings of the National Academy of Sciences, Vol. 111/9, pp. 3274-3279.

Nordhaus, W.D. (2011), Estimates of the social cost of carbon: Background and results from the RICE-2011 model, Cowles Foundation for Research in Economics, Yale University, New Haven.

Nordhaus, W.D. (2007), A question of balance, Yale University Press, New Haven, United States.

OECD (2015a), The Economic Consequences of Climate Change, OECD Publishing, Paris, http://dx.doi.org/10.1787/9789264235410-en.

OECD (2015b), Aligning Policies for a Low-carbon Economy, OECD Publishing, Paris, http://dx.doi.org/10.1787/9789264233294-en.

OECD (2009), "How Further Trade Liberalization Would Change Greenhouse-Gas Emissions From International Freight Transport”, COM/TAD/ENV/JWPTE/RD(2009)21.

OECD (2008), “Trade, Transport and Climate Change”, COM/TAD/ENV/JWPTE(2008)29/REV3.

OECD (2007), Environment and Regional Trade Agreements, OECD Publishing, Paris, http://dx.doi.org/10.1787/9789264006805-en.

Race, D. (2015), "The impacts of, and strategies to ameliorate, the intensity of climate change on enterprises in remote Australia”, CRC-REP Working Paper CW020. Ninti One Limited, Alice Springs.

Rogelj, J., M. Meinshausen and R. Knutti (2012), "Global warming under old and new scenarios using IPCC climate sensitivity range estimates”, Nature Climate Change, Vol. 2, pp. 248-253.

Roson, R. and D. van der Mensbrugghe (2012), "Climate change and economic growth: impacts and interactions", International Journal of Sustainable Economy, Vol. 4, pp. 270-285.

Schenker, O. and G. Stephan, (2014), "Give and take: How the funding of adaptation to climate change can improve the donor's terms-of-trade", Ecological Economics, Vol. 106, Pages 44-55, http://dx.doi.org/10.1016/j.ecolecon.2014.07.006. 
Schoyen et al. (2011), "The Northern Sea Route versus the Suez Canal: Cases from bulk shipping,” Journal of Transport Geography, Vol. 19, 977-983.

Sulser, T.B. et al. (2015), "Africa in the global agricultural economy in 2030 and 2050", in: O. Badiane and T. Makombe (eds.), Beyond a Middle Income Africa: Transforming African Economies for Sustained Growth with Rising Employment and Incomes, ReSAKSS Annual trends and outlook report 2014, IFPRI, Washington, D.C..

Tol, R.S.J. (2002), "New Estimates of the Damage Costs of Climate Change, Part I: Benchmark Estimates", Environmental and Resource Economics, Vol. 21/1, pp. 47-73.

UNCTAD (2014), “Review of Maritime Transport”, UNCTAD/RMT/2014, United Nations Publication, Geneva.

Vafeidis, A.T. et al. (2008), "A new global coastal database for impact and vulnerability analysis to sea level rise”, Journal of Coastal Research, Vol. 24/4, pp. 917-924.

Von Lampe, M., et al. (2014), "Why do global long-term scenarios for agriculture differ? An overview of the AgMIP Global Economic Model Intercomparison", Agricultural Economics, Vol. 45/1, pp. 3-20.

Wiebe, K. et al. (2015), "Climate change impacts on agriculture in 2050 under a range of plausible socioeconomic and emissions scenarios," Environmental Research Letters, Vol. 10/8, 085010.

Willenbockel D. (2012), "Extreme weather events and crop price spikes in a changing climate: illustrative global simulation scenarios", Oxfam Research Reports, September 2012.

WTO (2009), “Trade and Climate Change”, World Trade Organization (WTO) and United Nations Environment Programme (UNEP). 